\title{
An Advanced Neutronic Analysis Toolkit with Inline Monte Carlo Capability for VHTR Analysis
}

Final Report

\author{
DE-FC07-06ID14745
}

\author{
William R. Martin, PI \\ John C. Lee, co-PI \\ Kaushik Banerjee \\ Jeremy Conlin \\ Olivier Froment \\ Wei Ji \\ Shikha Prasad \\ Eva Sunny \\ Etienne de Villèle \\ Gokhan Yesilyurt
}

\begin{abstract}
University of Michigan
Department of Nuclear Engineering and Radiological Sciences

Ann Arbor, MI 48109-2104
\end{abstract}

December 2009 


\section{Table of Contents}

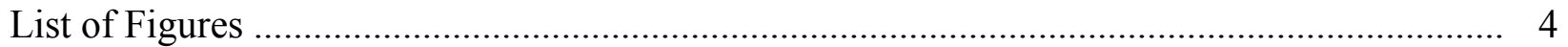

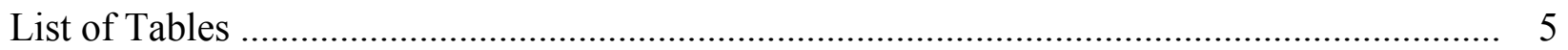

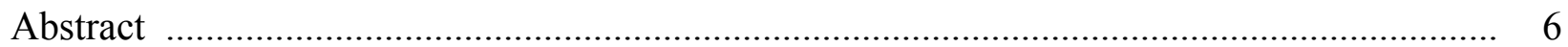

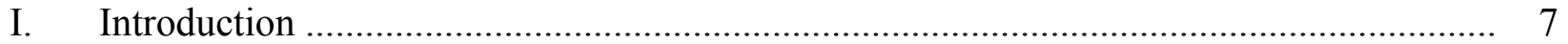

II. Background - Analysis of TRISO Particle Fuel ……...................................................... 7

III. Summary of Methodology _................................................................................... 9

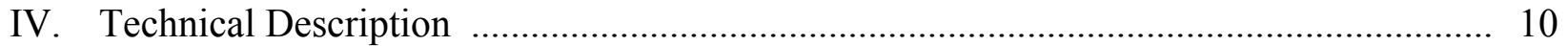

A. Accounting for the Double Heterogeneity ……................................................... 10

B. Description of Methodology ………………................................................... 11

1. Original Proposed Method: Direct (Inline) Replacement of Cross Sections ......... 11

2. Final Method: Double Heterogeneity Factors ………......................................... 12

3. Comparison of Direct Replacement and DHF Methodology ................................. 13

V. Computational Results ………........................................................................ 14

A. Summary of Test Problems and Sensitivity Calculations ........................................ 14

B. Analysis of PWR Pin Cell ……………….................................................. 14

1. Description of PWR Pin Cell ................................................................. 14

2. Numerical Results for the PWR Pin Cell ........................................................ 15

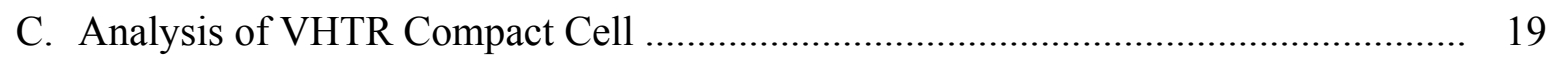

1. Description of VHTR Compact Cell ............................................................. 19

2. Numerical Results for the VHTR Fuel Compact Cell .......................................... 20

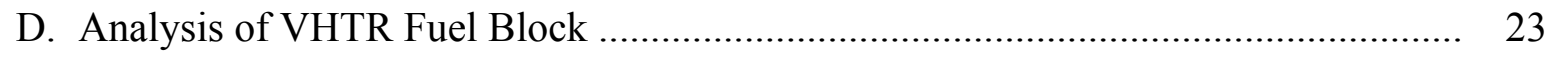

1. Description of VHTR Fuel Block ................................................................. 23

2. Numerical Results for the VHTR Fuel Block .................................................... 27

3. Comparison of CPM3 and HELIOS for the VHTR Fuel Block .......................... 28

E. Analysis of VHTR Fuel Block with "Deep Burn" Driver Fuel ................................. 29

1. Description of Deep Burn Driver Fuel Compact ................................................ 29

2. Numerical Results for Deep Burn Driver Fuel Compact .................................... 30

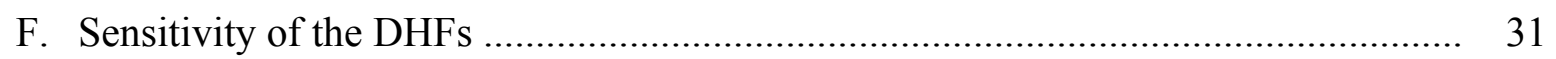

1. Sensitivity to Spatial Location ……............................................................. 32

2. Sensitivity to Material Composition (Burnup) ………....................................... 35

3. Sensitivity to Packing Fraction ..................................................................... 38

VI. Full Core VHTR Benchmark with T/H Feedback ………………............................. 39

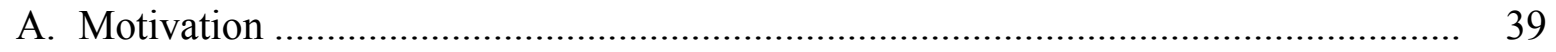

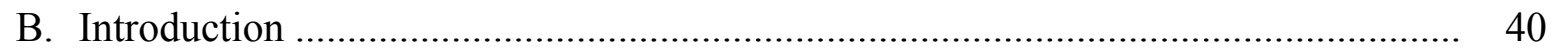

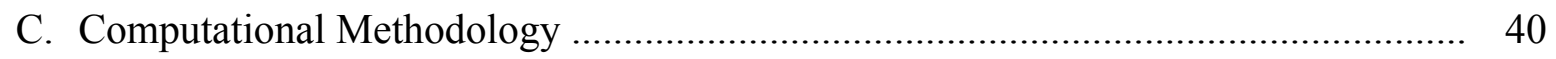

D. RELAP5-3D Analysis ...................................................................................... 41 
E. Fuel Particle Temperature Analysis ..................................................................... 41

F. Fission Heat Deposition ..................................................................................... 42

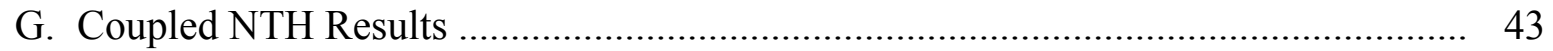

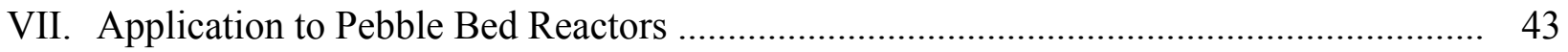

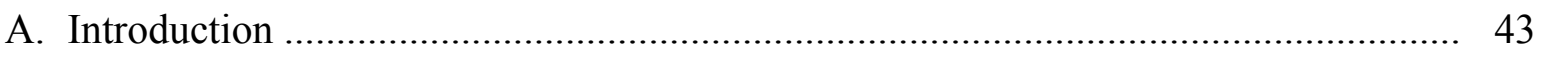

B. MCNP5 Modeling of a Single Pebble ................................................................. 44

1. Avoiding Clipped Fuel Pebbles .................................................................... 44

2. Alternative Stochastic Mixtures within a Pebble ................................................ 45

C. MCNP5 Modeling of Collections of Pebbles ......................................................... 47

1. Simple Configurations of Pebbles .................................................................. 47

2. Annular Configurations of Pebbles .............................................................. 48

3. Accounting for Interactions between Pebbles .................................................... 48

4. Simulation of Pebble Bed Reactor ................................................................. 50

D. Future Work with Pebble Bed Configurations …………….................................. 52

VIII. Summary and Conclusions ............................................................................... 52

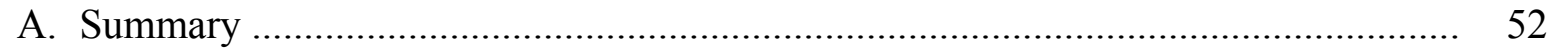

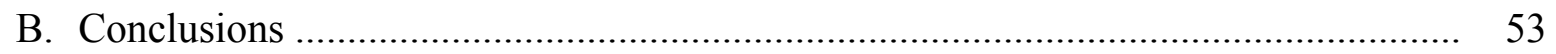

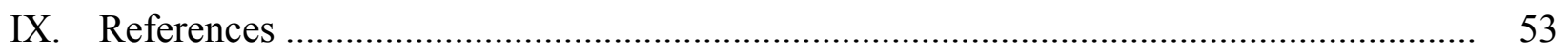

X. Achievement of Grant Objectives and Principal Tasks ............................................. 56

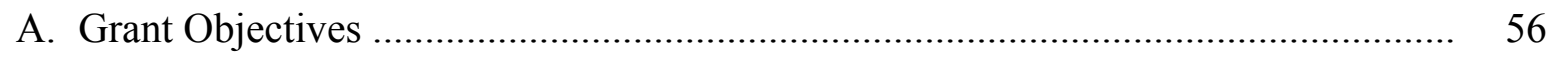

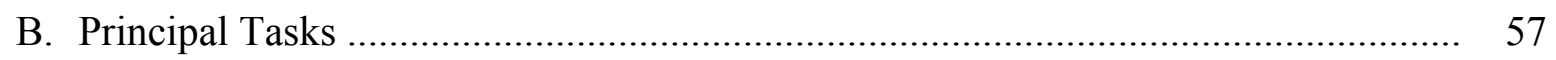

XI. Related Research Resulting from the Grant ............................................................ 61

A. Analysis of Stochastic Fuel Mixtures (Wei Ji) ……............................................. 61

1. Chord Length Sampling for Stochastic Mixtures .............................................. 61

2. Analytical Expressions for Dancoff Factors for VHTR Configurations ............... 61

B. Neutronic Analysis of VHTRs (Gokhan Yesilyurt) ……........................................ 62

1. Development of the DHF Methodology ........................................................... 62

2. Development of on-the-fly Doppler Broadening ................................................ 62

C. Monte Carlo Tallies using the Kernel Density Estimator (Kaushik Banerjee) .......... 62

1. Higher order, mesh-free tallies with KDE ...................................................... 62

2. Application of KDE to singular tallies ............................................................ 62

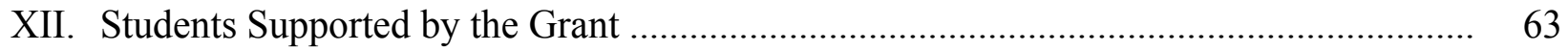

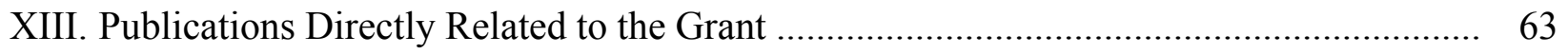

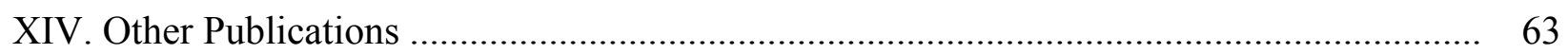

Appendix A. CPM3 - MCNP5 Direct Coupling Methodology .............................................. 65

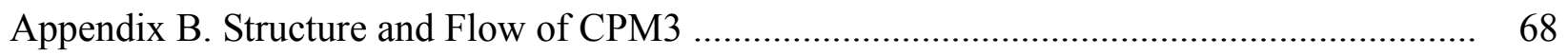

Appendix C. CPM3 Energy Group Structure ………….................................................. 72 


\section{List of Figures}

Figure 1. TRISO Fuel for Prismatic High Temperature Gas Reactors ................................. 8

Figure 2. TRISO Fuel for Pebble Bed High Temperature Gas Reactors ………………...... 8

Figure 3. Pin Cell Geometry and Dimensions ………................................................ 15

Figure 4. Comparison of MCNP5 and CPM3 Group Fluxes .......................................... 18

Figure 5. Comparison of MCNP5 97 and Fine Group Spectra ........................................ 18

Figure 6. VHTR Compact Cell Dimensions (cm) ........................................................... 19

Figure 7. Cross-section View of the VHTR Fuel Block .................................................... 23

Figure 8. Hexagonal Unit Cells in VHTR Core ……………............................................. 24

Figure 9. Hexagonal Unit Cells Available in CPM3 …………...................................... 24

Figure 10. CPM3 Model of the VHTR Fuel Block Lattice ................................................ 25

Figure 11. Heterogeneous and Corresponding Homogeneous Model .................................. 25

Figure 12. Limiting fuel blocks: interior and exterior fuel blocks. .................................... 32

Figure 13. Spatial comparison of DHFs over two limiting fuel blocks for group \#57 .......... 33

Figure 14. Spatial comparison of DHFs over two limiting fuel blocks for group \#53 ........... 33

Figure 15. Spatial comparison of DHFs over two limiting fuel blocks for group \#51 ........... 34

Figure 16. Spatial comparison of DHFs over two limiting fuel blocks for group \#38 ........... 34

Figure 17. Converged power distributions ...................................................................... 43

Figure 18. Converged temperature distributions ............................................................... 43

Figure 19. Fuel Pebble with Clipped Particles (left) and No Clipped Particles (right) .......... 45

Figure 20. Steps to Create "Semi-random" Lattice Structure for a Single Pebble .................. 46

Figure 21. Pebbles with Different TRISO Fuel Models ...................................................... 46

Figure 22. Models for Simple Configurations of Pebbles ..................................................... 47

Figure 23. Ballistic Packing for an Annular Container ..................................................... 48

Figure 24. Pebble Packing with 3DSMAX Animation Software ........................................... 49

Figure 25. Creating a Pile of Pebbles within a Cylinder with ESyS-Particle .......................... 50

Figure 26. Geometry Detail for the PBMR ………….................................................. 51

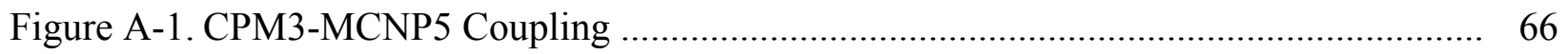

Figure A-2. Code to Import MCNP5-generated resonance cross sections in EFRES2 ............ 66

Figure B-1. Logic Flow Diagram for CPM3 ………...................................................... 69

Figure B-2. Calling Diagram for Module AGXSEC …….................................................. 70 


\section{List of Tables}

Table 1. Material Composition of the PWR Pin Cell ..................................................... 15

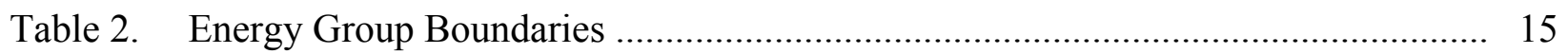

Table 3. $\mathrm{k}_{\infty}$ values Predicted by CPM-3 and MCNP5 for PWR Pin Cell ............................. 16

Table 4. Comparison of Microscopic Cross Sections for PWR Pin Cell ……….................. 16

Table 5. Comparison of Fine Group Macroscopic Cross Sections for PWR Pin Cell ........... 17

Table 6. Comparison of Two-group Macroscopic Cross Sections for PWR Pin Cell ............ 17

Table 7. Heterogeneous and Homogeneous VHTR Fuel Compact Cell Dimensions ............. 19

Table 8. Material Composition of Fuel Compact for MCNP5 and CPM3 Calculations ........ 20

Table 9. Comparison of Macroscopic Cross Sections for the VHTR Fuel Compact Cell ...... 21

Table 10. Two-group Macroscopic Cross Sections for the VHTR Fuel Compact Cell ............ 21

Table 11. Comparison of CPM3 and MCNP5 for VHTR Compact Cell ............................... 23

Table 12. Numerical Integration Parameters for CPM3 Calculations ..................................... 26

Table 13. MOC vs CP Options in CPM3 for VHTR Fuel Block …….................................. 26

Table 14. CPM3 vs MCNP5 for VHTR Fuel Block with Homogeneous Fuel ......................... 28

Table 15. CPM3 vs MCNP5 for VHTR Fuel Block with Heterogeneous Fuel ...................... 28

Table 16. Comparison of Original and Modified (with DHFs) CPM3 and HELIOS Codes.... 29

Table 17. Dimension for the Driver Fuel Compact Cell ........................................................ 29

Table 18. Material Compositions for the Driver Fuel Compact Cell ..................................... 30

Table 19. Explanation of Deep Burn Driver Fuel Cases .................................................... 31

Table 20. Infinite Medium Multiplication Factor Comparison ……........................................ 31

Table 21. Energy Group Boundaries ........................................................................ 32

Table 22. Burnup Steps in Terms of Accumulated Exposure in GWd/MT ........................... 35

Table 23. Heterogeneous and Homogeneous VHTR Fuel Compact Cell Dimensions ........... 35

Table 24. Material Compositions of Fuel Compacts for MCNP5 and CPM3 Analyses ........ 36

Table 25. Resonance Isotope Compositions as a Function of Burnup .................................. 37

Table 26. Fine Group DHFs as a Function of Burnup ..................................................... $\quad 38$

Table 27. Multi-group DHFs for U-238 as a Function of Packing Fraction ......................... 39

Table 28. RELAP5-3D/ATHENA Model Parameters ........................................................ 41

Table 29. MCNP5 Results for Pebble with Clipped vs. Unclipped Fuel Particles ................. 45

Table 30. MCNP5 Results for Pebbles with Different TRISO Fuel Models ......................... 47

Table 31. MCNP5 Results for Pebbles in a Lattice of Boxes ................................................. 48

Table 32. MCNP5 Results for Pebbles in a Lattice of Annular Containers .......................... 48

Table 33. MCNP5 Results for Full Core PBMR with Pebbles on a Lattice ........................... 51

Table 34. Effect of TRISO Fuel Model and Pebble Arrangement on $k_{\text {eff }}$ for PBMR ............ 52

Table 35. Primary Objectives for the Grant ………....................................................... 56

Table 36. Doctoral Students who Worked on the Grant .................................................. 61

Table C-1. CPM3 97 Multi-Group Energy Boundaries .......................................................... 72 


\begin{abstract}
Monte Carlo capability has been combined with a production LWR lattice physics code to allow analysis of high temperature gas reactor configurations, accounting for the double heterogeneity due to the TRISO fuel. The Monte Carlo code MCNP5 has been used in conjunction with CPM3, which was the testbench lattice physics code for this project. MCNP5 is used to perform two calculations for the geometry of interest, one with homogenized fuel compacts and the other with heterogeneous fuel compacts, where the TRISO fuel kernels are resolved by MCNP5. The ratio of these two cross sections for every fine energy group and every isotope, known as the Double Heterogeneity Factor (DHF), is an effective "self-shielding factor" that accounts for the kernellevel heterogeneity. These DHFs are input to CPM3 and used to multiply the corresponding fine group resonance cross sections in CPM3, effectively yielding the fine group resonance cross section determined by MCNP5 with heterogeneous fuel. These "adjusted" microscopic resonance cross sections are then used by CPM3 to perform the actual transport calculation, e.g., with collision probabilities (CP) or method of characteristics (MOC). In essence, the resonance cross sections that would have been generated by CPM3, normally a function of temperature and background cross section, are adjusted to be equivalent to the MCNP5 cross sections where the TRISO fuel kernels are fully resolved. The normal transport modules in CPM3, whether carried out by $\mathrm{CP}$ or $\mathrm{MOC}$, are not changed with this methodology - only the fine group resonance cross sections are changed. Proof-of-principle was established for CPM3 and the methodology was ported to HELIOS, a production lattice physics code, with excellent results for a VHTR fuel block. This methodology allows the analyst to take advantage of the downstream capabilities of CPM3 and HELIOS, including cross section generation for global nodal analysis and depletion, systematic preparation of cross section sets for accident analysis, and enabling efficient fuel cycle analyses and assessment of alternative fuel management schemes. The methodology has been tested on a number of configurations ranging from a single fuel kernel to full core, including lattices with a substantial amount of plutonium. Sensitivity studies have been conducted, indicating that the DHFs are not sensitive to depletion or location in the fuel block or location in the core.
\end{abstract}




\section{Introduction}

The design and analysis of the Very High Temperature Reactor (VHTR) represents a substantial challenge to current reactor analysis capabilities. In order to arrive at an optimal design for the VHTR, one needs the capability to include changes in enrichment, packing fraction, fuel temperature, depletion, and burnable poison loading. Complicating this is the presence of the double heterogeneities inherent in the TRISO fuel. The neutronic effect of the double heterogeneities is particularly significant because of the large effect on the resonance absorption and Doppler coefficient. This has important implications for fuel cycle analysis and the determination of fuel management schemes and the prediction of isotopic inventories for discharge fuel. For example, an accurate prediction of the conversion ratio will depend on the converged flux/power distribution that is in turn a sensitive function of temperature and depletion. In order to include all of these variables and determine an optimal design from the standpoint of reactor operation as well as fuel cycle considerations, the analyst needs access to a computational toolkit similar in capability to the mature suites of reactor analysis methods for light water reactor (LWR) design and analysis, including static design, depletion, fuel management, and thermal-hydraulic feedback. This report describes a methodology that allows VHTR designers and analysts to take advantage of current LWR neutronics methodology for their core design and fuel management needs.

\section{Background - Analysis of TRISO Particle Fuel}

The analysis of TRISO particle fuel is challenging due to the presence of tiny $(<1 \mathrm{~mm})$ fuel kernels that are large enough neutronically $(\sim 10 \mathrm{mfp}$ for neutrons near the $6.67 \mathrm{eV}$ resonance of U238) that one must account for the self-shielding (and "shadowing") of the fuel grains [1]. This constitutes the "first heterogeneity" posed by particle fuel, the second heterogeneity being the fuel compacts in the case of TRISO particle fuel for prismatic cores or the fuel pebbles in the case of pebble bed cores. Figures 1 and 2 illustrate TRISO fuel for prismatic and pebble bed cores, respectively. However, the particle heterogeneity is not important for neutrons with energies outside the resonance energy range and for most of the neutron energy spectrum, the particle fuel can be homogenized and conventional transport-based methods suffice to treat the fuel compact heterogeneity. This key observation underpins the methodology described in this report.

The CPM3 [2] assembly transport code is based on two methods: (1) the method of characteristics (MOC) and (2) the method of collision probabilities (CP). CPM3 may be used to analyze 2D heterogeneous configurations such as individual fuel blocks, multi-bundle fuel configurations, critical experiments and fuel transport casks. CPM3 can be set up to analyze hexagonal geometry although there are no standard input files for hexagonal geometry. Likewise, CASMO-4 [3] can also handle hexagonal geometry and has been used to analyze both Magnox and AGR cores. In addition, CPM3 generates cross section files that can be used in a number of global analysis codes while CASMO-4 generates cross section files for SIMULATE [4] for global nodal analysis of full-core configurations. Therefore, with the notable exception of the double heterogeneity, CPM3, HELIOS [5], and CASMO-4 all have the capability to analyze reactor configurations for the VHTR prismatic design [6]. The goal of this project was to develop a combined Monte Carlo/integral transport methodology that will enable MCNP5 [7] to perform 
the resonance absorption calculation within CPM3 (and other lattice physics codes such as HELIOS or CASMO-4) to complement the conventional approach used by these codes for nonresonance energy neutrons.

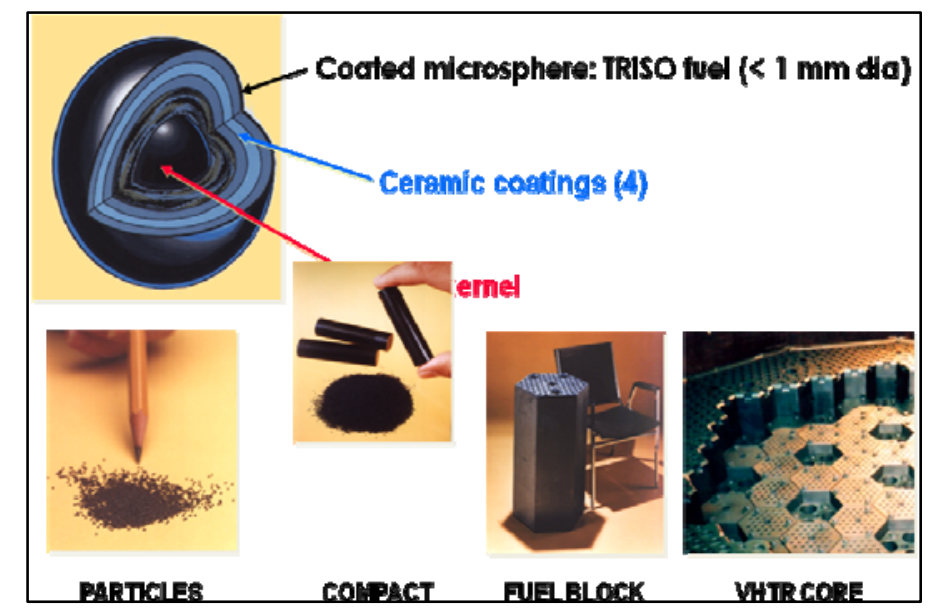

Figure 1. TRISO Fuel for Prismatic High Temperature Gas Reactors

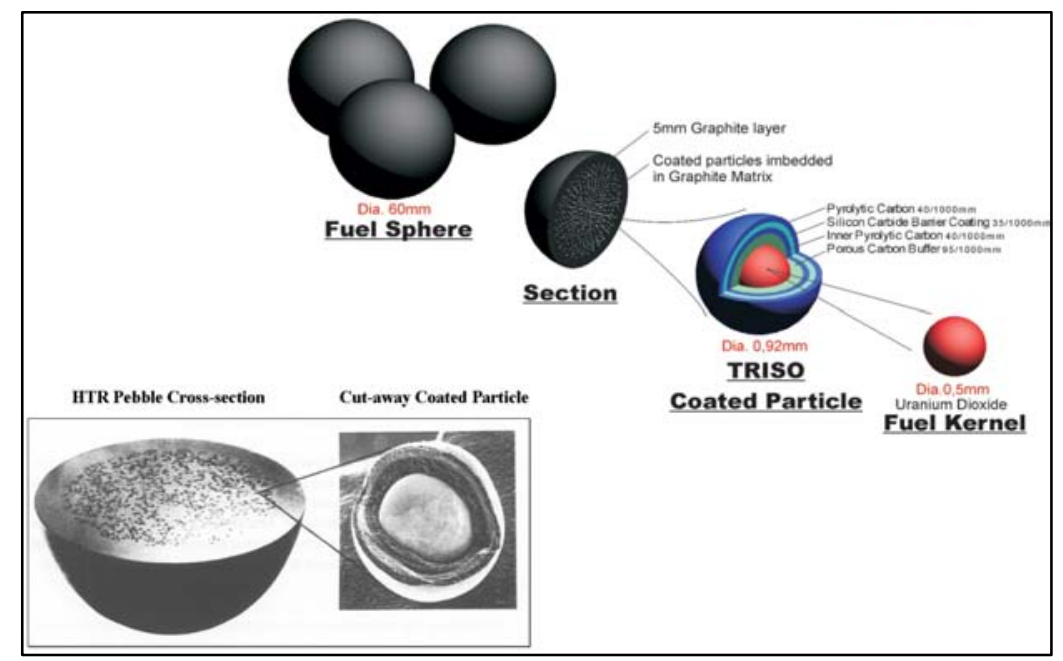

Figure 2. TRISO Fuel for Pebble Bed High Temperature Gas Reactors

Monte Carlo codes have been used extensively to analyze reactor configurations with TRISO particle fuel. A number of analysts have reported results by modeling the particle fuel as a regular lattice of cubical or hexagonal graphite cells with internal fuel microspheres [8-12]. The size of the graphite cell is determined by the packing fraction of the particle fuel. It has also been observed [13] that the predicted results are not very sensitive to the location of the microsphere within the graphite cell (i.e., random vs. centered), which provides some justification for assuming the microsphere is at the center of the cell. This is also an issue of input complexity and code capacity, since a fuel compact may have 6000 particles and it would be difficult to prepare an input file that described even a single compact, let alone a fuel block or full core. In addition, this would be a computational challenge because of tracking within hundreds of 
thousands of regions, each with thousands of microspheres. With microspheres located at the centers of the microsphere cells, "lattice" and/or "universe" options or equivalent can be employed, greatly simplifying the input preparation and allowing the simulation to proceed with substantial savings in computational time.

\section{Summary of Methodology}

The approach taken is a hybrid methodology that combines Monte Carlo and integral transport either collision probabilities (CP) or method of characteristics (MOC). It takes advantage of the fact that Monte Carlo can account for the double heterogeneity while conventional CP/MOC lattice physics codes cannot account for the kernel level heterogeneity but they do account for the second heterogeneity due to the fuel compacts, which is similar to the fuel pin level self shielding. This has been implemented by combining MCNP5 with CPM3, the demonstration integral transport code for this "proof-of-principle" demonstration. MCNP5 analyzes a geometry that is identical to or includes the geometry that is to be analyzed by CPM3, or other lattice physics code, and generates fine (e.g., library group) resonance group cross sections for all resonance isotopes in the problem geometry. The MCNP5 calculation is performed twice - once for a homogenized fuel region and once for a heterogeneous fuel region where the TRISO kernels are resolved. The ratio of these two cross sections for every fine energy group and every isotope, known as the Double Heterogeneity Factor (DHF), is an effective "self-shielding factor" (albeit dependent on isotope and energy group) that accounts for the kernel-level heterogeneity. These DHFs are input to CPM3 and used to multiply the corresponding fine group resonance cross sections in CPM3, effectively yielding the fine group resonance cross section determined by MCNP5 with heterogeneous fuel compacts. These "adjusted" microscopic resonance cross sections are then used by CPM3 to perform the actual transport calculation, e.g., with collision probabilities (CP) or method of characteristics (MOC). In essence, the resonance cross sections that would have been generated by CPM3, normally a function of temperature and background cross section, are adjusted to be equivalent to the MCNP5 cross sections where the TRISO fuel kernels are fully resolved. The normal transport modules in CPM3, whether carried out by CP or MOC, are not changed with this methodology - only the fine group resonance cross sections are changed.

This methodology allows the analyst to take advantage of the downstream capabilities of CPM3 and HELIOS, including cross section generation for global nodal analysis and depletion, systematic preparation of cross section sets for accident analysis, and enabling efficient fuel cycle analyses and assessment of alternative fuel management schemes. The methodology has been tested on a number of configurations ranging from a single fuel kernel to full core, including lattices with a substantial amount of plutonium. Sensitivity studies have been conducted, indicating that the DHFs are not sensitive to depletion or location in the fuel block or location in the core. 


\section{Technical Description}

\section{A. Accounting for the Double Heterogeneity}

As with other lattice physics codes, CPM3 handles resonance absorption by relating the heterogeneous problem to an equivalent homogeneous problem [2]. While the actual details may be different for different lattice physics codes, effective resonance integrals are obtained by interpolating (with temperature $\mathrm{T}$ and potential cross section $\sigma_{\mathrm{p}}$ ) within a table of homogeneous resonance integrals (or shielding factors in the case of CPM3) that are tabulated at library generation time. Corrections are made for resonance overlap due to several nuclides and the effect of rod shadowing is treated with a Dancoff factor determined by the lattice physics code for the specific geometry that is being analyzed. The calculation of resonance integrals is only done once at the beginning of the CPM3 calculation to compute effective fine group microscopic cross sections for use in the spectrum calculation that precedes the transport calculation. For example, the fine group $\mathrm{g}$ macroscopic absorption cross section for a given spatial region is given by:

$$
\Sigma_{a g}=\sum_{i=1}^{I} N_{i} \sigma_{a g}^{i, C P M}
$$

where $\mathrm{I}$ is the number of isotopes in the region, $N_{i}$ is the number density of isotope $\mathrm{i}$, and $\sigma_{a g}^{i, C P M}$ is the microscopic absorption cross section for isotope $\mathrm{i}$ in fine group $\mathrm{g}$, as determined by CPM3.

When TRISO fuel is being analyzed, the calculation of the fine group microscopic cross sections for resonance absorbers is performed assuming the fuel region is homogeneous, which will not account for the kernel-level heterogeneity, and the resultant $\sigma_{g}^{i}$ will be inaccurate. However, if a Monte Carlo code such as MCNP5 explicitly models the fuel kernels, it can determine the group $\mathrm{g}$ cross section $\sigma_{g}^{i}$ by tallying the overall absorption rate in group $\mathrm{g}$ :

$$
A_{g}^{i}=N_{i} \int_{\Delta E_{g}} \sigma_{a}^{i}(E) \phi(E) d E
$$

and the group g scalar flux:

$$
\phi_{g}=\int_{\Delta E_{g}} \phi(E) d E
$$

and combining to find:

$$
\sigma_{g}^{i}=\frac{A_{g}^{i}}{N_{i} \phi_{g}}
$$

Now define the "double heterogeneity" factor (DHF):

$$
f_{a g}^{i}=\frac{\sigma_{g}^{i}}{\sigma_{g}^{i, C P M}}
$$

By construction, multiplying the fine group microscopic absorption cross section from CPM3 by the corresponding DHF will yield the MCNP5 value of this cross section. In other words, the 
DHF modifies the CPM3 cross section to account for the double heterogeneity. The corrected cross sections will automatically account for all of the heterogeneities in the configuration being analyzed, including resonance overlap and spatial location within the core, to the extent this is modeled in the MCNP5 simulations. Once the adjusted resonance cross sections for the TRISO particle fuel regions are determined, they take the place of the usual CPM3 cross sections, so subsequent neutronic analyses, including preparation of global cross sections and depletion (MCNP5 would be called again in the next timestep), would proceed in accordance with the conventional CPM3/global analysis methodology.

The next section describes how the DHFs are computed and used in CPM3. This methodology is different from that originally described in the proposal to DoE. Partway through this project, after the original approach had been developed and tested, it was realized that this approach had some drawbacks and that an alternative approach was just as accurate but had several advantages: it was computationally simpler, it was capable of handling more general configurations, and it just as accurate. Both the original and new methods are described in the next section.

\section{B. Description of Methodology}

\section{Original Proposed Method: Direct (Inline) Replacement of Cross Sections}

The original idea was to have an "inline" Monte Carlo capability imbedded within a conventional lattice physics code such as CPM3. The Monte Carlo routine (MCNP5) would compute the fine group resonance cross sections for all the resonance absorbers in the actual geometry of interest, such as a TRISO fuel compact or a VHTR fuel block. This was accomplished early in the project when a preliminary version of an Application Program Interface (API) was developed. The API consisted of a Fortran-90 code that was embedded in the CPM3 source code to couple CPM3 and MCNP5. CPM3 and MCNP5 were run concurrently on the same VHTR geometry, except MCNP5 explicitly modeled the particle fuel in the fuel compact while CPM3 modeled a homogenized fuel compact. MCNP5 calculated 65-group resonance absorption and fission cross sections for all of the CPM3 resonance isotopes in the fuel kernels. These MCNP5-generated resonance group cross sections were then communicated to CPM3 which over-wrote the corresponding cross sections it had computed with its own (approximate) resonance absorption model. CPM3 then proceeded to perform its transport calculation (either with the collision probability method or the method of characteristics) and generated multigroup diffusion (MGD) cross sections for subsequent global analysis.

In essence, the original method proposed for this project can be summarized by the following equation:

$$
\sigma_{x g}^{i, C P M 3-M O D}=\sigma_{x g}^{i, M C N P 5-h e t}
$$

where $\sigma_{x g}^{i, M C N P 5-h e t}$ is the MCNP5-generated fine group $\mathrm{g}$ resonance cross section for isotope $\mathrm{i}$ and $\sigma_{x g}^{i, C P M 3-M O D}$ is the corresponding cross section in CPM3. In other words, the fine group resonance cross sections from a MCNP5 calculation with heterogeneous fuel replace the fine group resonance cross sections computed by CPM3 with homogeneous fuel. The CPM3 transport calculation, either MOC or CP, would then proceed using the modified set of MCNP5generated fine group microscopic cross sections for the resonance isotopes. 
The method worked very well but was relatively difficult to use because of the simultaneous execution of MCNP5 and CPM3. Also, this method could not account for fuel blocks near the core periphery versus the core interior unless an "environmental" region was included to account for the reflector. Finally, depletion was going to be a major headache if one insisted on simultaneous execution of the two codes. As a result, it was decided to try an alternative method that was much simpler to implement, gave satisfactory accuracy for TRISO configurations, could correctly account for a fuel block anywhere in the core, and depletion did not appear to be a significant obstacle.

Since the direct replacement method was not pursued beyond the development of the preliminary version of the API described above, the detailed description of this work has been included in Appendix A rather than the body of this report.

\section{Final Method: Double Heterogeneity Factors}

The new approach is ostensibly a minor variation on the original method but it has major implications for ease of use and practicality for routine analysis, and can be applied to more general configurations that the original method. The method requires two MCNP5 calculations of the desired VHTR configuration, typically full core, one with homogeneous TRISO fuel and one with heterogeneous (i.e., explicit kernels) fuel. The idea is to compute a double heterogeneity factor (DHF) as the ratio of fine group microscopic cross sections from the two MCNP5 calculations:

$$
\begin{aligned}
f_{x g}^{i} & =\frac{\text { fine group resonance cross section from MCNP5 (heterogeneous fuel compacts) }}{\text { fine group resonance cross section from MCNP5 (homogeneous fuel compacts) }} \\
& =\frac{\sigma_{x g}^{i, M C N P 5-h e t}}{\sigma_{x g}^{i, M C N P S-\mathrm{hom}}}
\end{aligned}
$$

The DHFs are then transmitted to CPM3 where they multiply the corresponding fine group microscopic cross section. The new method can be described by the following equation:

$$
\sigma_{x g}^{i, C P M 3-M O D} \approx \sigma_{x g}^{i, C P M 3} f_{x g}^{i}
$$

where $f_{x g}^{i}$ is the DHF.

In this case the correction factor multiplies the CPM3 cross section and consists of the ratio of fine group resonance cross sections computed by MCNP5 for heterogeneous fuel versus homogeneous fuel.

For comparison, the cross section replacement method in Eq. (8) is equivalent to using a correction factor defined by:

$$
\tilde{f}_{x g}^{i}=\frac{\sigma_{x g}^{i, M C N P 5-h e t}}{\sigma_{x g}^{i, C P M 3}}
$$

where 


$$
\begin{aligned}
\sigma_{x g}^{i, M C N P 5-h e t}= & \text { fine group } \mathrm{g} \text { cross section for reaction type } \mathrm{x} \text { for isotope } \mathrm{i} \text { from the MCNP5 } \\
& \text { calculation with heterogeneous fuel and } \\
\sigma_{x g}^{i, C P M 3}= & \text { fine group } \mathrm{g} \text { cross section for reaction type } \mathrm{x} \text { for isotope } \mathrm{i} \text { from the MCNP5 } \\
& \text { calculation with homogeneous fuel. }
\end{aligned}
$$

Since CPM3 can analyze a VHTR configuration with homogeneous fuel, the denominators of Eqs. (8) and (9) should be about the same, i.e., $\sigma_{x g}^{i, C P M 3} \approx \sigma_{x g}^{i, M C N P 5-\text { hom }}$ hence the resultant corrected resonance cross sections $\sigma_{x g}^{i, C P M 3-M O D}$ from both methods should be comparable.

The results with DHFs instead of direct replacement of CPM3 cross sections with MCNP5 cross sections are essentially the same and the recommended methodology as a result of this project is based on using DHFs. However, the next section reports on a number of analyses that include direct replacement as well as DHFs. This is due to the fact that a substantial number of cases had already been performed with direct replacement, and it was decided not to repeat these cases with the DHF method since the numerical results indicated the differences between the two methods were negligible.

\section{Comparison of Direct Replacement and DHF Methodology}

The original proposed method to update the CPM3 cross sections assumed the MCNP5 and CPM3 calculations were being performed concurrently on the same geometry. This approach has several disadvantages:

- Running MCNP5 and CPM3 simultaneously requires additional coding and communications links between the codes. The DHF approach avoids this because the DHFs do not depend on the CPM3 calculation.

- The implementation of this methodology into another lattice code, such as CASMO-4 or HELIOS, will be far simpler because the DHF approach is independent of the eventual lattice code that will use the adjusted resonance cross sections, except for the energy group structure which is readily handled by appropriately changing the MCNP5 tallies.

- The adjusted cross sections using the original approach will be the same no matter where the fuel block is located in the core because both MCNP5 and CPM3 will analyze the fuel block with zero current boundary conditions. However, with the DHF approach, both the MCNP5 heterogeneous and homogeneous runs can be the same full core calculation, allowing DHFs to be computed easily for any assembly in the core, such as a fuel block located near the reflector or in the center or the core. However, it has been found that the DHFs are relatively insensitive to location within the fuel block or within the core, as discussed in Section V.F.

- The treatment of depletion is straightforward with DHFs but would be quite tedious with the original approach because both CPM3 and MCNP5 would need to be depleted simultaneously for the same configuration. The use of DHFs simplifies this considerably because the CPM3 and MCNP5 calculations are decoupled.

- Branch cases and restarts would also require a level of synchronization with concurrent execution of MCNP5 and CPM3 that is not required with the DHF method. 
- In addition, it has been found (see Section V.F) that DHFs are relatively insensitive to depletion because they are ratios of cross sections that reflect the self-shielding of the particle fuel, whereas individual resonance cross sections may change considerably.

In summary, the DHFs are both accurate and useful for routine reactor analysis and design and have considerable advantages over the original method to treat resonance absorption in particle fuel by using "inline" Monte Carlo analysis within a conventional lattice physics code.

\section{Computational Results}

\section{A. Summary of Test Problems and Sensitivity Calculations}

The following test problems were analyzed with both the original methodology proposed for this project as well as the DHF methodology that was formulated and developed during the latter portion of the project. The configurations that were examined include:

- PWR pin cell

- VHTR fuel compact cell

- VHTR fuel block

- VHTR fuel block with plutonium (Deep Burn driver fuel)

In addition to the test problems, a substantial effort was made to assess the sensitivity of the DHFs to the following variables:

- Spatial position in a fuel block

- Spatial position in the core

- Fuel packing factor

The test problems and sensitivity calculations are described in the following sections.

\section{B. Analysis of PWR Pin Cell}

\section{Description of PWR Pin Cell}

The overall goal is to use this hybrid methodology for TRISO fuel but the decision was made to first consider a simple geometry such as a LWR pin cell, which can be analyzed with CPM3 and compared to MCNP5. This case was a feasibility check to make sure that the correct cross sections were being transferred from MCNP5 to CPM3 and that this methodology would give reasonable results for this simple case. This work was performed with the originally proposed replacement method, shown in Eq. (6), not the DHF method that was eventually adopted for this project.

The test problem is a classical PWR pin cell calculation. The pin cell consists of three material regions. The square outer region is the moderator region and the two inner cylindrical regions are the fuel cladding and fuel pellet. No gap was modeled. The pin cell is assumed to be at room 
temperature and reflective ("white") boundary conditions are applied to the outer boundaries for both MCNP5 and CPM3 models. Pin cell geometry and dimensions are shown in Figure 3 and Table 1 details the compositions of the three regions, which are consistent with standard PWR fuel.

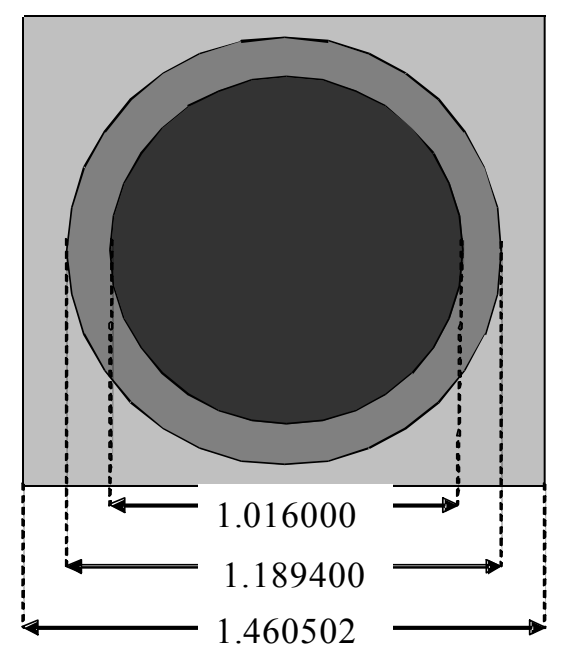

Figure 3. Pin Cell Geometry and Dimensions (cm).

Table 1. Material Composition of the PWR Pin Cell

\begin{tabular}{|c|c|c|c|c|c|c|}
\hline & Density & \multicolumn{5}{|c|}{ Weight Percent } \\
\cline { 3 - 7 } & $\left(\mathrm{g} / \mathrm{cm}^{3}\right)$ & ${ }^{235} \mathrm{U}$ & ${ }^{238} \mathrm{U}$ & ${ }^{16} \mathrm{O}$ & ${ }^{40} \mathrm{Zr}$ & ${ }^{1} \mathrm{H}$ \\
\hline Fuel & 10.40200 & 2.42561 & 85.72209 & 11.85230 & - & - \\
\hline Clad & 6.08126 & - & - & - & 100.0 & - \\
\hline Moderator & 0.99826 & - & - & 88.80900 & - & 11.19099 \\
\hline
\end{tabular}

\section{Numerical Results for the PWR Pin Cell}

Energy group structure. The MCNP5 and CPM3 calculations were performed with the 97 energy group structure from CPM3. The MCNP5 simulation includes tallies for all 97 energy groups but only selected groups are reported. Table 2 gives the energy group boundaries for selected energy groups, including group 57 which contains the $6.67 \mathrm{eV}$ resonance of U-238. This energy group structure was also used for the VHTR compact cell case that is discussed in the next section.

Table 2. Energy Group Boundaries.

\begin{tabular}{|c|c|c|}
\hline Group & Lower $(\mathbf{e V})$ & Higher $(\mathbf{e V})$ \\
\hline $\mathbf{5 7}$ & 6.476 & 8.315 \\
\hline $\mathbf{5 3}$ & 17.6 & 22.6 \\
\hline $\mathbf{5 1}$ & 29.02 & 37.27 \\
\hline $\mathbf{3 8}$ & 748.5 & 961.1 \\
\hline
\end{tabular}


Comparison of $\mathbf{k}_{\infty}$. The results for the prediction of $\mathbf{k}_{\infty}$ for the PWR pin cell are tabulated in Table 3. As can be seen, the $\mathrm{k}_{\infty}$ predictions by CPM-3 and MCNP5 agreed to within .095\% prior to the incorporation of the MCNP5-generated cross sections into CPM-3, which reduced this difference to $0.07 \%$, which is in the right direction. Since this is a PWR pin cell for which the CPM-3 calculation is considered quite accurate, the $\mathrm{k}_{\infty}$ difference between CPM-3 and MCNP5 may be due to other effects, including differences in the thermal models. This was investigated in some detail but no firm conclusions could be drawn. This is simply a consequence of different models and the fact that the current methodology impacts only the resonance cross sections.

Table 3. $\mathrm{k}_{\infty}$ values Predicted by CPM-3 and MCNP5 for PWR Pin Cell.

\begin{tabular}{|c|c|c|c|}
\hline & $\begin{array}{c}\text { Original } \\
\text { CPM-3 }\end{array}$ & $\begin{array}{c}\text { Modified } \\
\text { CPM-3 }\end{array}$ & MCNP5 \\
\hline $\mathbf{k}_{\infty}$ & 1.343617 & 1.34137 & 1.34234 \\
\hline Difference (\%) & 0.095 & 0.072 & \\
\hline
\end{tabular}

Comparison of microscopic cross sections. Table 4 presents the key microscopic cross sections $\sigma_{\mathrm{a}}$ and $\nu \sigma_{\mathrm{f}}$ for microgroups 57 and 58, with the energy intervals $[6.476,8.315] \mathrm{eV}$ and $[5.044$, 6.476] eV, respectively. Groups 57 and 58 were studied due to the presence of two ${ }^{235} \mathrm{U}$ resonances and one large ${ }^{238} \mathrm{U}$ resonance over the span of the energy groups thus allowing for direct comparisons of the two methods to represent large absorption resonances. Large differences are noted in $\nu \sigma_{\mathrm{f}}$ for both groups and for both ${ }^{235} \mathrm{U}$ and ${ }^{238} \mathrm{U}$, and for both pin cell cases. The order-of-magnitude differences noted in $v \sigma_{\mathrm{f}}$ for group 57 for ${ }^{238} \mathrm{U}$ are not quite as bad as they appear due to the small magnitude of the ${ }^{238} \mathrm{U}$ cross section.

Table 4. Comparison of Microscopic Cross Sections for MCNP5 and CPM3 for PWR Pin Cell.

\begin{tabular}{|c|c|c|c|c|c|}
\hline Nuclides & Group \# & $\begin{array}{l}\text { Cross } \\
\text { Section }\end{array}$ & MCNP5 & CPM3 & $\begin{array}{c}\% \\
\text { Difference }\end{array}$ \\
\hline \multirow{5}{*}{${ }^{235} \mathrm{U}$} & \multirow[b]{2}{*}{57} & $\sigma_{0}$ & $2.780 \mathrm{E}+01$ & $2939 \mathrm{E}+01$ & $5.7 \%$ \\
\hline & & $v_{\mathrm{a}}$ & $3.072 \mathrm{E}+01$ & $2.764 \mathrm{E}+01$ & $-10 \%$ \\
\hline & & & & & \\
\hline & \multirow{2}{*}{58} & $\sigma_{a}$ & $4.810 \mathrm{E}+01$ & $5.067 \mathrm{E}+01$ & $5.3 \%$ \\
\hline & & $v \sigma_{f}$ & $5.641 \mathrm{E}+01$ & $4.515 \mathrm{E}+01$ & $-20 \%$ \\
\hline \multirow{6}{*}{${ }^{238} \mathrm{U}$} & \multirow{3}{*}{57} & & $2050 \Gamma$ & & 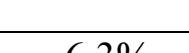 \\
\hline & & $\sigma_{\mathrm{a}}$ & $2.050 \mathrm{E}+01$ & $1.920 \mathrm{E}+01$ & $-6.3 \%$ \\
\hline & & $v \sigma_{\mathrm{f}}$ & $1.861 \mathrm{E}-05$ & 7.135E-07 & $-96 \%$ \\
\hline & \multirow{3}{*}{58} & & & & $030 /$ \\
\hline & & $\sigma_{\mathrm{a}}$ & $7.690 \mathrm{E}+00$ & $7.666 \mathrm{E}+00$ & $-0.3 \%$ \\
\hline & & $v \sigma_{f}$ & $1.531 \mathrm{E}-05$ & $1.261 \mathrm{E}-05$ & $-17.6 \%$ \\
\hline
\end{tabular}

Comparison of macroscopic cross sections. We now compare in Table 5 macroscopic cross sections $\Sigma_{\mathrm{a}}, \Sigma_{\mathrm{f}}$, and $v \Sigma_{\mathrm{f}}$ edited for each of the spatial regions of the PWR pin cell. The differences in $\Sigma_{\mathrm{f}}$ and $v \Sigma_{\mathrm{f}}$ for groups 57 and 58 are large due to the high concentration of ${ }^{238} \mathrm{U}$ in the fuel region. 
Table 5. Comparison of Fine Group Macroscopic Cross Sections between MCNP5 and CPM3 for PWR Pin Cell

\begin{tabular}{|c|c|c|c|c|c|}
\hline Regions & Group \# & $\begin{array}{c}\text { Cross } \\
\text { Section }\end{array}$ & MCNP5 & CPM3 & $\begin{array}{c}\% \\
\text { Difference }\end{array}$ \\
\hline & & & & & \\
\hline \multirow{4}{*}{ Fuel } & \multirow{3}{*}{57} & $\Sigma_{\mathrm{a}}$ & $4.810 \mathrm{E}-01$ & $4.522 \mathrm{E}-01$ & $-5.988 \%$ \\
\cline { 2 - 6 } & & $\nu_{\mathrm{f}}$ & $2.020 \mathrm{E}-02$ & $1.787 \mathrm{E}-02$ & $-11.535 \%$ \\
\cline { 2 - 6 } & & $\Sigma_{\mathrm{f}}$ & $8.290 \mathrm{E}-03$ & $7.343 \mathrm{E}-03$ & $-11.423 \%$ \\
\cline { 2 - 6 } & \multirow{3}{*}{58} & $\Sigma_{\mathrm{a}}$ & $2.050 \mathrm{E}-01$ & $2.057 \mathrm{E}-01$ & $0.341 \%$ \\
\cline { 2 - 6 } & & $\Sigma_{\mathrm{f}}$ & $3.720 \mathrm{E}-02$ & $2.919 \mathrm{E}-02$ & $-21.532 \%$ \\
\cline { 2 - 6 } & $\Sigma_{\mathrm{f}}$ & $1.520 \mathrm{E}-02$ & $1.199 \mathrm{E}-02$ & $-21.118 \%$ \\
\hline \multirow{2}{*}{ Clad } & 57 & $\Sigma_{\mathrm{a}}$ & $4.210 \mathrm{E}-04$ & $4.250 \mathrm{E}-04$ & $0.950 \%$ \\
\hline \multirow{2}{*}{ Moderator } & 58 & $\Sigma_{\mathrm{a}}$ & $4.860 \mathrm{E}-04$ & $4.843 \mathrm{E}-04$ & $-0.350 \%$ \\
\cline { 2 - 6 } & 57 & $\Sigma_{\mathrm{a}}$ & $1.300 \mathrm{E}-03$ & $1.304 \mathrm{E}-03$ & $0.308 \%$ \\
\hline & 58 & $\Sigma_{\mathrm{a}}$ & $1.480 \mathrm{E}-03$ & $1.478 \mathrm{E}-03$ & $-0.135 \%$ \\
\hline
\end{tabular}

Finally, we compare two-group macroscopic cross sections for the entire pin cell, with the group boundary at the traditional Cd cutoff of $0.625 \mathrm{eV}$. The comparison summarized in Table 6 indicates that the differences seen in Table 5 for $\Sigma_{\mathrm{f}}$ and $v \Sigma_{\mathrm{f}}$ in microgroups are largely integrated out in the two-group edits to yield acceptable agreement for two-group cross sections for the PWR pin cell. Some of the differences may be due to the use of the critical buckling search in CPM3 calculations, while simple infinite-medium calculations with reflecting boundaries have been performed with MCNP5.

Table 6. Comparison of Two-group Macroscopic Cross Sections between MCNP5 and CPM3 for PWR Pin Cell

\begin{tabular}{|c|c|c|c|c|}
\hline Group \# & $\begin{array}{c}\text { Cross } \\
\text { Section }\end{array}$ & MCNP5 & CPM3 & $\begin{array}{c}\% \\
\text { Difference }\end{array}$ \\
\hline \multirow{3}{*}{1} & $\Sigma_{\mathrm{a}}$ & $1.070 \mathrm{E}-02$ & $1.033 \mathrm{E}-02$ & $-3.458 \%$ \\
\hline & $\nu_{\mathrm{f}}$ & $7.890 \mathrm{E}-03$ & $7.713 \mathrm{E}-03$ & $-2.243 \%$ \\
\cline { 2 - 5 } & $\Sigma_{\mathrm{f}}$ & $3.090 \mathrm{E}-03$ & $3.010 \mathrm{E}-03$ & $-2.589 \%$ \\
\hline \multirow{3}{*}{2} & $\Sigma_{\mathrm{a}}$ & $1.110 \mathrm{E}-01$ & $1.103 \mathrm{E}-01$ & $-0.631 \%$ \\
\cline { 2 - 5 } & $\nu_{\mathrm{f}}$ & $1.860 \mathrm{E}-01$ & $1.850 \mathrm{E}-01$ & $-0.538 \%$ \\
\cline { 2 - 5 } & $\Sigma_{\mathrm{f}}$ & $7.650 \mathrm{E}-02$ & $7.601 \mathrm{E}-02$ & $-0.641 \%$ \\
\hline
\end{tabular}

Figure 4 compares the overall group fluxes for MCNP5 and CMP3 using the 97 group flux tallies from MCNP5 and the CPM3 group flux edit. As can be seen, the agreement appears to be quite good. For completeness, Figure 5 compares a 97 group MCNP5 cross section tally with a "finegroup" MCNP5 tally. 


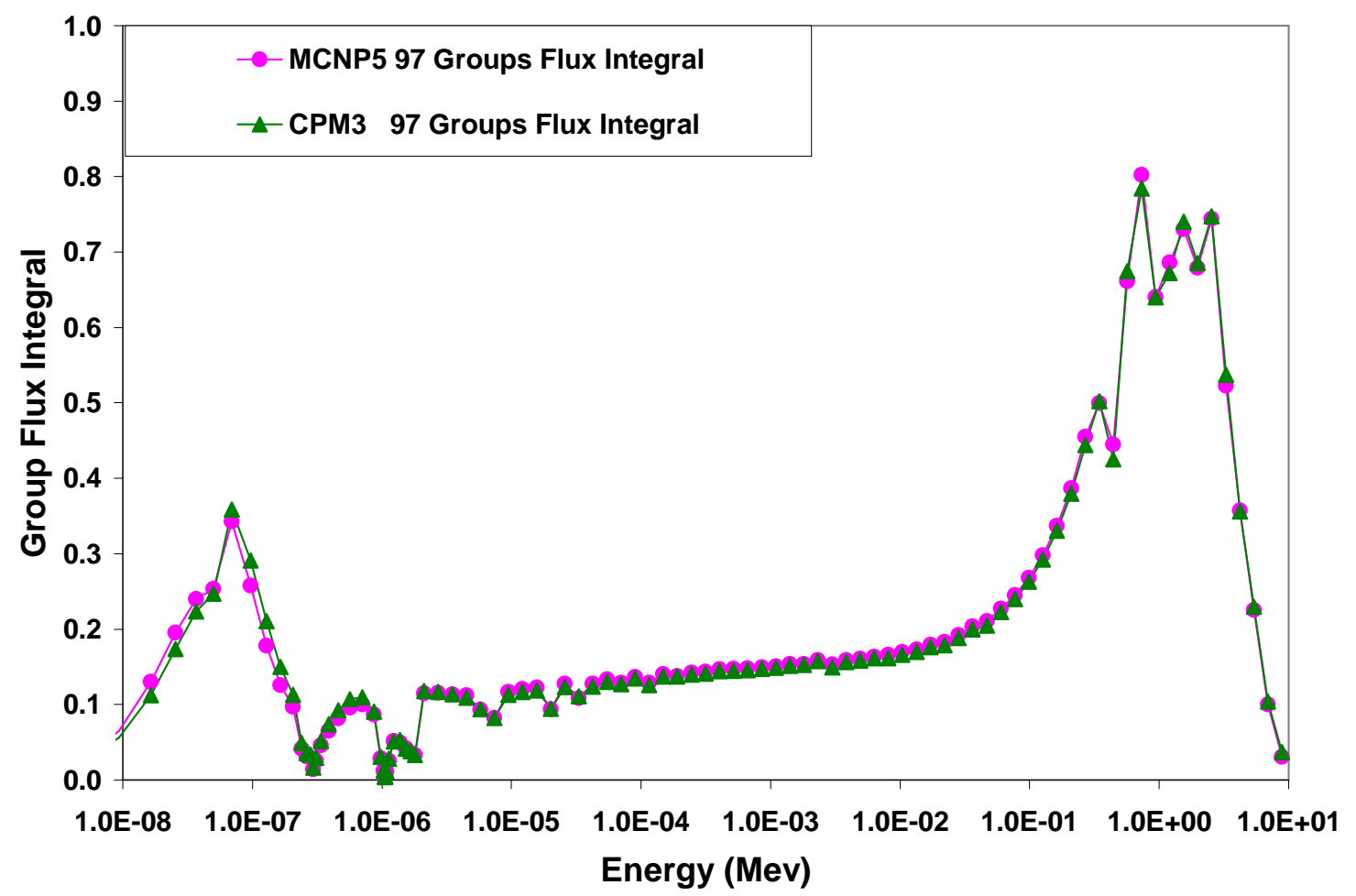

Figure 4. Comparison of MCNP5 and CPM3 Group Fluxes

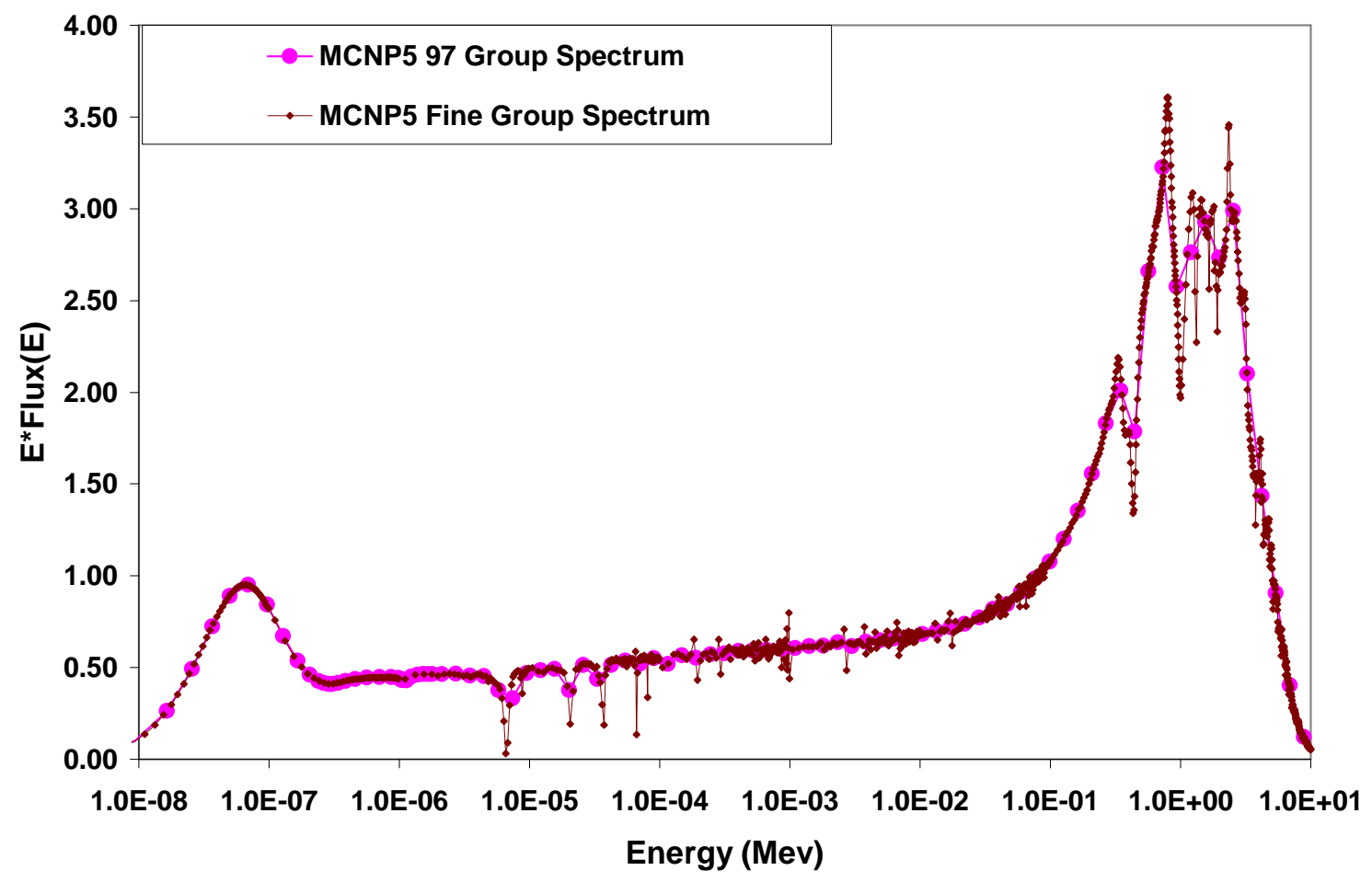

Figure 5. Comparison of MCNP5 97 and Fine Group Spectra 


\section{Analysis of VHTR Compact Cell}

\section{Description of VHTR Compact Cell}

The VHTR fuel compact cell is an idealized unit cell that consists of a fuel compact surrounded by its share of the graphite in a fuel block. It does not exist in reality but is a useful geometry because it is simple yet includes the double heterogeneity, and can be used to compare alternative computational models. The compact cell is composed of an inner cylindrical fuel compact and an outer hexagonal graphite moderator region. The outer region includes a proportional share of the graphite in the fuel block that "belongs" to the average fuel compact, including boron impurities. The fuel compact region consists of fuel kernels surrounded by $\mathrm{SiC}$ and PyC layers. The packing fraction is $29 \%$. Table 7 summarizes the dimensions of the VHTR fuel compact that is modeled by both MCNP5 and CPM3. Figure 6 is a diagram of the VHTR compact cell.

Table 7. Heterogeneous and Homogeneous VHTR Fuel Compact Cell Dimensions.

\begin{tabular}{|l|c|l|c|l|c|}
\hline \multicolumn{2}{|c|}{ Fuel Particle } & \multicolumn{2}{c|}{ Fuel Compact } & \multicolumn{2}{c|}{ Moderator } \\
\hline & Radius (cm) & & Radius (cm) & & Pitch (cm) \\
\hline Fuel Kernel & 0.0175 & Graphite & 0.6225 & Graphite & 1.8796 \\
\hline Porous PyC & 0.0275 & & Height (cm) & & Height (cm) \\
\hline Inner PyC & 0.0315 & Graphite & 4.5553 & Graphite & 4.5553 \\
\hline SiC & 0.0350 & & & & \\
\hline Outer PyC & 0.0390 & & & & \\
\hline
\end{tabular}

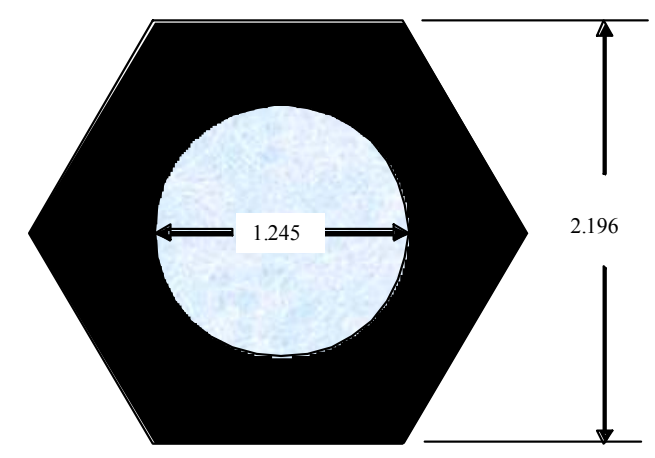

Figure 6. VHTR Compact Cell Dimensions (cm)

Material composition. Number densities and weight fractions that were input to MCNP5 and CPM3 for the fuel compacts are summarized in Table 8 . 
Table 8. Material Composition of Fuel Compact for MCNP5 and CPM3 Calculations.

\begin{tabular}{|c|c|c|c|c|c|}
\hline \multicolumn{2}{|c|}{ MCNP (Heterogeneous) } & \multicolumn{2}{|c|}{ MCNP (Homogeneous) } & \multicolumn{2}{|c|}{ CPM3 (Homogeneous) } \\
\hline Fuel Kernel & $(a t / c c)$ & Fuel Compact & $(a t / c c)$ & Fuel Compact & (Weight \%) \\
\hline U-235 & 2.4749E-03 & U-235 & 6.4622E-05 & U-235 & $1.2691 \mathrm{E}+00$ \\
\hline$U-238$ & $2.1142 \mathrm{E}-02$ & $U-238$ & $5.5204 \mathrm{E}-04$ & $U-238$ & $1.0981 \mathrm{E}+01$ \\
\hline$C$ & $1.1808 \mathrm{E}-02$ & $C$ & 7.9957E-02 & $C$ & $8.0153 E+01$ \\
\hline 0 & 3.5426E-02 & 0 & $9.2499 \mathrm{E}-04$ & 0 & $1.2363 \mathrm{E}+00$ \\
\hline & & Si & 2.7206E-03 & Si & $6.3603 \mathrm{E}+00$ \\
\hline Porous PyC & $(a t / c c)$ & & & & \\
\hline$C$ & 5.0183E-02 & & & & \\
\hline Inner PyC & $(a t / c c)$ & & & & \\
\hline C & $9.5348 \mathrm{E}-02$ & & & & \\
\hline $\mathrm{SiC}$ & $(a t / c c)$ & & & & \\
\hline$C$ & 4.8060E-02 & & & & \\
\hline Si & $4.8060 \mathrm{E}-02$ & & & & \\
\hline Outer PyC & $(a t / c c)$ & & & & \\
\hline$C$ & $9.5348 \mathrm{E}-02$ & & & & \\
\hline Graphite Matrix & $(a t / c c)$ & & & & \\
\hline$C$ & $8.5312 \mathrm{E}-02$ & & & & \\
\hline Moderator & $(a t / c c)$ & Moderator & $(a t / c c)$ & Moderator & (Weight \%) \\
\hline$C$ & 8.7241E-02 & $C$ & 8.7241E-02 & $C$ & $9.9999 \mathrm{E}+01$ \\
\hline B-10 & 1.4369E-07 & B-10 & 1.4369E-07 & B-10 & 1.3743E-04 \\
\hline $\mathrm{B}-11$ & 5.7838E-07 & $\mathrm{B}-11$ & $5.7838 \mathrm{E}-07$ & B-11 & $6.0823 \mathrm{E}-04$ \\
\hline
\end{tabular}

\section{Numerical Results for the VHTR Fuel Compact Cell}

This geometry was analyzed with the directly coupled CPM3/MCNP5 methodology. The CPM3 model used homogenized fuel while MCNP5 explicitly resolved the TRISO fuel particles.

MCNP5 and CPM3 simulations. The MCNP5 simulation had 25,000 starting particles per cycle with 250 active cycles and 50 inactive cycles. The 65 -group resonance cross sections for the fuel nuclides were calculated by MCNP5 and transferred into CPM3 with the previously implemented Fortran module, overwriting the resonance cross sections determined by CPM3 for the homogeneous fuel region. The spectrum and transport calculations for the VHTR compact cell were then performed by CPM3 in its standard way except with resonance cross sections from MCNP5 rather than from CPM3.

Table 9 includes macroscopic cross sections $\Sigma_{\mathrm{a}} \Sigma_{\mathrm{f}}$, and $v \Sigma_{\mathrm{f}}$ edited for each of the spatial regions of the VHTR fuel compact cell. The ${ }^{238} \mathrm{U}$ content is decreased significantly compared with the PWR case, thereby significantly reducing the differences in the macroscopic cross sections then observed with the PWR case results in Table 5. 
Table 9. Comparison of Fine Group Macroscopic Cross Sections between MCNP5 and CPM3 for the VHTR Fuel Compact Cell

\begin{tabular}{|c|c|c|c|c|c|}
\hline Regions & Group \# & $\begin{array}{c}\text { Cross } \\
\text { Section }\end{array}$ & MCNP5 & CPM3 & $\begin{array}{c}\% \\
\text { Difference }\end{array}$ \\
\hline & & & & & \\
\hline \multirow{4}{*}{ Fuel } & \multirow{3}{*}{57} & $\Sigma_{\mathrm{a}}$ & $9.888 \mathrm{E}-02$ & $1.004 \mathrm{E}-01$ & $1.537 \%$ \\
\cline { 3 - 6 } & & $\nu_{\mathrm{f}}$ & $2.160 \mathrm{E}-03$ & $2.183 \mathrm{E}-03$ & $1.065 \%$ \\
\cline { 2 - 6 } & & $\Sigma_{\mathrm{f}}$ & $8.874 \mathrm{E}-04$ & $8.970 \mathrm{E}-04$ & $1.082 \%$ \\
\cline { 2 - 6 } & \multirow{3}{*}{58} & $\Sigma_{\mathrm{a}}$ & $1.041 \mathrm{E}-02$ & $1.040 \mathrm{E}-02$ & $-0.096 \%$ \\
\cline { 2 - 6 } & & $\nu_{\mathrm{f}}$ & $4.459 \mathrm{E}-03$ & $4.364 \mathrm{E}-03$ & $-2.131 \%$ \\
\cline { 2 - 6 } & & $\Sigma_{\mathrm{f}}$ & $1.832 \mathrm{E}-03$ & $1.793 \mathrm{E}-03$ & $-2.129 \%$ \\
\hline \multirow{2}{*}{ Moderator } & 57 & & & & \\
\cline { 2 - 6 } & 58 & $\Sigma_{\mathrm{a}}$ & $4.970 \mathrm{E}-05$ & $4.990 \mathrm{E}-05$ & $0.402 \%$ \\
\hline
\end{tabular}

Finally, two-group macroscopic cross sections for the VHTR compact cell from MCNP5 and CPM3 are compared in Table 10, with the group boundary at the traditional Cd cutoff of 0.625 $\mathrm{eV}$.

Table 10. Comparison of Two-group Macroscopic Cross Sections between MCNP5 and CPM3 for the VHTR Fuel Compact Cell

\begin{tabular}{|c|c|c|c|c|}
\hline Group \# & $\begin{array}{c}\text { Cross } \\
\text { Section }\end{array}$ & MCNP5 & CPM3 & $\begin{array}{c}\% \\
\text { Difference }\end{array}$ \\
\hline & & & & \\
\hline \multirow{3}{*}{1} & $\Sigma_{\mathrm{a}}$ & $1.345 \mathrm{E}-03$ & $1.254 \mathrm{E}-03$ & $-6.766 \%$ \\
\cline { 2 - 5 } & $\nu \Sigma_{\mathrm{f}}$ & $6.646 \mathrm{E}-04$ & $6.270 \mathrm{E}-04$ & $-5.658 \%$ \\
\cline { 2 - 5 } & $\Sigma_{\mathrm{f}}$ & $2.719 \mathrm{E}-04$ & $2.564 \mathrm{E}-04$ & $-5.701 \%$ \\
\hline \multirow{3}{*}{2} & & & & \\
\hline & $\Sigma_{\mathrm{a}}$ & $9.005 \mathrm{E}-03$ & $8.684 \mathrm{E}-03$ & $-3.564 \%$ \\
\cline { 2 - 5 } & $\nu_{\mathrm{f}}$ & $1.697 \mathrm{E}-02$ & $1.636 \mathrm{E}-02$ & $-3.595 \%$ \\
\cline { 2 - 5 } & $\Sigma_{\mathrm{f}}$ & $6.964 \mathrm{E}-03$ & $6.722 \mathrm{E}-03$ & $-3.475 \%$ \\
\hline
\end{tabular}

The comparison summarized in Table 10 is not as good as might be expected given the good comparison in Table 9 with the fine group cross sections in the resonance range. However, the methodology that has been developed is only intended to modify the resonance cross sections, so the comparison in Table 9 is more important than that in Table 10, which is affected by other differences between MCNP5 and CPM3, such as the thermal calculation or the use of the critical buckling search in CPM3. For an assessment of the current methodology, it is more important to compare quantities that directly relate to resonance absorption and the double heterogeneity, as discussed in the next section.

Comparison of MCNP5 and CPM3 results. The MCNP5 and CPM3 predictions for the VHTR compact cell are compared for several quantities, including $\mathrm{k}_{\infty}$, the effective two-group cross sections for the cell, and the overall resonance escape probability for the cell. Since MCNP5 
does not calculate the downscattering cross section $\Sigma_{\text {s12 }}$, this quantity was inferred from the other quantities that are computed by MCNP5. Using the well-known expression for the infinite medium multiplication factor in terms of the standard two-group diffusion constants:

$$
k=\frac{v_{1} \Sigma_{f 1}}{\Sigma_{R 1}+D_{1} B^{2}}+\frac{\Sigma_{s 12}}{\Sigma_{R 1}+D_{1} B^{2}} \frac{v_{2} \Sigma_{f 2}}{\Sigma_{a 2}+D_{2} B^{2}}
$$

where $\Sigma_{\mathrm{R} 1}=\Sigma_{\mathrm{a} 1}+\Sigma_{\mathrm{s} 12}$. This assumes no upscattering which is not strictly correct for the VHTR cell but this has little effect on the comparison. The resonance escape probability is defined:

$$
p_{\text {esc }}=\frac{\Sigma_{s 12}}{\Sigma_{a 1}+\Sigma_{s 12}}
$$

However, MCNP5 does not have a tally for group transfer rates, and the downscattering cross section $\Sigma_{s 12}$ is not easily estimated. However, it can be obtained indirectly because the VHTR compact cell has zero leakage. In this case, Eq. (10) becomes:

$$
k_{\infty}=\frac{v_{1} \Sigma_{f 1}}{\Sigma_{a 1}+\Sigma_{s 12}}+\frac{\Sigma_{s 12}}{\Sigma_{a 1}+\Sigma_{s 12}} \frac{v_{2} \Sigma_{f 2}}{\Sigma_{a 2}}
$$

Equation (12) can be solved for $\Sigma_{s 12}$ :

$$
\Sigma_{s 12}=\frac{\Sigma_{a 2}\left(k_{\infty} \Sigma_{a 1}-v_{1} \Sigma_{f 1}\right)}{v_{2} \Sigma_{f 2}-k_{\infty} \Sigma_{a 2}}
$$

The terms on the right hand side of Eq. (13) are easily obtained from both MCNP5 tallies and CPM3 output. The resonance escape probability can then be calculated for both MCNP5 and CPM3.

Table 11 presents a comparison of MCNP5 and the original and modified versions of CPM3 for the VHTR compact cell shown in Figure 6. As expected, the unmodified CPM3 cannot predict the double heterogeneity due to the particle fuel and overestimates the resonance absorption, yielding a $\mathrm{k}_{\infty}$ that is $4 \%$ low. However, the modified version of CPM3, with MCNP5 resonance cross sections, yields excellent results for $\mathrm{k}_{\infty}$, agreeing to within .03\% with MCNP5. However, this agreement, while encouraging, is probably fortuitous, since there are substantial differences in the two-group cross sections that seem to cancel out. However, the resonance escape probability, which is underestimated by nearly $5 \%$ with the unmodified CPM3, agrees to within $.2 \%$ with the modified CPM3. This improvement is a direct consequence of the new methodology and is promising. The other differences between MCNP5 and the modified version of CPM3, such as the $2-3 \%$ differences in the two-group cross sections, are consequences of fundamental differences in MCNP5 versus CPM3 unrelated to the effort to improve the resonance treatment of CPM3 to handle TRISO fuel. 
Table 11. Comparison of CPM3 and MCNP5 for VHTR Compact Cell

\begin{tabular}{|c|c|c|c|c|c|}
\hline & MCNP5 & CPM3 & \% Difference & CPM3 (mod) & \% Difference \\
\hline $\mathbf{k}_{\infty}$ & 1.40102 & 1.341705 & -4.23 & 1.400619 & -0.029 \\
\hline $\boldsymbol{\Sigma}_{\mathbf{a} 1}$ & $1.438 \mathrm{E}-03$ & $1.550 \mathrm{E}-03$ & 7.79 & $1.398 \mathrm{E}-03$ & -2.82 \\
\hline $\boldsymbol{\Sigma}_{\mathbf{a} 2}$ & $5.418 \mathrm{E}-03$ & $5.5457 \mathrm{E}-03$ & 2.34 & $5.519 \mathrm{E}-03$ & 1.85 \\
\hline $\mathbf{v}_{\mathbf{1}} \boldsymbol{\Sigma}_{\mathbf{a} 1}$ & $7.272 \mathrm{E}-04$ & $6.845 \mathrm{E}-04$ & -5.88 & $6.921 \mathrm{E}-04$ & -4.83 \\
\hline $\mathbf{v}_{\mathbf{2}} \boldsymbol{\Sigma}_{\mathbf{a} 2}$ & $1.005 \mathrm{E}-02$ & $1.035 \mathrm{E}-02$ & 3.01 & $1.025 \mathrm{E}-02$ & 1.98 \\
\hline $\boldsymbol{\Sigma}_{\mathbf{s} \mathbf{2}}$ & $2.839 \mathrm{E}-03$ & $2.658 \mathrm{E}-03$ & -6.38 & $2.772 \mathrm{E}-03$ & -2.34 \\
\hline $\mathbf{p}_{\mathbf{e s c}}$ & .6637 & .6316 & -4.84 & & \multicolumn{2}{|c|}{.6482} & 0.16 \\
\hline
\end{tabular}

\section{Analysis of VHTR Fuel Block}

\section{Description of VHTR Fuel Block}

The VHTR fuel block is composed of 222 fuel compacts and 109 coolant holes as shown in Figure 7. The MCNP5 fuel block geometry consisted of three different hexagonal unit cells corresponding to coolant holes (white), fuel compacts (yellow), and graphite regions (green) as shown in Figure 8. The outer graphite edge of the fuel block was modeled explicitly with both MCNP5 and CPM3. No inter-block gap was modeled. It should be noted that the fuel cell in Figure 8 is a physical cell whereas the fuel compact cell in Figure 6 is an equivalent fuel compact cell with a moderator region containing its proportional share of all the graphite in the fuel block.

A heterogeneous VHTR fuel block with explicit TRISO fuel was constructed in MCNP5. The corresponding homogenized fuel block was modeled in both MCNP5 and CPM3. The VHTR fuel block is composed of 222 fuel compacts and 109 coolant holes. The MCNP5 fuel block geometry consisted of three different hexagonal unit cells corresponding to coolant holes (white), fuel compacts (yellow), and graphite regions (green) as shown in Figure 7. The outer graphite edge of the fuel block was modeled explicitly with both MCNP5 and CPM3. The flat-to-flat dimension is $0.3581 \mathrm{~m}$.

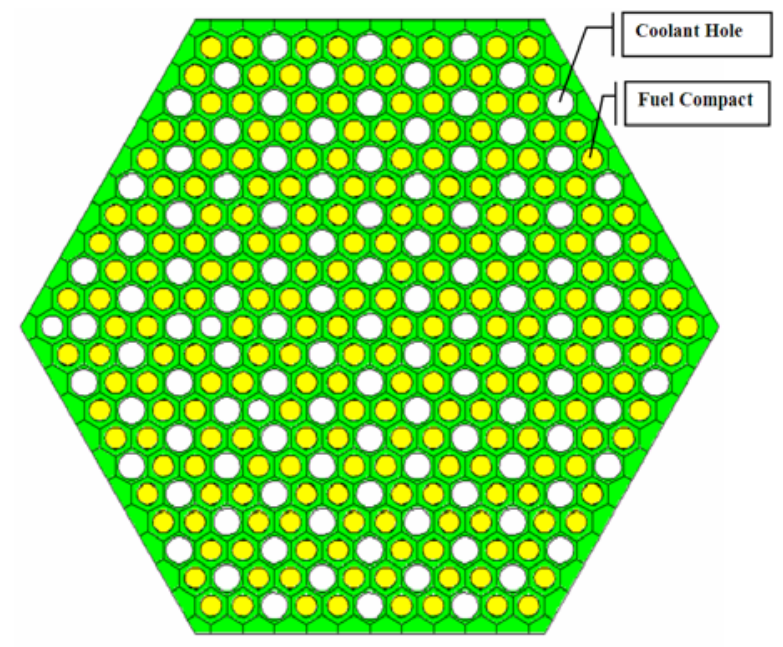

Figure 7. Cross-section View of the VHTR Fuel Block. 
Modeling of VHTR fuel block with MCNP5. A hexagonal fuel block universe was filled with the hexagonal unit cells shown in Figure 6 to obtain the full fuel block model shown in Figure 7. The repeated structure feature in MCNP5 makes this relatively easy. Reflecting boundary conditions were specified on each face of the hexagonal block.

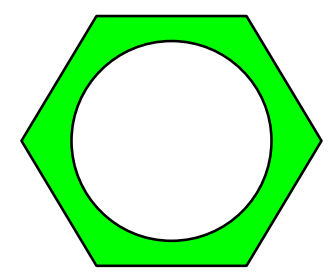

Coolant Cell

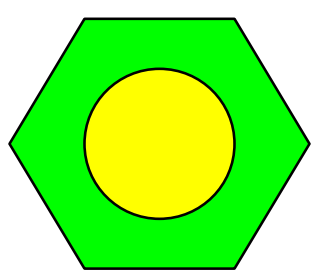

Fuel Cell

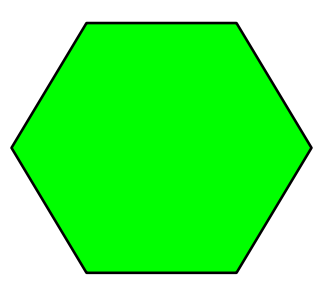

Graphite Cell

Figure 8. Hexagonal Unit Cells in VHTR Core

Modeling of VHTR fuel block with CPM3. A different approach to construct the fuel block had to be taken with CPM3 because of its restricted geometry features. Bodies must be defined explicitly in CPM3 but the graphite bodies on the outer surface of the fuel block are different sizes and are aligned at different rotational angles. The bodies that are available in CPM3 are shown in Figure 9 and these can only be rotated by 90, 180, or 270 degrees. Because of these restrictions, the VHTR fuel block shown in Figure 7 cannot be explicitly modeled with CPM3.

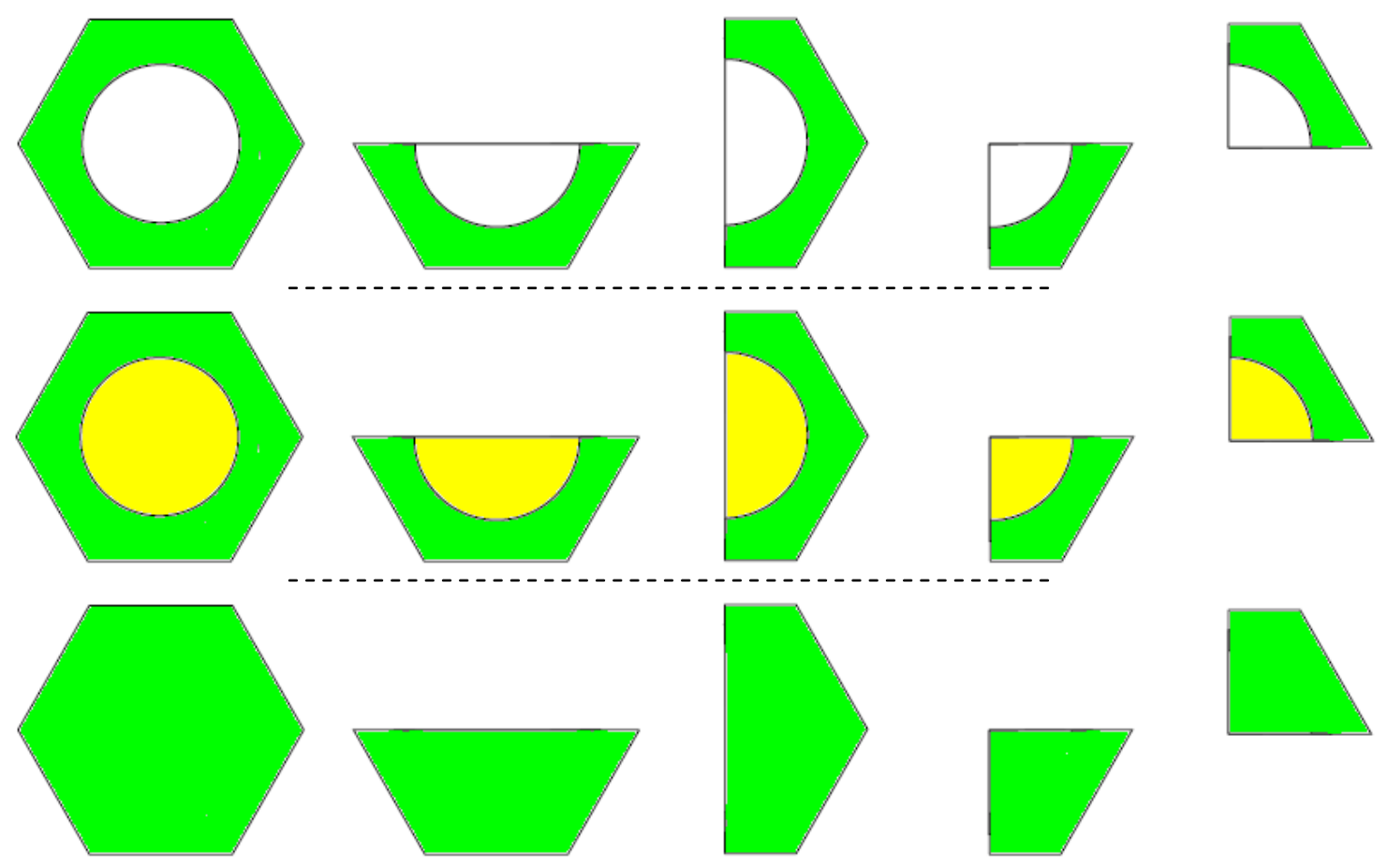

Figure 9. Hexagonal Unit Cells Available in CPM3 
This problem was overcome by identifying a portion of the repeating hexagonal lattice that is rectangular with reflecting boundary conditions, which can be modeled by CPM3. Portions of two blocks were combined to model an infinite hexagonal lattice of fuel blocks. This is shown in Figure 10, where the rectangle (marked with solid red lines) represents a repeating rectangular geometry that exactly represents an infinite lattice of hexagonal blocks. Thus the rectangle in Figure 10 models the VHTR fuel block, including the outer graphite edge. For this rectangular region, the available bodies and allowable rotational angles are sufficient to model the infinite lattice of hexagonal fuel blocks with CPM3.

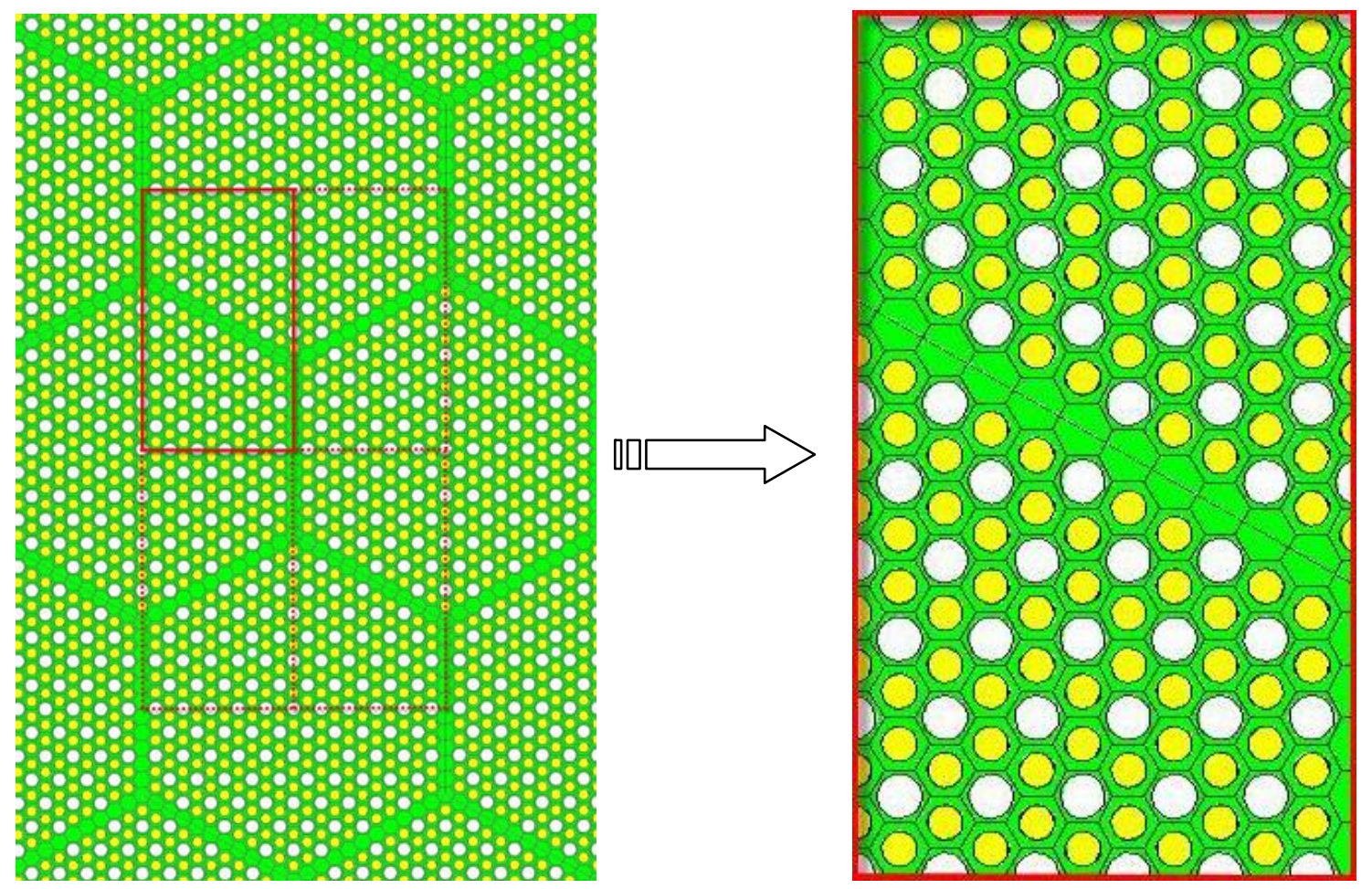

Figure 10. CPM3 Model of the VHTR Fuel Block Lattice

Homogeneous MCNP5 and CPM3 models were obtained by homogenizing the fuel region as shown in Figure 11. Only the TRISO fuel region is homogenized and the homogeneous and heterogeneous fuel blocks are otherwise identical to Figure 7.
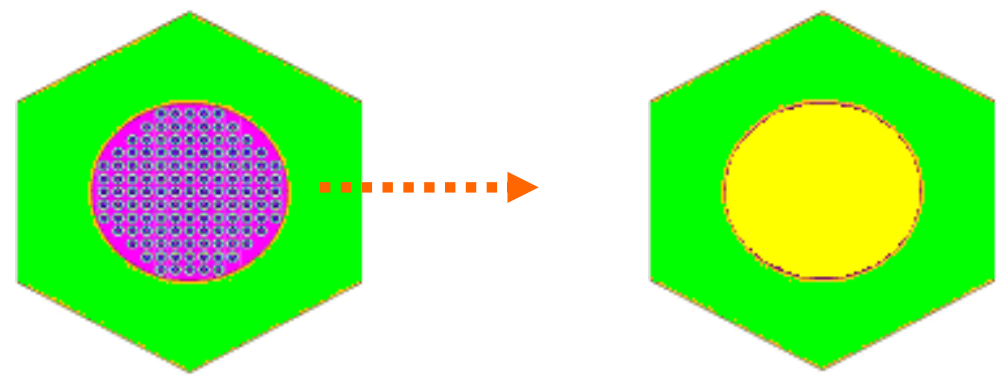

Figure 11. Heterogeneous and Corresponding Homogeneous Model 
CPM parameter study. Since CPM3 was designed to analyze LWR lattices, the key numerical integration parameters for the collision probability calculation were analyzed in detail for the infinite lattice of the VHTR fuel blocks. The integration parameters are the spacing between integration lines and the number of angles chosen to represent the 360 degree rotation of the integration lines. Table 12 shows the resultant multiplication factors for the case of the VHTR fuel block shown in Figure 7. The default spacing and number of angles in CPM3 are $0.1 \mathrm{~cm}$ and 9 angles, respectively.

Table 12. Numerical Integration Parameters for CPM3 Calculations.

\begin{tabular}{|c|c|c|}
\hline Spacing (cm) & Number of Angles & $\mathrm{k}_{\infty}$ \\
\hline $\mathbf{0 . 1}$ & 9 & 1.4375 \\
\hline $\mathbf{0 . 1}$ & 12 & 1.4391 \\
\hline $\mathbf{0 . 1}$ & 60 & 1.4380 \\
\hline $\mathbf{0 . 1}$ & 90 & 1.4381 \\
\hline $\mathbf{0 . 0 5}$ & 9 & 1.4375 \\
\hline $\mathbf{0 . 0 5}$ & 12 & 1.4391 \\
\hline $\mathbf{0 . 0 5}$ & 60 & 1.4380 \\
\hline $\mathbf{0 . 0 5}$ & 90 & 1.4381 \\
\hline $\mathbf{0 . 0 1}$ & 9 & 1.4374 \\
\hline $\mathbf{0 . 0 1}$ & 12 & 1.4390 \\
\hline $\mathbf{0 . 0 1}$ & 60 & 1.4380 \\
\hline $\mathbf{0 . 0 1}$ & 90 & 1.4381 \\
\hline
\end{tabular}

As a result of the CPM3 sensitivity study, the spacing was chosen to be $0.1 \mathrm{~cm}$ and the number of angles was chosen to be 60 (shaded yellow in Table 12), yielding the optimum CPM3 ray tracing parameters for the VHTR block configuration.

Method of characteristics versus collision probabilities for CPM3. Another issue with CPM3 is the option of using the method of characteristics (MOC) or the collision probability (CP) method for the transport calculation following the determination of the fine group resonance cross sections. To examine this, the CPM3 calculation was performed with both transport options and the results are shown in Table 13. The difference between the MOC and CP options in CPM3 was found to be negligible for the VHTR fuel block. For the purpose of comparing the coupled MCNP5/CPM3 methodology, the CP option was chosen for the transport calculation and was used for the rest of the fuel block calculations discussed in this report.

Table 13. MOC vs CP Options in CPM3 for VHTR Fuel Block.

\begin{tabular}{|c|c|c|c|c|c|}
\hline & $\begin{array}{c}\text { MCNP5 } \\
\text { (ref) }\end{array}$ & $\begin{array}{c}\text { CPM3 } \\
\text { (original) }\end{array}$ & $\begin{array}{c}\text { Difference } \\
\text { (\%) }\end{array}$ & $\begin{array}{c}\text { CPM3 } \\
\text { (modified) }\end{array}$ & $\begin{array}{c}\text { Difference } \\
\text { (\%) }\end{array}$ \\
\hline $\mathrm{k}_{\infty}$ (MOC) & 1.4975 & 1.4409 & 3.8 & 1.4970 & .03 \\
\hline $\mathrm{k}_{\infty}(\mathbf{C P})$ & 1.4975 & 1.4409 & 3.8 & 1.4970 & .03 \\
\hline $\mathbf{p}_{\text {esc }}$ & 0.704 & 0.675 & 4.1 & 0.705 & -.14 \\
\hline
\end{tabular}




\section{Numerical Results for the VHTR Fuel Block}

The MCNP5 calculations used 50K histories per cycle with 250 active cycles. Both MCNP5 and CPM3 calculations were performed at room temperature (293.6K). The CPM3 calculations were done with the $\mathrm{CP}$ option. Both homogeneous and heterogeneous fuel regions were analyzed. The original CPM3 was used to analyze the homogeneous fuel case. A consistency check was performed by using the modified version of CPM3 to re-analyze the homogeneous fuel case by transferring MCNP5 cross sections from the homogeneous fuel case to CPM3. The results showed, but the modified version of CPM3 was also used for this case, which involved computing

The results for the homogeneous fuel case are still problematical, with the original CPM3 $\mathrm{k}_{\infty}$ agreeing only to within $0.6 \%$ with MCNP5 and $p_{\text {esc }}$ only within $.3 \%$. Since CPM3 should be capable of handling homogeneous VHTR fuel, this discrepancy is unexpected but consistent with essentially every comparison of MCNP5 versus CPM3 for homogeneous fuel, for both PWR and VHTR fuel lattices. At this point we can only surmise that there are other differences between MCNP5 and CPM3, such as the thermal spectrum calculation, but this has not been resolved since it is not a key

For the heterogeneous fuel case, the original CPM3 can only treat the fuel as homogeneous and yields $\mathrm{k}_{\infty}=1.44093$, compared to 1.49752 for MCNP5, showing that it totally misses the particle fuel heterogeneity due to the TRISO fuel. On the other hand, if MCNP5 resonance cross sections are inserted into CPM3, $\mathrm{k}_{\infty}$ agrees to within $.04 \%$ of the MCNP5 result. This agreement is very encouraging and affirms the basic methodology.

Since $\mathrm{k}_{\infty}$ is a global parameter, it may be masking errors from different portions of the CPM3 calculation unrelated to the resonance calculation. To understand this better, Tables 14 and 15 include comparisons of collapsed two group constants and resonance escape probabilities for the VHTR fuel block cases with homogeneous and heterogeneous fuel. The methodology for computing the two-group cross sections and resonance escape probabilities with MCNP5 was described earlier. Since our methodology primarily affects the resonance absorption, the comparison of the resonance escape probability is particularly important. Table 15 indicates that the modified CPM3 case agrees fairly well with the MCNP5 results, agreeing to within $0.16 \%$ for the resonance escape probability. 
Table 14. Comparison of CPM3 and MCNP5 for VHTR Fuel Block with Homogeneous Fuel

\begin{tabular}{|c|c|c|c|}
\hline & \multicolumn{2}{|c|}{ VHTR Fuel Block with Homogeneous Fuel } \\
\hline $\mathrm{k}_{\infty}$ & MCNP5 & $\begin{array}{c}\mathbf{C P M 3} \\
\text { (original) }\end{array}$ & \% Difference \\
\hline $\boldsymbol{\Sigma}_{\mathbf{a} 1}$ & 1.43262 & 1.44089 & -0.57747 \\
\hline $\boldsymbol{\Sigma}_{\mathbf{a} 2}$ & $7.18256 \mathrm{E}-03$ & $1.0965 \mathrm{E}-03$ & 2.51314 \\
\hline $\mathbf{v}_{\mathbf{1}} \boldsymbol{\Sigma}_{\mathbf{a} 1}$ & $5.6664 \mathrm{E}-04$ & $7.3403 \mathrm{E}-03$ & -2.19629 \\
\hline $\mathbf{v}_{\mathbf{2}} \boldsymbol{\Sigma}_{\mathbf{a} 2}$ & $1.3524 \mathrm{E}-02$ & $5.5432 \mathrm{E}-04$ & 2.17542 \\
\hline $\boldsymbol{\Sigma}_{\mathbf{s} 12}$ & $2.32004 \mathrm{E}-03$ & $1.3876 \mathrm{E}-02$ & -2.60236 \\
\hline $\mathbf{p}_{\mathbf{e s c}}$ & $6.73496 \mathrm{E}-01$ & $2.28165 \mathrm{E}-03$ & 1.65518 \\
\hline
\end{tabular}

Table 15. Comparison of CPM3 and MCNP5 for VHTR Fuel Block with Heterogeneous Fuel

\begin{tabular}{|c|c|c|c|}
\hline & \multicolumn{2}{|c|}{ VHTR Fuel Block with Heterogeneous Fuel } \\
\hline & MCNP5 & $\begin{array}{c}\text { CPM3 } \\
\text { (modified) }\end{array}$ & \% Difference \\
\hline $\mathrm{k}_{\infty}$ & 1.49752 & 1.49697 & 0.03699 \\
\hline $\boldsymbol{\Sigma}_{\mathbf{a} 1}$ & $1.00910 \mathrm{E}-03$ & $9.89537 \mathrm{E}-04$ & 1.93827 \\
\hline $\boldsymbol{\Sigma}_{\mathbf{a} 2}$ & $7.22535 \mathrm{E}-03$ & $7.32853 \mathrm{E}-03$ & -1.42801 \\
\hline $\mathbf{v}_{\mathbf{1}} \boldsymbol{\Sigma}_{\mathbf{a} 1}$ & $5.67323 \mathrm{E}-04$ & $5.57486 \mathrm{E}-04$ & 1.73391 \\
\hline $\mathbf{v}_{\mathbf{2}} \boldsymbol{\Sigma}_{\mathbf{a} 2}$ & $1.36637 \mathrm{E}-02$ & $1.38343 \mathrm{E}-02$ & -1.24871 \\
\hline $\boldsymbol{\Sigma}_{\mathbf{s} \mathbf{2}}$ & $2.39819 \mathrm{E}-03$ & $2.36412 \mathrm{E}-03$ & 1.42062 \\
\hline $\mathbf{p}_{\mathbf{e s c}}$ & $7.03842 \mathrm{E}-01$ & $7.04938 \mathrm{E}-01$ & -0.15576 \\
\hline
\end{tabular}

\section{Comparison of CPM3 and HELIOS for the VHTR Fuel Block}

The DHF methodology was ported to the lattice physics code HELIOS by Studsvik-Scandpower (Studsvik), the company that owns and distributes HELIOS to the nuclear industry. This was done as part of a subcontract between Studsvik and the UM. A senior analyst at Studsvik modified HELIOS to read in DHFs that were generated by the UM for the VHTR fuel block described in Figure 6 and Table 8. The table of DHFs, which are calculated for the capture and fission cross sections for every resonance group for every resonance isotope were identical to the DHFs that led to the results given in Table 15 for CPM3.

Both CPM3 and HELIOS were run with and without DHFs for the VHTR fuel block and compared with the MCNP5 benchmark calculation with heterogeneous fuel. The results are given in Table 16. 
Table 16. Comparison of Original and Modified (with DHFs) CPM3 and HELIOS Codes.

\begin{tabular}{|c|c|c|c|c|c|}
\hline & MCNP5 $_{\infty}$ & CPM3 $_{\infty}$ & \% Difference & HELIOS $_{\infty}$ & \% Difference \\
\hline Original codes & 1.4975 & 1.4409 & 3.8 & 1.4458 & 3.4 \\
\hline With DHFs & 1.4975 & 1.4970 & .04 & 1.4951 & .16 \\
\hline
\end{tabular}

The relative difference in infinite multiplication factor was found to be $-0.10 \%$ with CPM3 whereas the difference goes up to $0.16 \%$ with HELIOS. Although the results for both codes are quite good, the fact they disagree can be explained in terms of the differences in nuclear data files, different resonance approximation methods and different resonance energy group structures. In summary, both CPM3 and HELIOS lattice physics codes yield reasonable results in $\mathrm{k}_{\infty}$ for VHTR configurations when used with the DHF approach.

\section{E. Analysis of VHTR Fuel Block with "Deep Burn" Driver Fuel}

\section{Description of Deep Burn Driver Fuel Compact}

The applicability of the double heterogeneity factor (DHF) approach was tested for the analysis of TRISO fuel in CPM3 lattice physics calculations for a realistic TRU fuel composition characteristic of the GA Deep Burn concept. The MCNP5 and CPM3 cases were performed for the fuel compact, where the fuel kernel comprises $\mathrm{Pu}-\mathrm{Np}-\mathrm{CO}$, representing the $\mathrm{Pu}-\mathrm{Np}$ isotopics in typical used nuclear fuel (UNF) from light water reactors. The purpose of this simulation was to check the applicability of the Double Heterogeneity Factor (DHF) methodology to treat the low-lying resonances of Pu-loaded fuel. Although the uranium-fueled cases have TRU isotopes as a result of burnup, the concentration of these isotopes is far less than would be encountered with the Deep Burn driver fuel, and one can expect the DHFs will be somewhat different as a result.

Driver fuel compact cell dimensions are different than that of VHTR. The kernel diameter and the buffer layer thickness were chosen to limit particle internal pressure arising from the fission products from the deep burnup and the helium generated from alpha decay of the transuranics. Driver fuel geometry and resonance nuclide compositions are presented in Tables 17 and 18, respectively.

Table 17. Dimension for the Driver Fuel Compact Cell

\begin{tabular}{|c|c|}
\hline \multicolumn{2}{|c|}{ Dimensions } \\
\hline Region & Radius(cm) \\
Fuel Kernel & 0.0150 \\
\hline Buffer PyC & 0.0300 \\
\hline Inner PyC & 0.0335 \\
\hline SiC & 0.0370 \\
\hline Outer PyC & 0.0410 \\
\hline Driver Fuel Compact & 0.6223 \\
\hline Region & Radius(cm) \\
\hline Moderator & 0.9398 \\
\hline
\end{tabular}


Since the DHFs require two MCNP5 runs - one for heterogeneous fuel and one for homogeneous fuel - the fuel compact was homogenized to determine number densities for the homogeneous MCNP5 and CPM3 runs. Material compositions for all three cases are presented in Table 18.

Table 18. Material Compositions for the Driver Fuel Compact Cell

\begin{tabular}{|c|c|c|c|c|c|}
\hline \multicolumn{2}{|c|}{ MCNP5 (HET) } & \multicolumn{2}{|c|}{ MCNP5 (HOM) } & \multicolumn{2}{|c|}{ СРM3 } \\
\hline Fuel Kernel & (at/cc) & Fuel Compact & (at/cc) & Fuel Compact & Weight (\%) \\
\hline NP-237 & 1.2290E-03 & NP-237 & $2.0221 \mathrm{E}-05$ & NP-237 & 4.2374E-01 \\
\hline PU-238 & 3.5303E-04 & PU-238 & 5.8085E-06 & PU-238 & 1.2223E-01 \\
\hline PU-239 & 1.3359E-02 & PU-239 & 2.1980E-04 & PU-239 & $4.6448 \mathrm{E}+00$ \\
\hline PU-240 & 5.3679E-03 & PU-240 & 8.8321E-05 & PU-240 & $1.8742 \mathrm{E}+00$ \\
\hline PU-241 & $1.9291 \mathrm{E}-03$ & PU-241 & 3.1740E-05 & PU-241 & $6.7635 \mathrm{E}-01$ \\
\hline PU-242 & 1.1573E-03 & PU-242 & $1.9041 \mathrm{E}-05$ & PU-242 & 4.0744E-01 \\
\hline $0-16$ & 3.9772E-02 & 0-16 & $6.5438 \mathrm{E}-04$ & $0-16$ & 9.2552E-01 \\
\hline Porus PyC & (at/cc) & C-12 & $7.8482 \mathrm{E}-02$ & C-12 & $8.3330 \mathrm{E}+01$ \\
\hline B-10 & 1.6073E-08 & B-10 & $2.5160 \mathrm{E}-08$ & B-10 & $2.2270 \mathrm{E}-05$ \\
\hline $\mathrm{C}-12$ & $5.0138 \mathrm{E}-02$ & SI-28 & 3.0594E-03 & SI-28 & $7.5957 \mathrm{E}+00$ \\
\hline Inner PyC & (at/cc) & & & & \\
\hline B-10 & 2.9735E-08 & & & & \\
\hline $\mathrm{C}-12$ & $9.2756 \mathrm{E}-02$ & & & & \\
\hline SiC & (at/cc) & & & & \\
\hline B-10 & 1.5407E-08 & & & & \\
\hline C-12 & $4.8061 \mathrm{E}-02$ & & & & \\
\hline $\mathrm{SI}-28$ & 4.8061E-02 & & & & \\
\hline Outer PyC & (at/cc) & & & & \\
\hline B-10 & $2.9735 \mathrm{E}-08$ & & & & \\
\hline $\mathrm{C}-12$ & 9.2756E-02 & & & & \\
\hline Graphite Matrix & (at/cc) & & & & \\
\hline B-10 & $2.7324 \mathrm{E}-08$ & & & & \\
\hline C-12 & $8.5235 \mathrm{E}-02$ & & & & \\
\hline Moderator & (at/cc) & Moderator & (at/cc) & Moderator & Weight (\%) \\
\hline B-10 & $2.7324 \mathrm{E}-08$ & B-10 & $2.7324 \mathrm{E}-08$ & B-10 & 2.6725E-05 \\
\hline C-12 & $8.5235 \mathrm{E}-02$ & C-12 & $8.5235 \mathrm{E}-02$ & $\mathrm{C}-12$ & $1.0000 \mathrm{E}+02$ \\
\hline
\end{tabular}

\section{Numerical Results for Deep Burn Driver Fuel Compact}

Three different CPM3 calculations were performed for homogenized driver fuel, using different cross sections for the 65 resonance groups in CPM3. The MCNP5 and CPM3 runs are summarized in Table 19. 
Table 19. Explanation of Deep Burn Driver Fuel Cases.

\begin{tabular}{|c|c|l|}
\hline Case \# & Case Name & \multicolumn{1}{|c|}{ Description } \\
\hline $\mathbf{1}$ & MCNP5 (het) & MCNP5 calculation with heterogeneous TRISO fuel. \\
\hline $\mathbf{2}$ & CPM3 (orig) & $\begin{array}{l}\text { Original version of CPM3 with its own 65 group } \\
\text { resonance cross sections. }\end{array}$ \\
\hline $\mathbf{3}$ & CPM3 (mod2) & $\begin{array}{l}\text { lirect replacement of 65 group resonance absorption } \\
\text { and nu-fission cross sections with MCNP5 cross } \\
\text { sections. }\end{array}$ \\
\hline $\mathbf{4}$ & CPM3 (mod3) & $\begin{array}{l}\text { Using DHFs from MCNP5 to correct 65 group } \\
\text { resonance absorption and nu-fission cross sections in } \\
\text { CPM3. }\end{array}$ \\
\hline
\end{tabular}

In order for CPM3 to run for the Pu lattices, a trace amount of uranium (.00001 \%) was required. This is small enough to have no effect on the resultant CPM3 run. This is probably a consequence of the fact that CPM3 was designed for slightly enriched uranium fuel. The infinite medium multiplication factors $\mathrm{k}_{\infty}$ for the three CPM3 cases are compared in Table 20 with the MCNP5 reference result.

Table 20. Infinite Medium Multiplication Factor Comparison.

\begin{tabular}{|c|c|c|}
\hline Case \# & Case Name & $\mathrm{k}_{\infty}$ \\
\hline 1 & MCNP5 (het) & 1.1043 \\
\hline 2 & CPM3 (orig) & 1.0347 \\
\hline 3 & CPM3 $(\bmod 1)$ & 1.1038 \\
\hline 4 & CPM3 $(\bmod 2)$ & 1.1032 \\
\hline
\end{tabular}

The test of the DHF methodology is the comparison of Cases 1 and 4, where the difference is approximately $0.1 \%$, indicating the DHF methodology is yielding excellent results for Pu-fueled fuel compacts. A comparison of Cases 1 and 3 indicates that our original methodology of replacing CPM3 cross sections with MCNP5 cross sections yields slightly better results than the DHF methodology. However, the advantages of the DHF approach, as discussed in Section V.F, coupled with its excellent results, makes this the preferred methodology. Overall, the comparison indicates that the DHF approach provides a sufficiently accurate treatment for the TRISO double heterogeneity for realistic Pu-Np compositions for Deep Burn applications.

\section{F. Sensitivity of the DHFs}

In order to determine the applicability of the DHF approach for the realistic analysis of TRISO fuel in lattice physics calculations, an effort was made to assess the DHF sensitivity to (1) spatial location in the fuel block, (2) spatial location in the core, (3) burnup, and (4) packing fraction. The motivation for this work was an idea to minimize the number of MCNP5 runs by parameterizing the calculation of DHFs from a few MCNP5 runs and then build a "library" of DHFs that CPM3 could use without having to repeat the MCNP5 calculations. The actual parameterization of the DHFs was beyond the scope of the current grant but the sensitivity 
calculations indicate that this might be a reasonable thing to pursue to further develop the DHF methodology for routine analysis of VHTR configurations with LWR lattice physics codes.

\section{Sensitivity to Spatial Location}

DHFs were calculated for fuel compacts throughout a fuel block to assess the spatial dependence of the DHFs. Two limiting fuel block configurations were analyzed to calculate 65 group DHFs for U-235 and U-238. One case is a fuel block with reflecting boundary conditions representative of an interior fuel block near the center of the core, and the second represents an exterior fuel block near the periphery of the core. The exterior fuel block also has reflecting boundary conditions but a substantial outer graphite region that represents the reflector. These limiting fuel block configurations are shown in Figure 12. The hexagonal figures in Figure 12 are not to scale as the fuel blocks are identical in size.

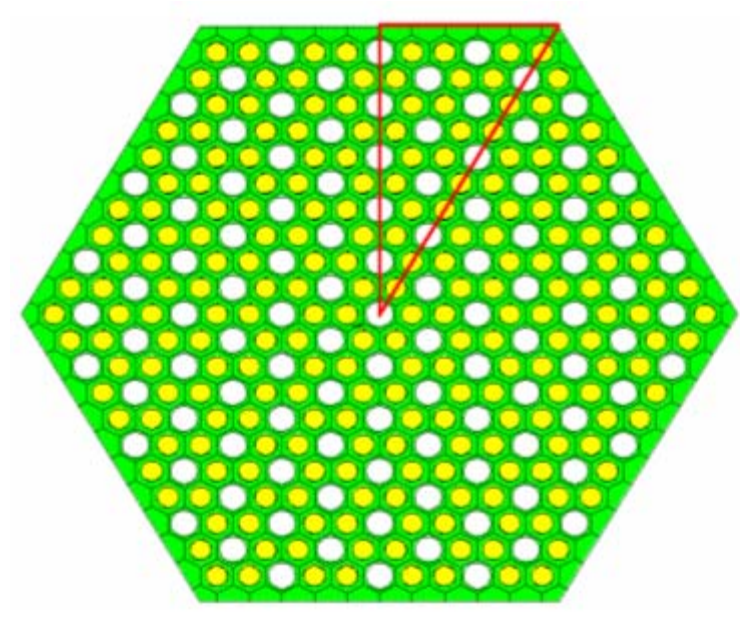

Interior fuel block

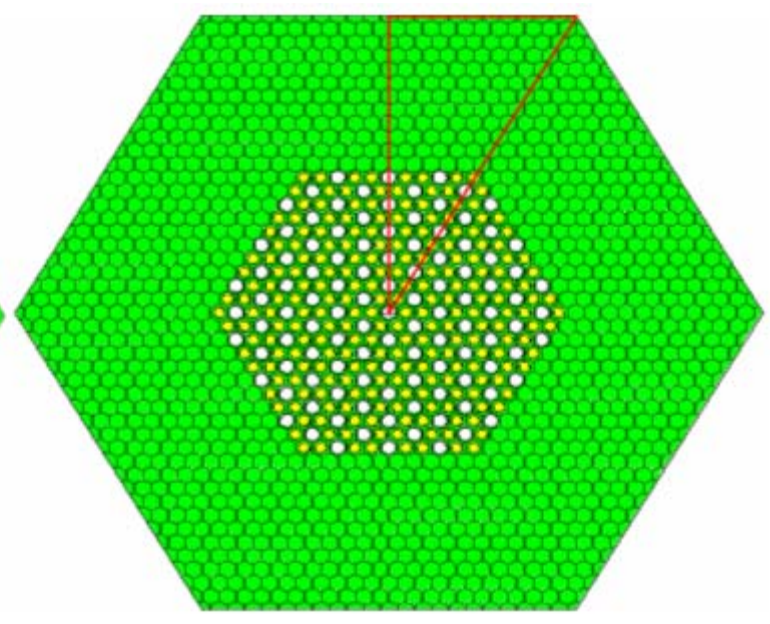

Exterior fuel block

Figure 12. Limiting fuel blocks: interior and exterior fuel blocks. (Not to scale.)

The spatial distribution of DHFs was determined for a 1/12 symmetric portion of the fuel block as shown in Figure 12 marked with red triangles. Results were obtained for all fuel compacts in this portion of the fuel block for all 65 resonance groups, although the DHFs are only shown for the important resonance energy groups for U-238 that are shown in Table 21.

Table 21. Energy Group Boundaries.

\begin{tabular}{|c|c|c|}
\hline Group & Lower $(\mathbf{e V})$ & Higher $(\mathbf{e V})$ \\
\hline $\mathbf{5 7}$ & 6.476 & 8.315 \\
\hline $\mathbf{5 3}$ & 17.6 & 22.6 \\
\hline $\mathbf{5 1}$ & 29.02 & 37.27 \\
\hline $\mathbf{3 8}$ & 748.5 & 961.1 \\
\hline
\end{tabular}

The MCNP5 simulations for the heterogeneous and the corresponding homogeneous fuel block configurations used 500,000 histories per cycle with a total of 400 active cycles, yielding standard deviations in $\mathrm{k}_{\text {eff }}$ of less than $.004 \%$ and in the DHF of less than $0.5 \%$. Figures $13-16$ show the comparison of the space-dependent DHFs within the fuel block for the energy groups 
given in Table 21 for both limiting fuel blocks. Standard deviations in flux as well as Reaction Rate (R.R.) are also shown.
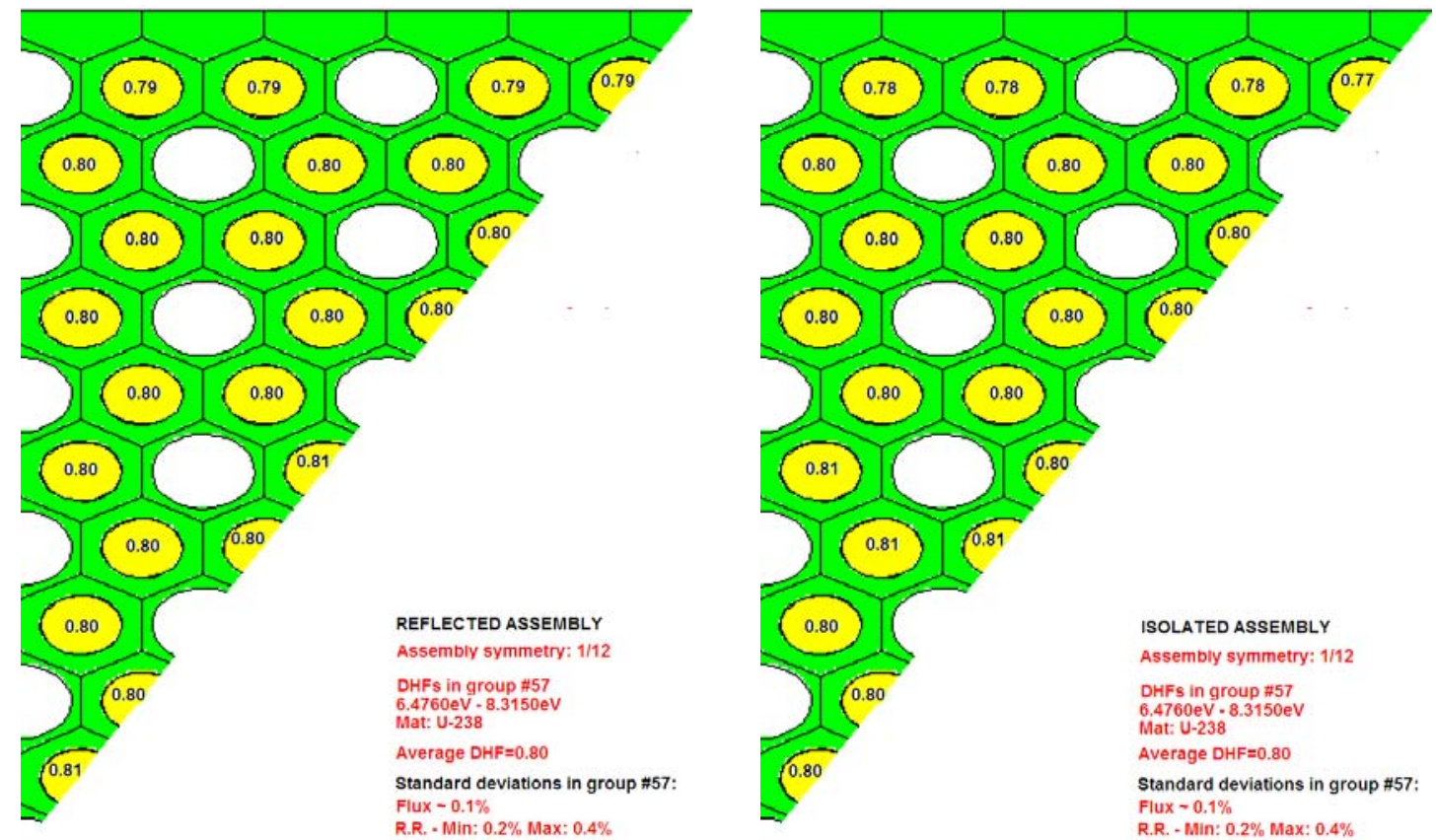

Figure 13. Spatial comparison of DHFs over two limiting fuel blocks for group \#57.
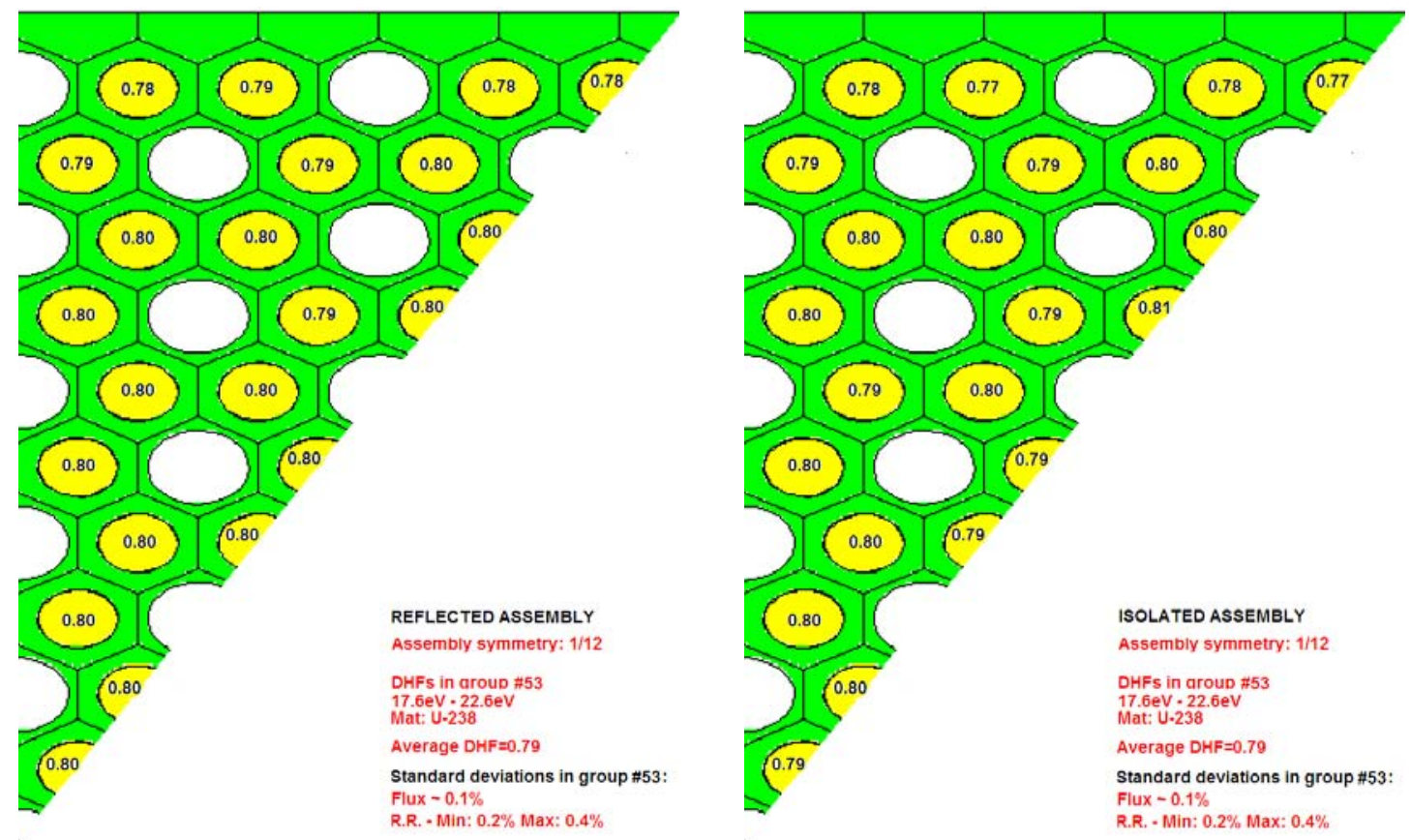

Figure 14. Spatial comparison of DHFs over two limiting fuel blocks for group \#53. 

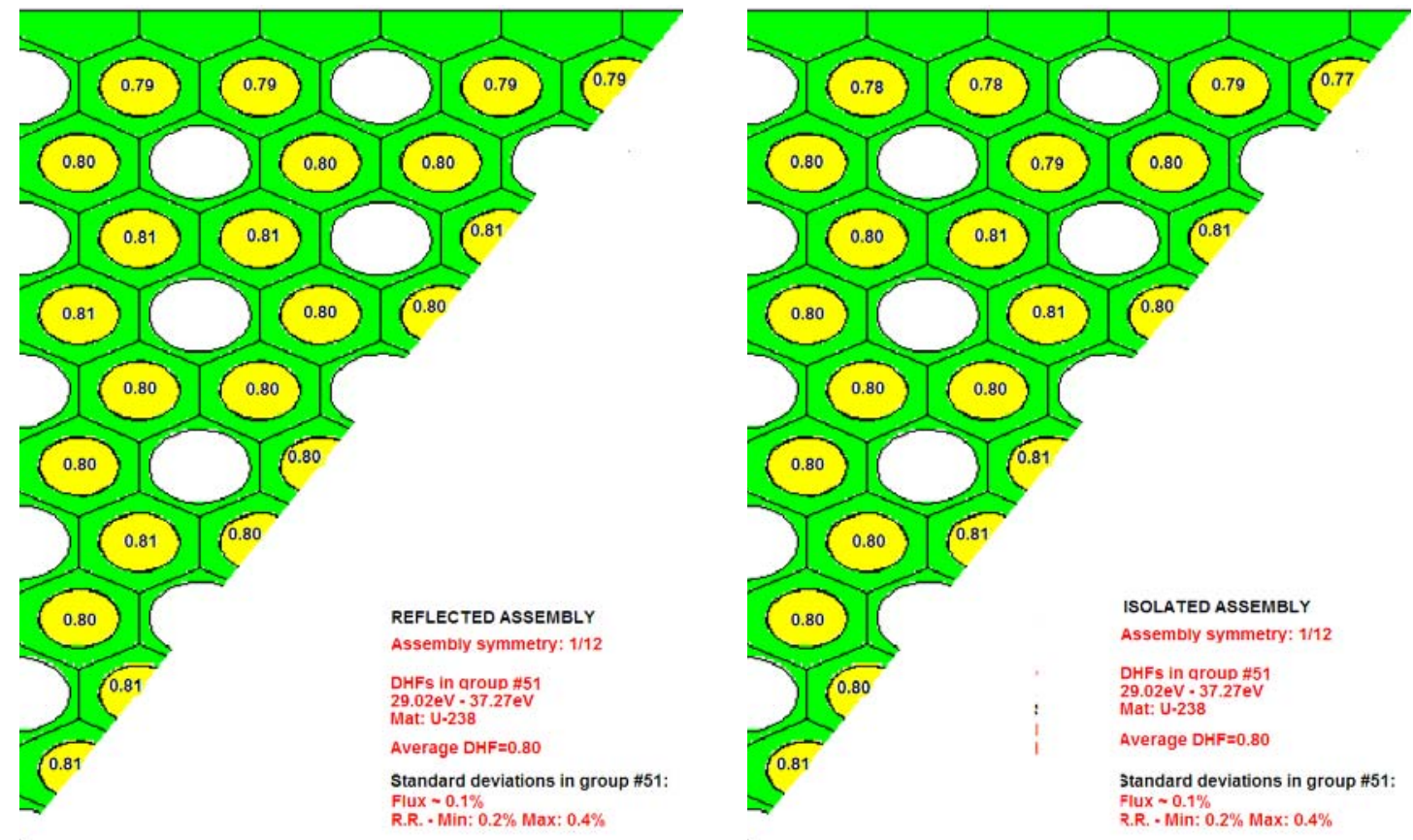

Figure 15. Spatial comparison of DHFs over two limiting fuel blocks for group \#51.
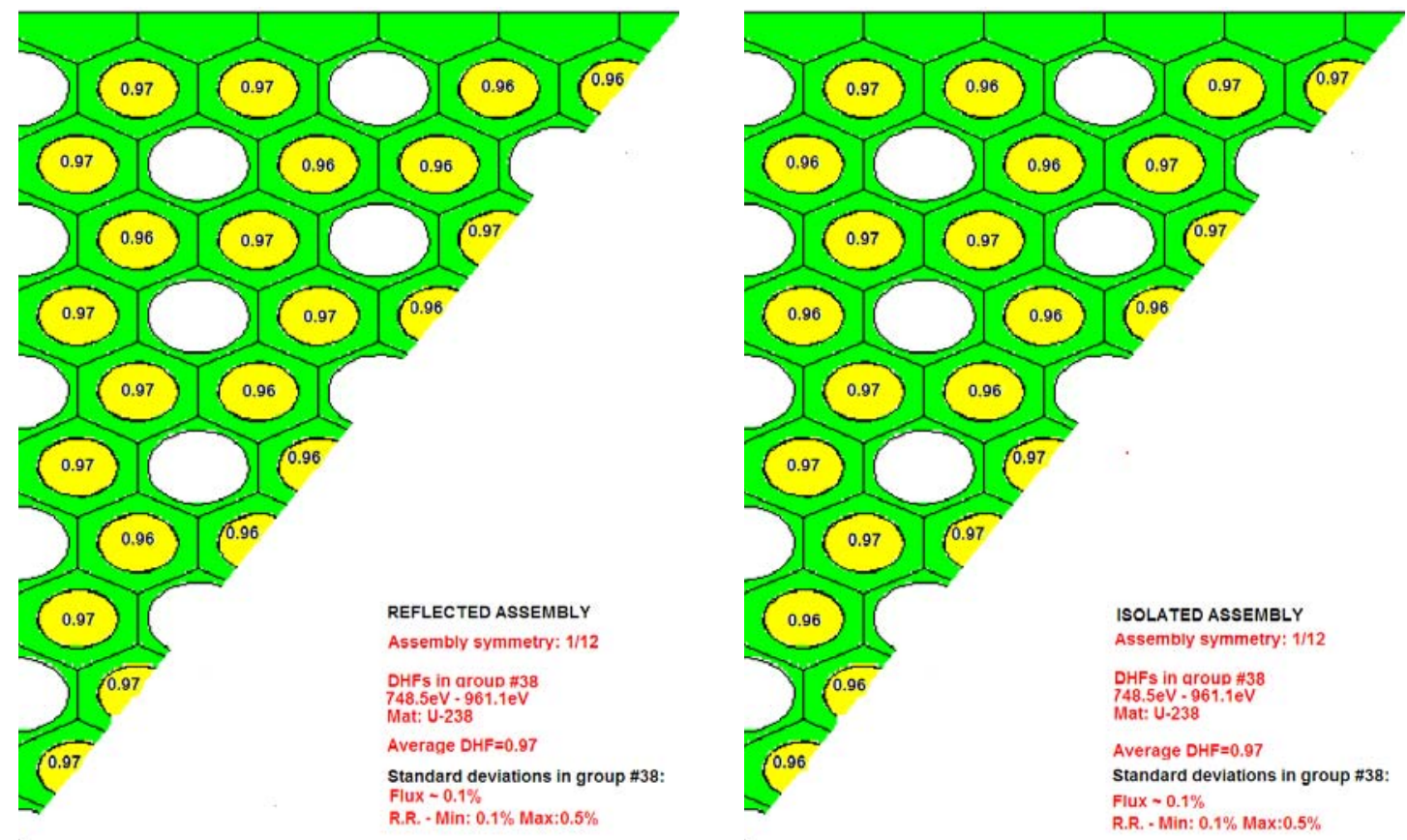

Figure 16. Spatial comparison of DHFs over two limiting fuel blocks for group \#38.

As can be seen in Figures 13-16, the spatial dependence of the DHFs, calculated in fuel kernels and averaged over each fuel compact, is negligible for these limiting fuel blocks. They were found to be within the standard deviation in each of the limiting fuel blocks except the edges. The small deviation of the DHFs at the edges is due to the effect of the moderator region 
surrounding the fuel blocks. Dancoff factors at the edges change slightly but the DHFs are still very close to fuel block averaged multi-group DHFs, yielding a negligible effect on $\mathrm{k}_{\infty}$ as shown previously. As will be shown later, Dancoff factors mainly depend on the kernel packing fraction in fuel compacts.

Furthermore, DHFs are almost the same for the corresponding fuel compact locations within the two limiting fuel blocks, suggesting the use of one set of multi-group DHFs for each resonance nuclide and VHTR fuel block at any location in the full core. It should also be pointed out that the DHFs for U-235 are equal to, or close to, unity for all resonance groups. This is due to the fact that the concentration of U-235 is relatively dilute compared to U-238, hence the selfshielding is relatively small, leading to a DHF close to unity.

\section{Sensitivity to Material Composition (Burnup)}

The original CPM3 code was used to deplete the TRISO fuel in an infinite lattice of fuel compact cells with a total burnup of $100 \mathrm{GWd} / \mathrm{MT}$. Burnup time steps are presented in Table 22 . The accumulation of the fission products were accurately determined by specifying very fine initial time steps. The accumulation of the fission products were accurately accounted by specifying very fine initial time steps. The initial heterogeneous and homogeneous VHTR fuel compact cell dimensions and material compositions are given in Tables 23 and 24, respectively.

Table 22. Burnup Steps in Terms of Accumulated Exposure in GWd/MT.

\begin{tabular}{|cc|cc|cc|cc|}
\hline $\begin{array}{c}\text { Burnup } \\
\text { Step }\end{array}$ & GWd/MT & $\begin{array}{c}\text { Burnup } \\
\text { Step }\end{array}$ & GWd/MT & $\begin{array}{c}\text { Burnup } \\
\text { Step }\end{array}$ & GWd/MT & $\begin{array}{c}\text { Burnup } \\
\text { Step }\end{array}$ & GWd/MT \\
$\mathbf{0}$ & 0.0 & $\mathbf{1 0}$ & 1.0 & $\mathbf{2 0}$ & 12.5 & $\mathbf{3 0}$ & 55.0 \\
$\mathbf{1}$ & 0.1 & $\mathbf{1 1}$ & 2.0 & $\mathbf{2 1}$ & 15.0 & $\mathbf{3 1}$ & 60.0 \\
$\mathbf{2}$ & 0.2 & $\mathbf{1 2}$ & 3.0 & $\mathbf{2 2}$ & 17.5 & $\mathbf{3 2}$ & 65.0 \\
$\mathbf{3}$ & 0.3 & $\mathbf{1 3}$ & 4.0 & $\mathbf{2 3}$ & 20.0 & $\mathbf{3 3}$ & 70.0 \\
$\mathbf{4}$ & 0.4 & $\mathbf{1 4}$ & 5.0 & $\mathbf{2 4}$ & 25.0 & $\mathbf{3 4}$ & 75.0 \\
$\mathbf{5}$ & 0.5 & $\mathbf{1 5}$ & 6.0 & $\mathbf{2 5}$ & 30.0 & $\mathbf{3 5}$ & 80.0 \\
$\mathbf{6}$ & 0.6 & $\mathbf{1 6}$ & 7.0 & $\mathbf{2 6}$ & 35.0 & $\mathbf{3 6}$ & 85.0 \\
$\mathbf{7}$ & 0.7 & $\mathbf{1 7}$ & 8.0 & $\mathbf{2 7}$ & 40.0 & $\mathbf{3 7}$ & 90.0 \\
$\mathbf{8}$ & 0.8 & $\mathbf{1 8}$ & 9.0 & $\mathbf{2 8}$ & 45.0 & $\mathbf{3 8}$ & 95.0 \\
$\mathbf{9}$ & 0.9 & $\mathbf{1 9}$ & 10.0 & $\mathbf{2 9}$ & 50.0 & $\mathbf{3 9}$ & 100.0 \\
\hline
\end{tabular}

Table 23. Heterogeneous and Homogeneous VHTR Fuel Compact Cell Dimensions

\begin{tabular}{|l|c|c|c|c|c|}
\hline \multicolumn{2}{|c|}{ Fuel Particle } & \multicolumn{2}{c|}{ Fuel Compact } & \multicolumn{2}{c|}{ Hexagonal Compact Cell } \\
\hline & Radius $(\mathrm{cm})$ & Radius $(\mathrm{cm})$ & Height $(\mathrm{cm})$ & Pitch $(\mathrm{cm})$ & Height $(\mathrm{cm})$ \\
\hline Fuel Kernel & 0.0175 & 0.6225 & 4.5553 & 1.8796 & 4.5553 \\
\hline Porous PyC & 0.0275 & \multicolumn{2}{|c|}{ Coolant Hole } & & \\
\hline Inner PyC & 0.0315 & Radius $(\mathrm{cm})$ & Height $(\mathrm{cm})$ & & \\
\hline SiC & 0.0350 & 0.7938 & 4.5553 & & \\
\hline Outer PyC & 0.0390 & & & & \\
\hline
\end{tabular}


Table 24. Material Compositions of Fuel Compacts for MCNP5 and CPM3 Analyses.

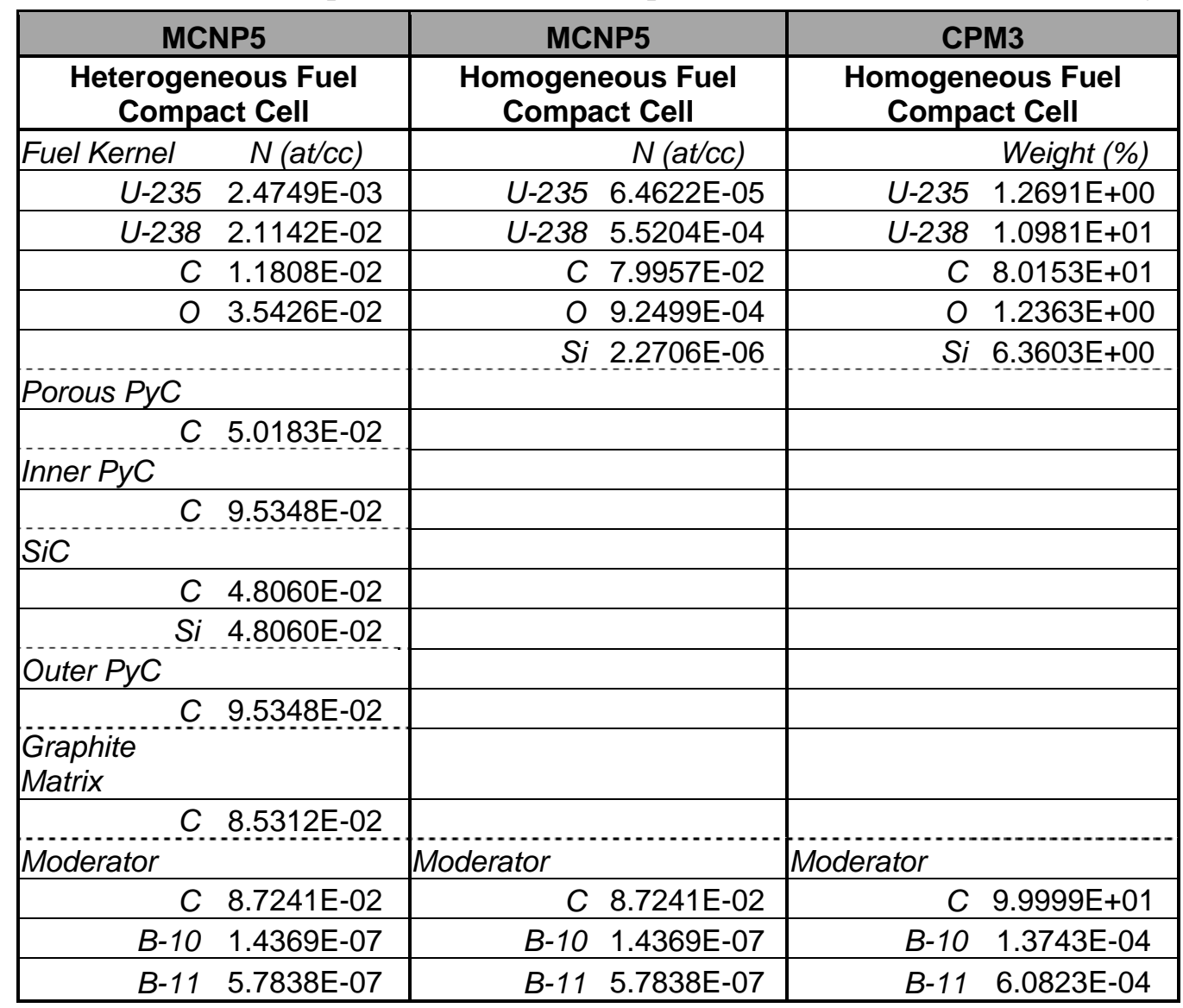

Resonance isotope compositions as a function of burnup time steps are shown in Table 25 for the MCNP5 heterogeneous and the corresponding homogeneous configurations as well as CPM3. 
Table 25. Resonance Isotope Compositions as a Function of Burnup.

\begin{tabular}{|c|c|c|c|}
\hline & 0 GWd/MT-HM & 50 GWd/MT-HM & $100 \mathrm{GWd} / \mathrm{MT}-\mathrm{HM}$ \\
\hline Compact & $\begin{array}{c}\text { MCNP Het } \\
\text { (at/cc) }\end{array}$ & $\begin{array}{l}\text { MCNP Het } \\
\text { (at/cc) }\end{array}$ & $\begin{array}{c}\text { MCNP Het } \\
(\mathrm{at} / \mathrm{cc})\end{array}$ \\
\hline \multicolumn{4}{|l|}{ Fuel } \\
\hline $\mathrm{U}-235$ & 2.4749E-03 & $1.2494 \mathrm{E}-03$ & 4.6613E-04 \\
\hline U-238 & $2.1142 \mathrm{E}-02$ & $2.0426 \mathrm{E}-02$ & $1.9546 \mathrm{E}-02$ \\
\hline PU-239 & $0.0000 \mathrm{E}+00$ & $3.4243 \mathrm{E}-04$ & $3.6760 \mathrm{E}-04$ \\
\hline PU-240 & $0.0000 \mathrm{E}+00$ & $6.0620 \mathrm{E}-05$ & $1.0465 \mathrm{E}-04$ \\
\hline Compact & $\begin{array}{c}\text { MCNP Hom } \\
(\text { at } / \mathrm{cc})\end{array}$ & $\begin{array}{c}\text { MCNP Hom } \\
(\text { at } / \mathrm{cc})\end{array}$ & $\begin{array}{c}\text { MCNP Hom } \\
(\text { at } / \mathrm{cc})\end{array}$ \\
\hline \multicolumn{4}{|l|}{ Fuel } \\
\hline $\mathrm{U}-235$ & $6.4621 \mathrm{E}-05$ & $3.2622 \mathrm{E}-05$ & $1.2171 \mathrm{E}-05$ \\
\hline U-238 & $5.5203 \mathrm{E}-04$ & $5.3335 \mathrm{E}-04$ & $5.1036 \mathrm{E}-04$ \\
\hline PU-239 & $0.0000 \mathrm{E}+00$ & 8.9412E-06 & $9.5983 \mathrm{E}-06$ \\
\hline PU-240 & $0.0000 \mathrm{E}+00$ & $1.5828 \mathrm{E}-06$ & $2.7325 \mathrm{E}-06$ \\
\hline Compact & $\begin{array}{c}\text { CPM3 } \\
\text { Weight }(\%)\end{array}$ & $\begin{array}{c}\text { CPM3 } \\
\text { Weight }(\%)\end{array}$ & $\begin{array}{c}\text { CPM3 } \\
\text { Weight }(\%)\end{array}$ \\
\hline Fuel & & & \\
\hline $\mathrm{U}-235$ & $1.2689 \mathrm{E}+00$ & $6.4566 \mathrm{E}-01$ & $2.4291 \mathrm{E}-01$ \\
\hline U-238 & $1.0978 \mathrm{E}+01$ & $1.0691 \mathrm{E}+01$ & $1.0316 \mathrm{E}+01$ \\
\hline PU-239 & $0.0000 \mathrm{E}+00$ & $1.7999 \mathrm{E}-01$ & $1.9483 \mathrm{E}-01$ \\
\hline PU-240 & $0.0000 \mathrm{E}+00$ & $3.1996 \mathrm{E}-02$ & $5.5697 \mathrm{E}-02$ \\
\hline
\end{tabular}

As can be seen in Table 25, the initial number density of U-235 decreases by $50 \%$ at $50 \mathrm{GWd} / \mathrm{MT}$ and $81 \%$ at $100 \mathrm{GWd} / \mathrm{MT}$. On the other hand, total Pu concentration at $100 \mathrm{GWd} / \mathrm{MT}$ becomes almost the same as the final concentration of U-235. The decrease in U-238 concentration was found to be $6 \%$ at $100 \mathrm{GWd} / \mathrm{MT}$.

MCNP5 calculations were performed by using 50,000 histories/batch with a total of 200 active cycles. The resultant statistics were found to be less than the $0.1 \%$. The DHFs were calculated for each nuclide at burnup steps 0,50 , and $100 \mathrm{MWd} / \mathrm{MT}$. The resultant DHFs are tabulated in Table 26. For convenience, the U-238 and Pu-239 DHFs are shaded. The DHFs for fine groups 61-89 were all unity and are not shown in the table. In addition, the DHF's for Pu-239 and Pu240 at BOL are not computed since these isotopes do not exist at BOL, but are shown to be unity for convenience.

As can be seen from Table 26, the slow changes in composition that accompany depletion do not affect the DHFs, even out to high burnup $(100 \mathrm{GWd} / \mathrm{MT})$. Furthermore, DHFs for most of the important transmutation nuclides like Pu-239 and $\mathrm{Pu}-240$ are equal to, or close to, unity throughout the burnup process as can be seen in Table 26. Therefore, it is concluded that fuel depletion of the resonance nuclides has a negligible effect on DHFs for the resonance nuclides. The concentrations of these nuclides is insufficient to cause significant self-shielding within a 
fuel kernel hence the only heterogeneity that needs to be accounted for is the fuel compact heterogeneity and this is already accounted for by the original CPM3 calculation.

Table 26. Fine Group DHFs as a Function of Burnup.

\begin{tabular}{|c|c|c|c|c|c|c|c|c|c|c|c|c|}
\hline & \multicolumn{4}{|c|}{$0 \mathrm{GWd} / \mathrm{MT}$} & \multicolumn{4}{|c|}{$50 \mathrm{GWd} / \mathrm{MT}$} & \multicolumn{4}{|c|}{$100 \mathrm{GWd} / \mathrm{MT}$} \\
\hline & $U^{235}$ & $U^{238}$ & $P u^{239}$ & $P u^{240}$ & $U^{235}$ & $U^{238}$ & $P u^{239}$ & $P u^{240}$ & $U^{235}$ & $U^{238}$ & $P u^{239}$ & $P u^{240}$ \\
\hline 25 & 1.00 & 1.00 & 1.00 & 1.00 & 1.00 & 1.00 & 1.00 & 1.00 & 1.00 & 1.00 & 1.00 & 1.00 \\
\hline 26 & 1.00 & 1.00 & 1.00 & 1.00 & 1.00 & 1.00 & 1.00 & 1.00 & 1.00 & 1.00 & 1.00 & 1.00 \\
\hline 27 & 1.00 & 1.00 & 1.00 & 1.00 & 1.00 & 1.00 & 1.00 & 1.00 & 1.00 & 1.00 & 1.00 & 1.00 \\
\hline 28 & 1.00 & 1.00 & 1.00 & 1.00 & 1.00 & 1.00 & 1.00 & 1.00 & 1.00 & 1.00 & 1.00 & 1.00 \\
\hline 29 & 1.00 & 1.00 & 1.00 & 1.00 & 1.00 & 1.00 & 1.00 & 1.00 & 1.00 & 1.00 & 1.00 & 1.00 \\
\hline 30 & 1.00 & 0.99 & 1.00 & 1.00 & 1.00 & 0.99 & 1.00 & 1.00 & 1.00 & 0.99 & 1.00 & 1.00 \\
\hline 31 & 1.00 & 1.00 & 1.00 & 1.00 & 1.00 & 1.00 & 1.00 & 1.00 & 1.00 & 1.00 & 1.00 & 1.00 \\
\hline 32 & 1.00 & 0.99 & 1.00 & 1.00 & 1.00 & 0.99 & 1.00 & 1.00 & 1.00 & 0.99 & 1.00 & 1.00 \\
\hline 33 & 1.00 & 0.99 & 1.00 & 1.00 & 1.00 & 0.99 & 1.00 & 1.00 & 1.00 & 0.99 & 1.00 & 1.00 \\
\hline 34 & 1.00 & 0.98 & 1.00 & 1.00 & 1.00 & 0.98 & 1.00 & 1.00 & 1.00 & 0.98 & 1.00 & 1.00 \\
\hline 35 & 1.00 & 0.97 & 1.00 & 1.00 & 1.00 & 0.97 & 1.00 & 1.00 & 1.00 & 0.97 & 1.00 & 1.00 \\
\hline 36 & 1.00 & 0.98 & 1.00 & 1.00 & 1.00 & 0.98 & 1.00 & 1.00 & 1.00 & 0.98 & 1.00 & 1.00 \\
\hline 37 & 1.00 & 0.97 & 1.00 & 1.00 & 1.00 & 0.97 & 1.00 & 1.00 & 1.00 & 0.97 & 1.00 & 1.00 \\
\hline 38 & 1.00 & 0.97 & 1.00 & 1.00 & 1.00 & 0.97 & 1.00 & 1.00 & 1.00 & 0.97 & 1.00 & 1.00 \\
\hline 39 & 1.00 & 0.96 & 1.00 & 1.00 & 1.00 & 0.96 & 1.00 & 1.00 & 1.00 & 0.96 & 1.00 & 1.00 \\
\hline 40 & 1.00 & 0.96 & 1.00 & 1.00 & 1.00 & 0.96 & 1.00 & 1.00 & 1.00 & 0.96 & 1.00 & 1.00 \\
\hline 41 & 1.00 & 0.98 & 1.00 & 1.00 & 1.00 & 0.98 & 1.00 & 1.00 & 1.00 & 0.98 & 1.00 & 1.00 \\
\hline 42 & 1.00 & 0.93 & 1.00 & 1.00 & 1.00 & 0.93 & 1.00 & 1.00 & 1.00 & 0.93 & 1.00 & 1.00 \\
\hline 43 & 1.00 & 0.93 & 1.00 & 1.00 & 1.00 & 0.93 & 1.00 & 1.00 & 1.00 & 0.93 & 1.00 & 1.00 \\
\hline 44 & 1.00 & 0.87 & 1.00 & 1.00 & 1.00 & 0.87 & & 1.00 & 1.00 & 0.87 & 1.00 & 1.00 \\
\hline 45 & 1.00 & 0.98 & 1.00 & 1.00 & 1.00 & 0.98 & 1.00 & 1.00 & 1.00 & 0.98 & 1.00 & 1.00 \\
\hline 46 & 1.00 & 0.86 & 1.00 & 1.00 & 1.00 & 0.86 & 1.00 & 1.00 & 1.00 & 0.86 & 1.00 & 1.00 \\
\hline 47 & 1.00 & 0.97 & 1.00 & 1.00 & 1.00 & 0.97 & 1.00 & 1.00 & 1.00 & 0.97 & 1.00 & 1.00 \\
\hline 48 & 1.00 & 0.84 & 1.00 & 1.00 & 1.00 & 0.84 & 0.98 & 0.99 & 1.00 & 0.84 & 0.98 & 0.99 \\
\hline 49 & 1.00 & 1.00 & 1.00 & 1.00 & 1.00 & 1.00 & 1.00 & 1.00 & 1.00 & 1.00 & 1.00 & 1.00 \\
\hline 50 & 1.00 & 1.00 & 1.00 & 1.00 & 1.00 & 1.00 & 1.00 & 0.99 & 1.00 & 0.99 & 1.00 & 0.99 \\
\hline 51 & 1.00 & 0.81 & 1.00 & 1.00 & 1.00 & 0.81 & 1.00 & 0.99 & 1.00 & 0.81 & 1.00 & 0.99 \\
\hline 52 & 1.00 & 1.00 & 1.00 & 1.00 & 1.00 & 1.00 & 1.00 & 1.00 & 1.00 & 1.00 & 1.00 & 1.00 \\
\hline 53 & 0.99 & 0.81 & 1.00 & 1.00 & 0.99 & 0.81 & 1.00 & 1.00 & 0.99 & 0.81 & 1.00 & 1.00 \\
\hline 54 & 1.00 & 1.00 & 1.00 & 1.00 & 1.00 & 1.00 & 1.00 & 1.00 & 1.00 & 1.00 & 1.00 & 1.00 \\
\hline 55 & 0.99 & 1.00 & 1.00 & 1.00 & 1.00 & 1.00 & 1.00 & 1.00 & 1.00 & 1.00 & 1.00 & 1.00 \\
\hline 56 & 0.99 & 1.00 & 1.00 & 1.00 & 0.99 & 1.00 & 1.00 & 1.00 & 1.00 & 1.00 & 1.00 & 1.00 \\
\hline 57 & 1.00 & 0.81 & 1.00 & 1.00 & 1.00 & 0.81 & 1.01 & 1.00 & 1.00 & 0.81 & 1.01 & 1.00 \\
\hline 58 & 0.99 & 0.99 & 1.00 & 1.00 & 0.99 & 0.99 & 1.00 & 1.00 & 0.99 & 0.99 & 1.00 & 1.00 \\
\hline 59 & 1.00 & 1.00 & 1.00 & 1.00 & 1.00 & 1.00 & 1.00 & 1.00 & 1.00 & 1.00 & 1.00 & 1.00 \\
\hline 60 & 1.00 & 1.00 & 1.00 & 1.00 & 1.00 & 1.00 & 1.00 & 1.00 & 1.00 & 1.00 & 1.00 & 1.00 \\
\hline
\end{tabular}

\section{Sensitivity to Packing Fraction}

Detailed analysis of the grain shielding factor developed by Wälti [14] suggests that DHFs should mainly depend on the relative volume of the fuel kernels and moderator region (coatings + binder) in a given fuel compact cell. It was already shown that material composition has a negligible effect on the DHFs and the spatial dependence over a fuel block (and core) is weak. To examine the sensitivity of the DHFs to the packing fraction, DHFs were calculated for each 
resonance energy group for U-235 and U-238 with varying packing fractions. Table 27 shows how the multi-group DHFs change as a function of packing fraction. The nominal packing fraction for the prismatic VHTR is highlighted in red.)

Table 27. Multi-group DHFs for U-238 as a Function of Packing Fraction.

\begin{tabular}{|c|c|c|c|c|c|c|c|}
\hline \multirow[t]{2}{*}{ Case \# } & \multirow{2}{*}{$\begin{array}{l}\text { Packing } \\
\text { Fraction }\end{array}$} & \multicolumn{6}{|c|}{ Fine group DHFs for U-238 } \\
\hline & & 44 & 46 & 48 & 51 & 53 & 57 \\
\hline 1 & $13.2 \%$ & 0.84 & 0.80 & 0.79 & 0.66 & 0.68 & 0.72 \\
\hline 2 & $14.5 \%$ & 0.83 & 0.81 & 0.79 & 0.68 & 0.69 & 0.72 \\
\hline 3 & $16.0 \%$ & 0.83 & 0.80 & 0.79 & 0.69 & 0.70 & 0.72 \\
\hline 4 & $17.5 \%$ & 0.84 & 0.81 & 0.79 & 0.71 & 0.71 & 0.73 \\
\hline 5 & $19.1 \%$ & 0.84 & 0.82 & 0.79 & 0.73 & 0.73 & 0.75 \\
\hline 6 & $20.9 \%$ & 0.85 & 0.82 & 0.80 & 0.74 & 0.75 & 0.76 \\
\hline 7 & $22.7 \%$ & 0.85 & 0.83 & 0.81 & 0.77 & 0.76 & 0.77 \\
\hline 8 & $24.7 \%$ & 0.86 & 0.84 & 0.82 & 0.78 & 0.78 & 0.79 \\
\hline 9 & $26.7 \%$ & 0.86 & 0.85 & 0.82 & 0.80 & 0.80 & 0.80 \\
\hline 10 & $28.9 \%$ & 0.87 & 0.86 & 0.83 & 0.81 & 0.81 & 0.81 \\
\hline 11 & $31.2 \%$ & 0.88 & 0.86 & 0.84 & 0.83 & 0.82 & 0.83 \\
\hline 12 & $33.6 \%$ & 0.88 & 0.87 & 0.86 & 0.84 & 0.83 & 0.84 \\
\hline 13 & $36.1 \%$ & 0.89 & 0.88 & 0.86 & 0.85 & 0.85 & 0.85 \\
\hline 14 & $38.7 \%$ & 0.90 & 0.88 & 0.87 & 0.86 & 0.86 & 0.86 \\
\hline 15 & $41.5 \%$ & 0.90 & 0.89 & 0.88 & 0.87 & 0.87 & 0.87 \\
\hline 16 & $44.4 \%$ & 0.91 & 0.90 & 0.89 & 0.88 & 0.87 & 0.87 \\
\hline 17 & $47.4 \%$ & 0.91 & 0.90 & 0.90 & 0.90 & 0.89 & 0.88 \\
\hline 18 & $50.6 \%$ & 0.92 & 0.91 & 0.90 & 0.90 & 0.89 & 0.89 \\
\hline 19 & $53.9 \%$ & 0.92 & 0.92 & 0.91 & 0.91 & 0.90 & 0.90 \\
\hline
\end{tabular}

As can be seen, the effect of packing fraction is finite but not large. For example, the packing fraction changes by $8 \%$ going from Case 10 to Case 11 but the DHF changes by only $2 \%$. Since the fuel packing fraction is a consequence of the fuel design and does not change during operation, DHFs would probably be generated for each packing fraction although it may be possible to parameterize the DHFs as a function of packing fraction. This dependence can also be expressed as a function of Dancoff factor, which could account for the weak spatial dependence as well as the packing factor dependence.

\section{Full Core VHTR Benchmark with T/H Feedback}

\section{A. Motivation}

The nominal VHTR design is the NGNP Point Design ${ }^{1}$ from INL. It consists of identical VHTR fuel assemblies (Figure 7) without control. Temperature feedback will be accounted for using RELAP5/Athena. Gamma heat deposition due to fission and capture gammas will be modeled to

\footnotetext{
${ }^{1}$ P. E. MacDonald, et al., "NGNP Preliminary Point Design - Results of the Initial Neutronics and ThermalHydraulic Assessments During FY-03", INEEL/EXT-03-00870 Rev. 1, Idaho National Engineering and Environmental Laboratory (2003).
} 
determine core and reflector heating contributions. The benchmark case will be performed with both homogeneous and heterogeneous TRISO fuel. These calculations will allow the prediction of space-dependent DHFs throughout the core. This benchmark problem will allow an assessment of how well CPM3-generated cross sections (with DHFs) compare with full-core MCNP5.

The basic full core VHTR configuration without $\mathrm{T} / \mathrm{H}$ feedback is a standard element of the VHTR benchmark suite and has been used for determination of position-dependent DHFs, as discussed in Section V.F.2. Adding T/H feedback complicates this benchmark case considerably and is outside the scope of the grant; however, effort was expended to develop this benchmark case because it will provide a realistic VHTR case to demonstrate the accuracy and practicality of the DHF methodology. The work is not complete on this benchmark case but will be continued at the University of Michigan with other grants and internal resources.

The following gives the current status of our effort to develop the full-core VHTR benchmark case with $\mathrm{T} / \mathrm{H}$ feedback.

\section{B. Introduction}

The analysis of coupled nuclear-thermal-hydraulics (NTH) for VHTRs is presented, taking into account the heat deposition in the reflector regions as well as the reactor core. This work is an extension of previously reported work that did not account for reflector heating and did not adequately converge the NTH iterations to account for the TRISO fuel. The MCNP5 code was coupled with the RELAP5-3D/ATHENA code [15] through a master process utilizing cross platforms to automate the process of performing coupled NTH calculations. Calculations were performed to determine the beginning-of-cycle (BOC) power and temperature distributions for the VHTR core at rated power of $600 \mathrm{MWt}$. The effect of heterogeneous fuel and reflector heating on the converged flux-power distributions for a typical VHTR configuration at BOC is discussed.

\section{Computational Methodology}

MCNP5 input decks were set up to represent the VHTR core with homogeneous fuel assemblies, which are surrounded by reflectors and grouped into three annular rings, each ring comprising 10 axial fuel segments and clusters of 30,36, and 36 fuel assemblies, respectively, for the inner, middle, and outer core rings. Fuel and graphite in each assembly are uniformly mixed in the homogeneous representation. The pseudo material construct [16] was used to perform interpolations of cross section libraries generated at a few temperature points by the DOPPLER code [17].

Axial power fractions were determined from MCNP5 calculations for 10 axial zones for each of the three fuel rings and the inner and outer reflectors. Axial power fractions were input to RELAP5 to determine assembly-average temperature distributions. New RELAP5 temperature distributions were used for the next MCNP simulation to obtain new power fractions. MCNP5 and RELAP5 iterations were performed in a cyclic fashion until convergence in temperature and power distributions is obtained. For each MCNP5 calculation, 30K particles per cycle were used with a total of 120 active cycles. A cross platform architecture was used to couple the MCNP5 and RELAP5 code systems. 


\section{RELAP5-3D Analysis}

For RELAP5-3D/ATHENA calculations, the core was modeled with three fuel and two reflector annular regions, consistent with the MCNP5 setup. Each annular fuel region is axially discretized into ten segments and was represented [18] as a cylindrical coolant channel comprising a central coolant hole, surrounded by three inner graphite rings, four fuel rings, and one outer graphite ring. Table 28 presents the number of fuel and reflector assemblies as well as converged mass flow rates from the RELAP5-3D calculations.

Table 28. RELAP5-3D/ATHENA Model Parameters

\begin{tabular}{|l|c|c|}
\hline & $\begin{array}{c}\text { Number of } \\
\text { Assemblies (at } \\
\text { every axial level) }\end{array}$ & $\begin{array}{c}\text { Converged } \\
\text { Flow Rate } \\
\text { (kg/s) }\end{array}$ \\
\hline $\begin{array}{l}\text { Inner } \\
\text { Reflector }\end{array}$ & 61 & 2.6 \\
\hline Inner Ring & 30 & 61.2 \\
\hline Middle Ring & 36 & 79.4 \\
\hline Outer Ring & 36 & 76.4 \\
\hline $\begin{array}{l}\text { Outer } \\
\text { Reflector }\end{array}$ & 156 & 6.3 \\
\hline
\end{tabular}

An adiabatic boundary condition is imposed at the outer boundary of each coolant channel. Based on the NGNP target [19] for the helium outlet temperature of $1273 \mathrm{~K}$, together with the inlet temperature of $763 \mathrm{~K}$, a helium mass flow rate of $226 \mathrm{~kg} / \mathrm{s}$ was determined for the rated power output of $600 \mathrm{MWt}$. An initial bypass flow fraction of $12.5 \%$ was assumed for the reflectors, with the remaining flow distributed according to the number of fuel assemblies for each of the three coolant channels. Due to small flow areas modeled for the inner and outer reflectors, RELAP5-3D converges on bypass flow rates that are considerably reduced from the initial estimates.

\section{E. Fuel Particle Temperature Analysis}

Since the Doppler effect is a very important phenomena for resonance cross sections of strong absorbers, a hand calculation was performed to find the temperature distribution across the layers of a TRISO fuel particle to decide whether or not it is necessary to represent distributed temperatures at the fuel particle level. The steady-state heat conduction equation was solved for the heterogeneous TRISO microsphere, consisting of uranium oxy-carbide (UCO) fuel kernel in the center and surrounded by the coatings:

$$
\frac{1}{r^{2}} \frac{d}{d r}\left(k r^{2} \frac{d T}{d r}\right)+q^{\prime \prime \prime}=0
$$

where $\mathrm{k}$ is the thermal conductivity and $q^{\prime \prime}$ is the volumetric heat source, which is set to zero for the surrounding coatings. The solution of the steady-state heat conduction equations over five microsphere layers is given by 


$$
T_{0}-T_{5}=\frac{q^{\prime \prime \prime} r_{1}^{3}}{3}\left[\frac{1}{2 k_{1} r_{1}}+\sum_{i=2}^{5} \frac{1}{k_{i}}\left\{\frac{1}{r_{i-1}}-\frac{1}{r_{i}}\right\}\right]
$$

where $T_{0}$ and $T_{5}$ are the temperatures at the center and surface of the microsphere, respectively, and $r_{i}$ is the radius of the $i^{\text {th }}$ region, $i=1, \ldots, 5$. The thermal conductivity for different regions was obtained from $[20,21]$. The difference between $\mathrm{T}_{0}$ and $\mathrm{T}_{5}$ was calculated by using a uniform volumetric heat deposition $q$ "' inside the fuel kernel. It was found that the temperature rise across the TRISO particle is on the order of $1 \mathrm{~K}$. Due to this negligible temperature rise, it was decided to use a single uniform temperature distribution for the TRISO particles and surrounding graphite region for each of the three annular fuel regions and inner and outer reflectors at each of the 10 axial levels.

\section{F. Fission Heat Deposition}

The power fractions in the fuel and reflector regions accounted for global deposition of heat by explicit MCNP5 calculations with the following assumptions:

- Fission fragments and betas deposit their energy locally

- Prompt and delayed gammas (from fission product decay) deposit their energy globally

- Fission neutrons deposit energy globally due to: - deposition of kinetic energy during moderation

- emission of gammas as a result of neutron capture

- Capture gammas deposit heat globally.

Three MCNP5 calculations were performed to sort out the various energy deposition modes listed above. However, two MCNP5 calculations are sufficient: a base calculation with F6np and F7 tallies and a second calculation using the PIKMT card to tally only the prompt gamma deposition. The heat deposition due to fission fragments, neutrons, prompt gammas, and capture gammas is obtained from the base run with the F6np tally. By scaling the F7 tally in the first MCNP5 run, the local deposition of heat due to betas can be estimated. Similarly, scaling the prompt gamma tally in the second MCNP5 run yields the heat deposition due to the delayed gammas. 


\section{G. Coupled NTH Results}

Preliminary converged power and temperature distributions for the fuel and the reflector rings are illustrated in Figures 17 and 18, respectively, for the homogeneous full core model.

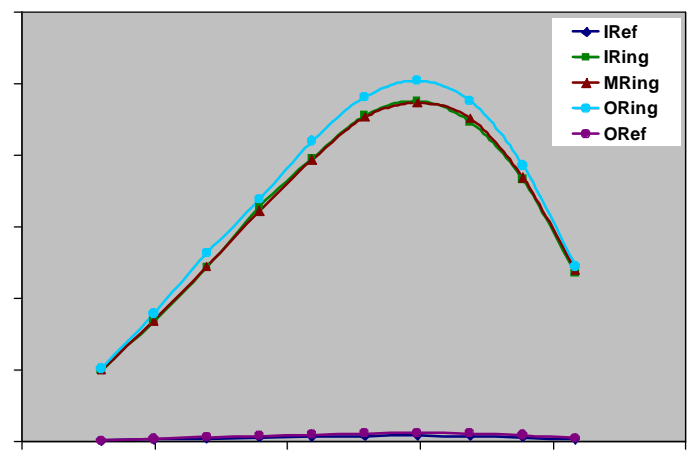

Figure 17. Converged power distributions

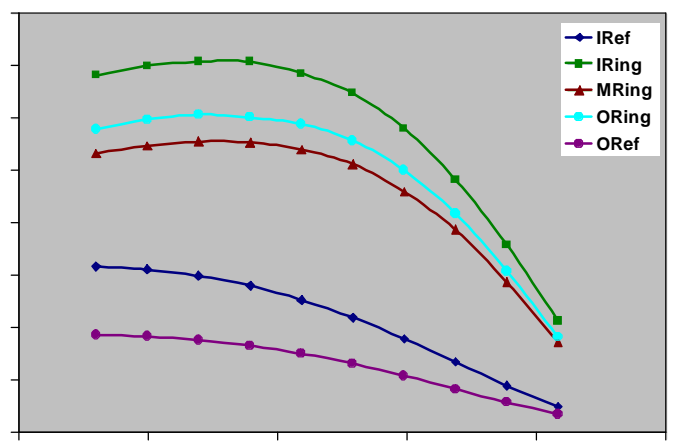

Figure 18. Converged temperature distributions

Despite small power fractions in the reflectors, the reflector temperature rises in our preliminary NTH calculations are substantial due to the small bypass flow rates that the RELAP5-3D calculations have converged on. This was summarized in Table 28.

\section{Application to Pebble Bed Reactors}

\section{A. Introduction}

The DHF methodology should in principle work with pebble bed configurations, since the basic methodology is not dependent on a specific geometry. To test this assertion, the following efforts were performed [22]:

- A single pebble was modeled with MCNP5, including a comparison of alternative methods to model the random mixture of TRISO fuel particles within the pebble 
- Alternative sphere packing codes were investigated to construct MCNP5 models of a full core pebble bed configuration, and the MCNP5 results were used to assess the sensitivity of the results to how the pebbles were modeled.

\section{B. MCNP5 Modeling of a Single Pebble}

\section{Avoiding Clipped Fuel Kernels.}

Previous results have shown that the stochastic particle fuel can be adequately modeled by putting the fuel particles on a lattice. This is easily handled by MCNP5 and the results are reasonably close to what would be obtained using a random collection of particles with the same packing fraction. However, to model this with MCNP5, one first creates the lattice then encloses it in a sphere for a pebble (or cylinder for a compact) and this latter step may cut through ("clip") some of the fuel kernels on the periphery. This is a non-physical artifact of the geometry engine that will bias the resultant Monte Carlo calculation, due to the fact that the clipped kernel has a substantially reduced self-shielding, causing the resonance absorption to be over-estimated, and yielding a negative bias for $\mathrm{k}_{\text {eff. }}$. This has been found to be a substantial effect for prismatic VHTRs and since it is relatively straightforward to modify the lattice to avoid clipping, this methodology was applied to the pebble bed VHTR.

The basic idea is that fuel kernels of radius $r$ cannot be within a distance $r$ of the boundary, hence the effective volume of the fuel region is equivalent to a sphere of radius $R^{e f f}=R-r$, where $R$ is the radius of the fuel pebble. This in turn yields an effective packing fraction which has to be larger in order to accommodate moving clipped kernels to the interior of the pebble,

$$
f^{e f f}=f\left(\frac{R}{R-r}\right)^{3}
$$

where $f$ is the nominal packing fraction. If this effective packing fraction is then used and one removes all fuel kernels whose centers are within $r$ of the spherical boundary, one will have a lattice that preserves the fuel packing fraction and which has no clipped kernels. This analysis is approximate, so one may need to iterate on $f^{\text {eff }}$ a couple times to get the exact packing fraction. A code was written to implement this procedure for a fuel pebble, including a script to prepare an MCNP5 geometry input file based on this approach.

The pebble models are shown in Figure 19 and include the moderator region at the outer edge of the pebble. Model 1 allows the TRISO fuel particles to be "clipped" at the inner boundary of the moderator region while Model 2 has no clipped particles. Each model has the same amount of fuel, but Model 2 has a slightly higher packing fraction to allow the movement of partial particles on the boundary to be totally within the fuel region. MCNP5 simulations were performed for these two models depicted in Figure 19. The resultant $k_{\text {eff }}$ values were essentially the same, as shown in Table 28. 


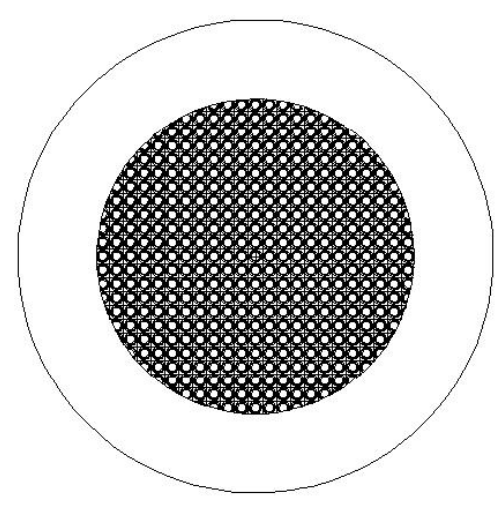

Model 1

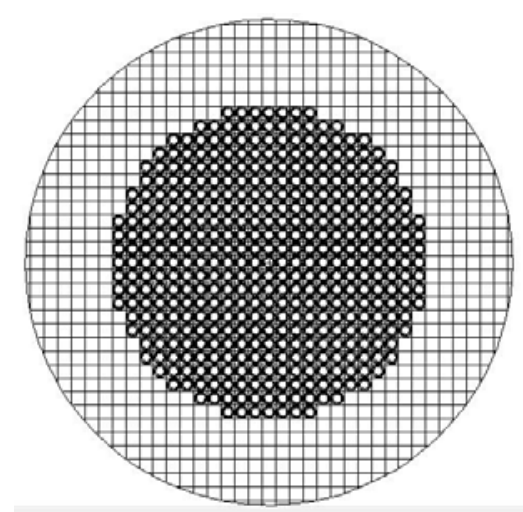

Model 2

Figure 19. Fuel Pebble with Clipped Particles (left) and No Clipped Particles (right)

Table 29. MCNP5 Results for Pebble with Clipped vs. Unclipped Fuel Particles

\begin{tabular}{|c|c|c|}
\hline Model & $\mathbf{k}_{\text {eff }}$ & $\sigma$ \\
\hline Clipped & 1.5478 & 0.00068 \\
\hline Not clipped & 1.5482 & 0.00080 \\
\hline
\end{tabular}

The difference in $\mathrm{k}_{\mathrm{eff}}$ for the two models is $\sim 40 \mathrm{pcm}$, a factor of 10 smaller than observed for the prismatic case that had a much higher packing fraction $(29 \%)$. It should be noted that this difference is somewhat less than the standard deviation for either simulation which is about 70 pcm. The small difference is due to the fact that far fewer kernels are clipped at the outer boundary for a $6 \%$ packing fraction for a fuel pebble compared to the $29 \%$ packing fraction for a fuel compact. While clipped fuel kernels may not have a large neutronic effect for pebble bed configurations, they should be avoided as it is straightforward to do so and it removes a small but finite bias in the neutronic analysis.

\section{Alternative Stochastic Mixtures within a Pebble}

An alternative model for the TRISO fuel arrangement in a single pebble was investigated. It is a two-step process. The first step is to construct a simple cubic lattice with the particles just touching each other, which yields the maximum packing fraction of 52\% (simple cubic lattice). Step 2 consists of removing particles randomly from the lattice until the desired packing fraction is achieved. Since the desired packing fraction for the pebble is $\sim 6 \%$, most of the fuel particles must be removed. Figure 20 depicts one realization of this process. 


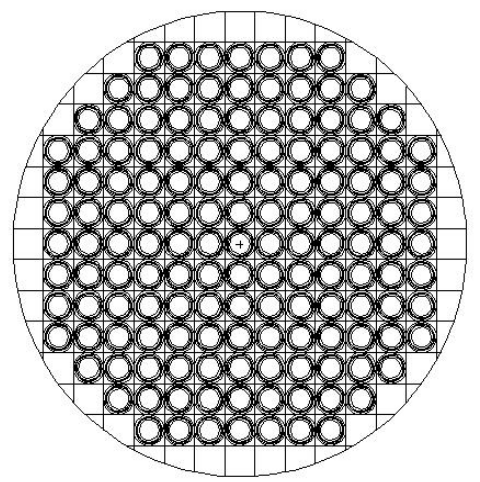

Step 1

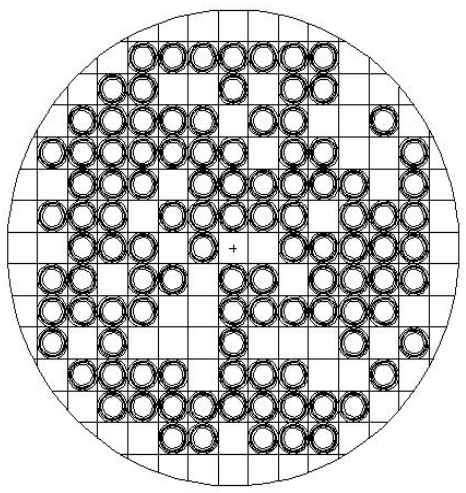

Step 2 (repeat)

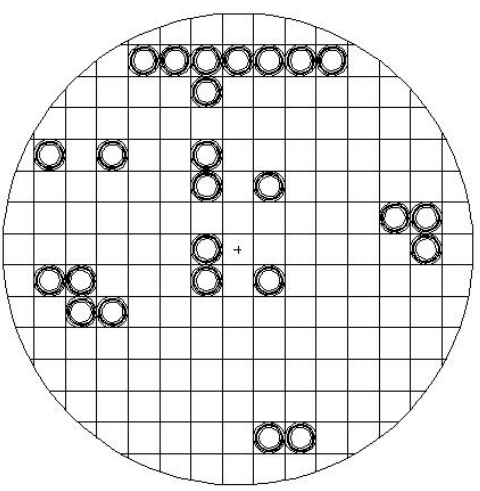

Semi-Random

Figure 20. Steps to Create "Semi-random" Lattice Structure for a Single Pebble

Figure 20 only shows a single layer of fuel particles but the actual lattice structure is $3 \mathrm{D}$. The Matlab code that performs these manipulations includes the ability to write out MCNP5 input cards that describe the resultant lattice, which is designated "semi-random".

MCNP5 was run for three cases - the simple cubic lattice, the semi-random lattice, and the true random lattice that was constructed using RSA. Since a pebble contains 15,500 fuel particles which far exceeds the MCNP5 limit for the number of cells, the RSA case was "stratified" horizontally yielding a reduced number of cells in each horizontal band that satisfied the MCNP5 limit. Figure 21 illustrates the three cases although for viewing convenience, the diagrams correspond to reduced-size pebbles with less than 1000 fuel particles. However, the MCNP5 simulations were performed with 15,500 fuel particles.

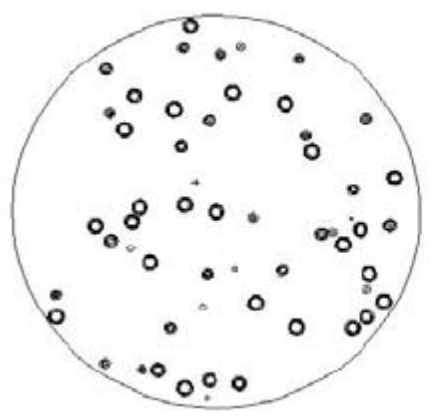

Random (RSA)

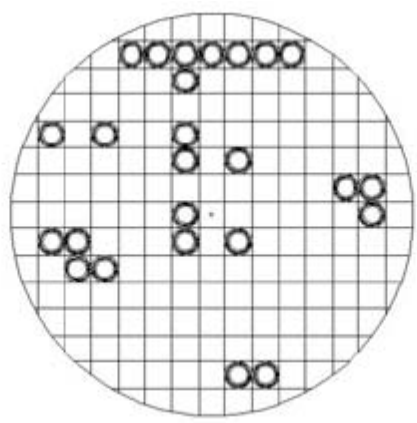

Semi-random

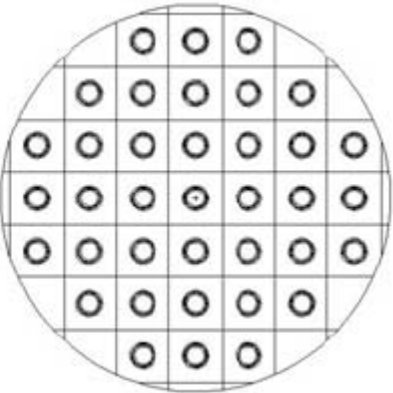

Simple cubic

Figure 21. Pebbles with Different TRISO Fuel Models

The MCNP5 results for the three different TRISO fuel models in a single pebble are given in Table 30. The results indicate that the simple cubic lattice is about $300 \mathrm{pcm}$ lower in $\mathrm{k}_{\text {eff }}$ than either the random or semi-random models, which are within $30 \mathrm{pcm}$ of each other. These results can be explained in terms of increased (random) clumping of the fuel particles for the random and semi-random cases compared to the simple cubic case. The increased clumping is evident visually from Figure 21 and will result in a local increase in self-shielding hence an increase in $\mathrm{k}_{\text {eff. }}$ This could be verified by computing the average Dancoff factors for these cases, which should be greater for the random and semi-random cases, but that has not been done yet. 
Table 30. MCNP5 Results for Pebbles with Different TRISO Fuel Models

\begin{tabular}{|c|c|c|}
\hline TRISO Fuel Model & $\mathbf{k}_{\text {eff }}$ & $\sigma$ \\
\hline Simple cubic & 1.5482 & 0.00080 \\
\hline Semi-random & 1.5515 & 0.00074 \\
\hline Random (RSA) & 1.5512 & 0.00077 \\
\hline
\end{tabular}

\section{MCNP5 Modeling of Collections of Pebbles}

The previous section concerned the modeling of a single pebble with MCNP5. This section compares different models for collections of pebbles, including:

- Simple cubic lattice (SC)

- Body-centered cubic lattice (BCC)

- Ballistic packing

- Simple hexagonal lattice (HEX)

- Discrete element method (DEM)

These simulations included simple arrangements of pebbles as well as a full annular core based on the South African Pebble Bed Modular Reactor (PBMR) design.

\section{Simple Configurations of Pebbles}

The SC, BCC, and ballistic packing configurations of pebbles were analyzed with MCNP5, as shown in Figure 22. All configurations are cubes containing pebbles. There are no clipped pebbles for any of these models. The SC and BCC lattices were directly modeled with MCNP5. The ballistic packing model was taken from Vasquez and Larsen [23] and consists of dropping pebbles randomly into the cube. A pebble falls under the influence of gravity and may bounce (off the walls, the floor, or other pebbles) until the pebble is in stable contact with neighboring pebbles and/or the cubic container. Once in contact, the pebble does not move. There are no interactions between pebbles and gravity is the only force that affects the path of the pebble as it falls and bounces. A Matlab code reads the resultant coordinates of the pebbles and generates MCNP5 input lines to represent the resultant ballistic configuration of pebbles. The MCNP5 simulation utilized reflecting boundary conditions on all sides so this is tantamount to an infinite lattice with periodic edge effects.

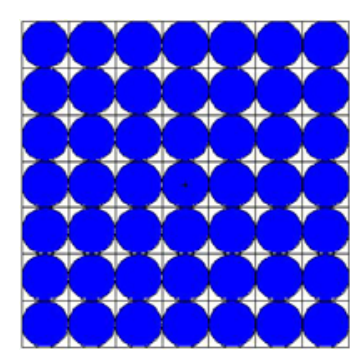

Simple Cubic

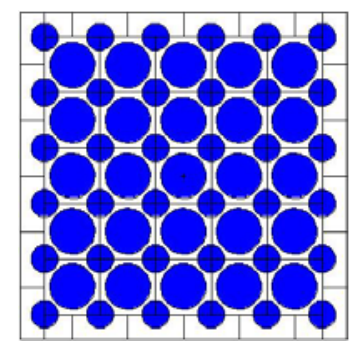

Body-centered Cubic

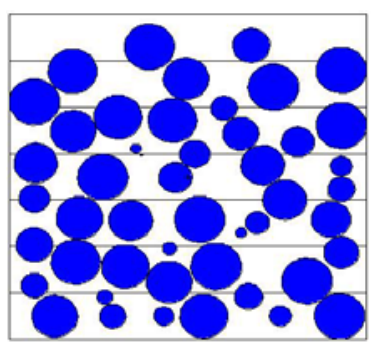

Ballistic Packing

Figure 22. Models for Simple Configurations of Pebbles 
Table 31 gives the results of the MCNP5 simulations of these three cases. The packing fractions are also given for each case. Neutronically, it is hard to conclude anything from these results because the packing fractions are different, hence different fuel loadings, for each case. The purpose of this exercise was to develop the capability to model these pebble arrangements and prepare the corresponding MCNP5 input decks.

Table 31. MCNP5 Results for Pebbles in a Lattice of Boxes

(All cases utilize $6 \%$ simple cubic lattice for pebble fuel.)

\begin{tabular}{|c|c|c|c|}
\hline Pebble Packing Model & Packing Fraction & $\mathbf{k}_{\text {eff }}$ & $\sigma$ \\
\hline Simple cubic & $52 \%$ & 1.39626 & 0.00095 \\
\hline Body-centered cubic & $58 \%$ & 1.39595 & 0.00085 \\
\hline Ballistic packing & $49 \%$ & 1.39553 & 0.00083 \\
\hline
\end{tabular}

\section{Annular Configurations of Pebbles}

The same three pebble models were studied for an annular container. This required some work because the ballistic packing model only works for a cubic container. So an approximate ballistic packing was arrived at for the annular container by first constructing a large cubic pile that was larger than the outer diameter of the annular container and then removing all pebbles that touched or were on the wrong side of the inner or outer cylinders. Figure 23 shows a typical configuration following this ballistic packing methodology for an annular container. Table 32 presents the results of the MCNP5 simulations for these three annular arrangements of pebbles, again assuming reflecting boundary conditions on all sides, so these do not represent realistic pebble bed core configurations. As with the cubic case, not much can be concluded from these results except that the methodology for generating the MCNP5 input decks has been exercised and appears to be working fine.
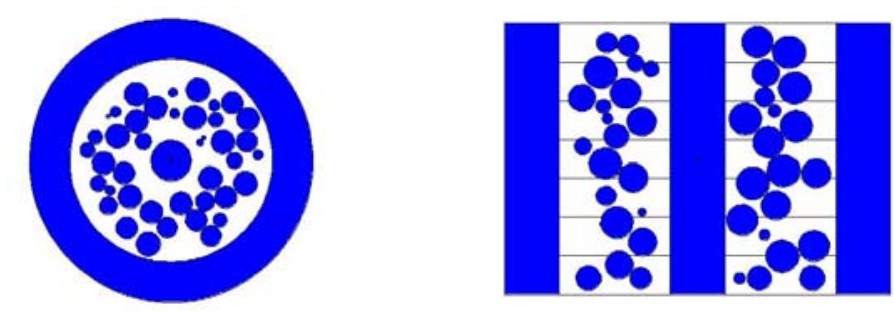

Figure 23. Ballistic Packing for an Annular Container

Table 32. MCNP5 Results for Pebbles in a Lattice of Annular Containers (All cases utilize 6\% SC lattice for TRISO fuel.)

\begin{tabular}{|c|c|c|c|}
\hline Pebble Packing Model & Packing Fraction & $\mathbf{k}_{\text {eff }}$ & $\sigma$ \\
\hline Simple cubic & $40 \%$ & 1.66209 & 0.00059 \\
\hline Body-centered cubic & $48.5 \%$ & 1.65933 & 0.00050 \\
\hline Ballistic packing & $37 \%$ & 1.66239 & 0.00060 \\
\hline
\end{tabular}

\section{Accounting for Interactions between Pebbles}

The ballistic packing methodology discussed above is a substantial improvement with respect to modeling the physics, compared to using static models based on SC or BCC lattices for the 
pebbles. Ballistic packing models the influence of gravity and the point contact between pebbles and other pebbles or surfaces, but interactions between pebbles and with surfaces due to friction or external forces such as flow pressure due to the flow of helium through the pebbles, are not accounted for. The desire to account for these important interactions led to the consideration of two different software packages - 3D animation software and discrete element method software used for modeling granular materials. These alternative software packages are discussed in the next sections.

3D animation software. The animation software 3DSMax creates realistic simulations with realistic physics. It is used by the cinema industry to create $3 \mathrm{D}$ movies and for CAD. To apply it to the pebble packing problem, a MAXScript was developed that generates a box and drops pebbles into the box and one can specify quantities such as the pebble mass, friction coefficient, and the time between each drop. At the end of the calculation the script generates a file with the coordinates of each pebble. A Matlab code generates the MCNP input deck from this file.

The software was tested with a simple problem: filling a $30 \mathrm{~cm}$ cube with $3 \mathrm{~cm}$ radius pebbles including gravity and friction. The 3DSMAX code placed 115 pebbles in the cube versus 111 pebbles with the ballistic packing method described above. (A simple cubic lattice would have placed 125 pebbles.) Figure 24 shows screen shots during the simulation with 3DSMAX.

However, the computational time to perform a realistic simulation is exorbitant. Even a small simulation with 300 pebbles takes several hours on a laptop. This is due to the fact that every pebble interacts with every other pebble, and the code has not been adapted to run on parallel computers. An attempt was made to run the code with 100,000 pebbles on a large cluster operated by the University of Michigan Center for Advanced Computing, but the code was not operable. Since we want to simulate full core pebble bed configuration with nearly 500,000 pebbles, the use of 3DSMAX was deemed not successful.

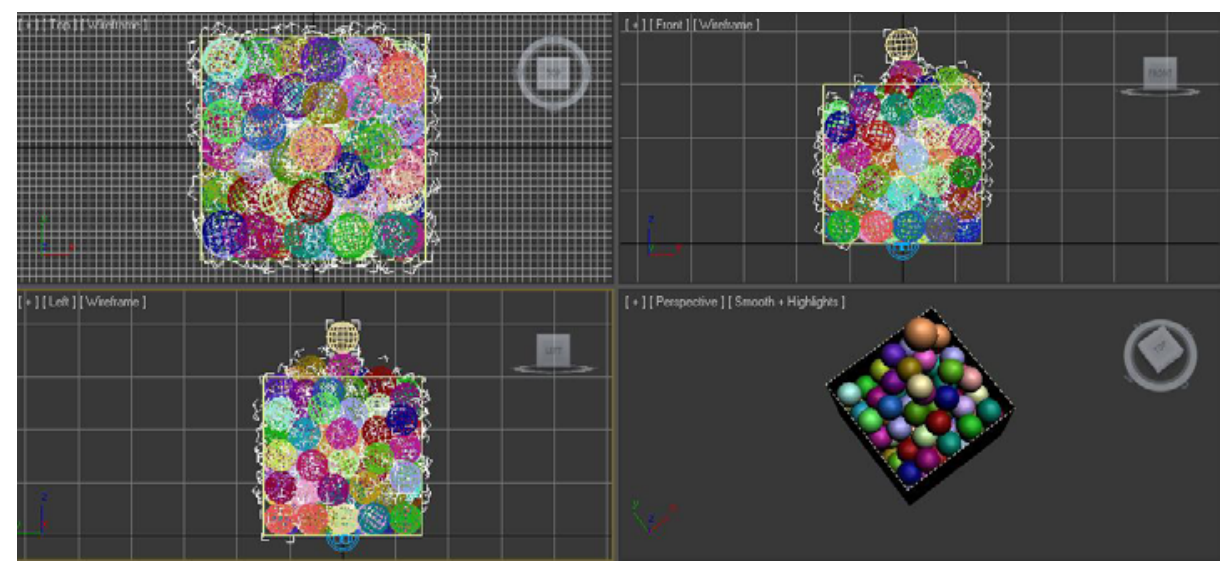

Figure 24. Pebble Packing with 3DSMAX Animation Software

Discrete element software. Although the animation software 3DSMax accounts for realistic physics between pebbles and with the bounding surfaces, it is limited by computational expense to relatively small problems. As a result, an alternative methodology was considered based on the discrete element method (DEM). This method, an extension of the finite element method to treat granular materials such as soil or sand, is capable of handling a large number of spheres and 
allows interactions between spheres and between the spheres and bounding surfaces, such as friction. It may also be able to account for flow forces due to helium flow through the pebbles, an important effect for pebble bed reactors.

A DEM simulation is started by putting all particles in a certain position and giving them an initial velocity. The forces which act on each particle are computed from the initial data and the relevant physical laws. The following forces can be considered: friction, damping, and gravity. Helium flow can be accounted for by modifying the force of gravity although this has to be tested.

One production code that is in wide use is PFC3D [24] but a license for this code costs $\$ 20,000$. The University of Michigan Department of Civil and Environmental Engineering has a PFC3D license but the code is always in use and we were unable to get access to it.

However, there is a DEM code, ESyS-Particle, which is an open source Linux code that is freely available. It has been developed since 1994 at the Earth Systems Science Computational Centre at the University of Queensland. Input consists of a Python script and there are tutorials [25] and an on-line Wiki. It is capable of simulating a large number of spheres and would be able to simulate a pebble bed configuration with over 400,00 pebbles. It is capable of taking advantage of parallel computing through its use of OpenMPI.

To run ESyS-Particle, a simulation zone is defined with the walls, particles, interactions between particles and between particles and walls, gravity, and other forces. The next step consists of generating all the pebbles within a cube that encompasses the eventual container to be used. There is an integrated script that does this automatically. Then the walls of the slabs are removed and particles interact between themselves and fall into the cylinder. For the annular container, a Python script was provided by Don Weatherley, the developer for ESyS-Particle. A Matlab code completes the job by creating the MCNP5 input lines from the positions of the pebbles in the annular container. Figure 25 illustrates the results.

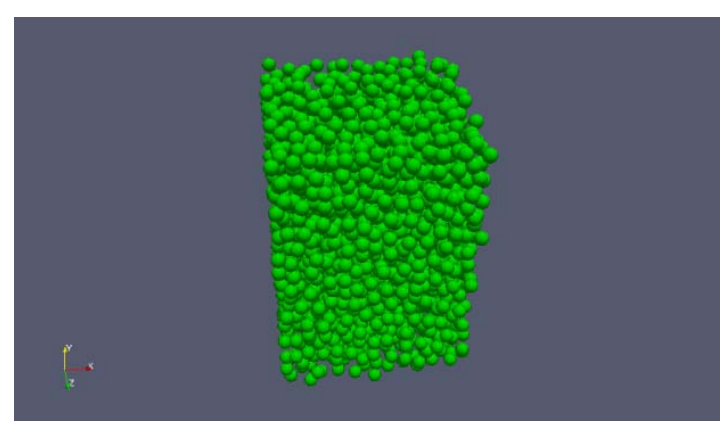

Initial step: pebbles are generated within a box

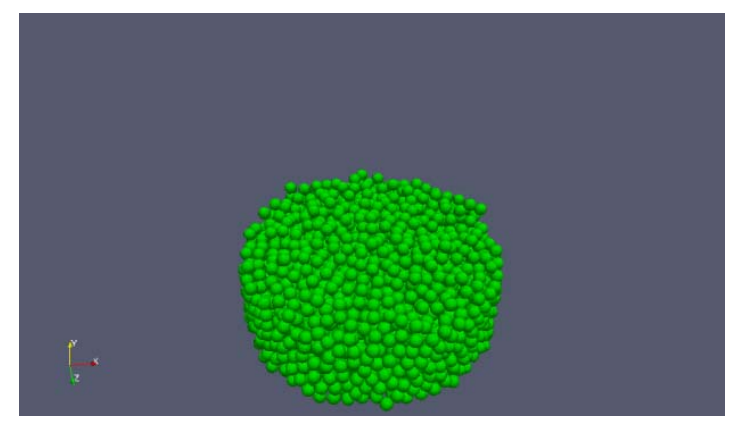

Final step: remove the box and let the particles relax under influence of gravity and friction

Figure 25. Creating a Pile of Pebbles within a Cylinder with ESyS-Particle.

\section{Simulation of Pebble Bed Reactor}

The ESyS-Particle code was used to develop the geometry for a full core description of the Pebble Bed Modular Reactor (PBMR) under construction in South Africa. The geometry and composition detail come from [26] and are shown in Figure 26 below. Full-core PBMR cases 
were also run with the pebbles modeled as a lattice and with different fuel pebble models (e.g., semi-random). The following sections present the details of these PBMR simulations.

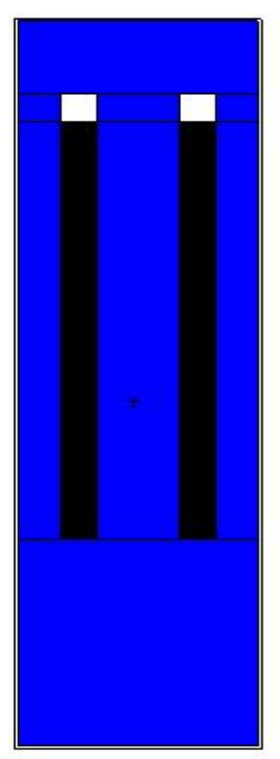

\begin{tabular}{|l|l|}
\hline Inner reflector radius (cm) & 100 \\
\hline Core radius (cm) & 185 \\
\hline Outer reflector thickness (cm) & 102.5 \\
\hline Active Core Height (cm) & 1162.5 \\
\hline Top Reflector thickness (cm) & 199.3 \\
\hline Bottom Reflector thickness (cm) & 572 \\
\hline Top Void thickness (cm) & 78.5 \\
\hline
\end{tabular}

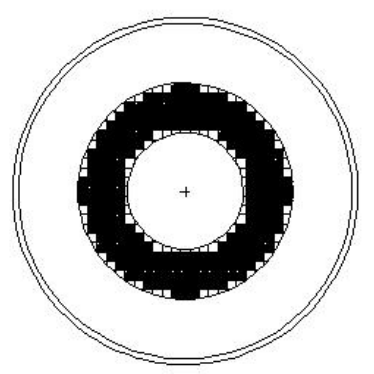

Figure 26. Geometry Detail for the PBMR

Pebbles modeled on a lattice. The pebbles were modeled as both SC and BCC lattices. Since the theoretical packing fractions are different and there are significant edge effects due to the annular design, there are large differences in the amount of fuel in the PBMR for SC versus BCC lattices: 376,736 pebbles for SC and an associated packing fraction of 48\% versus 480,964 pebbles for BCC with a packing fraction of $62 \%$. For these two cases, pebbles consist of TRISO particles on a simple cubic lattice with a packing fraction equal to $6 \%$. As one might expect from such a disparity in the amount of fuel, the MCNP5 results for $k_{\text {eff }}$ given in Table 33 are quite different.

Table 33. MCNP5 Results for Full Core PBMR with Pebbles on a Lattice

\begin{tabular}{|c|c|c|}
\hline Pebble Lattice & $\mathbf{k}_{\text {eff }}$ & $\sigma$ \\
\hline Simple cubic & 1.37132 & 0.00080 \\
\hline Body-centered cubic & 1.40439 & 0.00081 \\
\hline
\end{tabular}

The difference in $\mathrm{k}_{\mathrm{eff}}$ is over $3 \%$, showing the importance of the arrangement of pebbles within the PBMR core. It is interesting that the comparison of infinite lattices of pebbles, shown in Tables 31 and 32, shows no differences among the SC, BCC, and ballistic packing models. This is due to the fact that these cases were very under-moderated and for the PBMR case, the reflectors provide sufficient moderation to cause a substantial difference for the denser pebble arrangement associated with the BCC lattice.

Effect of TRISO Packing Model and Pebble Arrangement. These four runs consist of two TRISO fuel models (SC and semi-random) for two different pebble arrangements, SC lattice and BCC lattice. As can be seen from Table 34, the effect of the TRISO fuel model is small but finite, with a slight increase in $\mathrm{k}_{\text {eff }}$ due to semi-random TRISO fuel for either pebble 
arrangement. As discussed earlier, this is due to the increased clumping of TRISO fuel particles for the semi-random case. On the other hand, for either TRISO fuel model, going from a SC lattice of pebbles to a BCC lattice of pebbles results in a substantial increase (>3\%) in $\mathrm{k}_{\text {eff }}$. This is due to the increased amount of fuel in the core with the BCC lattice.

Several variations on these simulations were performed to ascertain the fluctuations in the results. It was found that changing the number of different "semi-random" pebbles had very little effect on $\mathrm{k}_{\text {eff }}$. In addition, by running an ensemble of cases, the intrinsic standard deviation in $\mathrm{k}_{\text {eff }}$ for different "semi-random" TRISO fuel models was found to be $\sim 80-90 \mathrm{pcm}$.

Table 34. Effect of TRISO Fuel Model and Pebble Arrangement on $\mathrm{k}_{\text {eff }}$ for PBMR

\begin{tabular}{|c|c|c|}
\hline \multirow{2}{*}{$\begin{array}{c}\text { TRISO Fuel Model } \\
\text { within a Pebble }\end{array}$} & \multicolumn{2}{|c|}{ Arrangement of Pebbles within the Core } \\
\cline { 2 - 3 } & SC lattice & BCC lattice \\
\hline SC lattice model & 1.37132 & 1.40439 \\
\hline Semi Random model & 1.37326 & 1.40712 \\
\hline
\end{tabular}

\section{Future Work with Pebble Bed Configurations}

Work is still needed to characterize the sensitivity of the pebble bed results to changes in the TRISO fuel model and the arrangement of pebbles within the annular core. For example, simple hexagonal packing of both TRISO fuel as well as pebbles should be considered. The next step would be to assess whether or not the DHF methodology can be applied to pebble bed configurations. As noted earlier, there is every reason to expect the DHF methodology will work for pebble bed configurations.

\section{Summary and Conclusions}

\section{A. Summary}

This project combined Monte Carlo capability with a production LWR lattice physics code to allow analysis of high temperature gas reactor configurations, accounting for the double heterogeneity due to the TRISO fuel. The Monte Carlo code MCNP5 has been used in conjunction with CPM3, which was the testbench code for this integrated methodology and which established "proof-of-principle" for this approach. The basic idea is to use MCNP5 to perform two calculations for the geometry of interest, one with homogenized fuel compacts and the other with heterogeneous fuel compacts, where the TRISO fuel kernels are resolved by MCNP5. The ratio of these two cross sections for every fine energy group and every isotope, known as the Double Heterogeneity Factor (DHF), is an effective "self-shielding factor" (albeit dependent on isotope and energy group) that accounts for the kernel-level heterogeneity. These DHFs are input to CPM3 and used to multiply the corresponding fine group resonance cross sections in CPM3, effectively yielding the fine group resonance cross section determined by MCNP5 with heterogeneous fuel compacts. These "adjusted" microscopic resonance cross sections are then used by CPM3 to perform the actual transport calculation, e.g., with collision probabilities $(\mathrm{CP})$ or method of characteristics $(\mathrm{MOC})$. In essence, the resonance cross sections that would have been generated by CPM3, normally a function of temperature and background cross section, are adjusted to be equivalent to the MCNP5 cross sections where the TRISO fuel kernels are fully resolved. The normal transport modules in CPM3, whether carried out by $\mathrm{CP}$ or 
MOC, are not changed with this methodology - only the fine group resonance cross sections are changed.

The use of DHFs represents a major change in the research direction of this project, because the original idea was to explicitly link MCNP5 and CPM3 by running them concurrently on the same heterogeneous fuel configuration and overwriting the CPM3-generated fine group resonance cross sections with the corresponding MCNP5-generated cross sections. In order to develop this link, an early deliverable was the Application Program Interface (API), that served as the communications link between the two codes. A draft version of the API was created and tested and worked very well, but it was soon realized that the simultaneous execution of the two codes was awkward and required sophisticated coding to establish the communications links between the two codes. This led to the idea to simplify the approach and define a correction factor instead, which would be a cross section ratio.

The idea to use MCNP5 to compute both the numerator and denominator of the DHFs came from the observation that CPM3 is capable of analyzing homogenized fuel compacts, so the MCNP5 and CPM3 fine group cross sections should be comparable for this case. Proof-of-principle was established for CPM3 and the methodology was ported to HELIOS, a production lattice physics code, with excellent results for a VHTR fuel block. This methodology allows the analyst to take advantage of the downstream capabilities of CPM3 and HELIOS, including cross section generation for global nodal analysis and depletion, systematic preparation of cross section sets for accident analysis, and enabling efficient fuel cycle analyses and assessment of alternative fuel management schemes. The methodology has been tested on a number of configurations ranging from a single fuel kernel to full core, including lattices with a substantial amount of plutonium. Sensitivity studies have been conducted, indicating that the DHFs are not sensitive to depletion or location in the fuel block or location in the core.

\section{B. Conclusions}

The DHF methodology allows LWR lattice physics codes to analyze VHTR configurations, accounting for the double heterogeneity due to the TRISO fuel kernels. The cost is two MCNP5 calculations of the same configuration, one with homogenized fuel compacts and one resolving the fuel kernels. These are needed to compute the DHFs. Because the DHFs are a function of energy group and isotope, they should yield more accurate isotopics than methods which are based on preserving overall absorption rates. Since the sensitivity studies have shown that the DHFs are not sensitive to spatial location or depletion, there is a good chance that they can be parameterized in terms of quantities such as Dancoff factor or background cross section, for example, similar to how resonance integrals are parameterized. This would remove the need to perform the two Monte Carlo calculations to determine the DHFs.

\section{References}

[1] L. Massimo, Physics of High-Temperature Reactors, Pergamon Press, 1976.

[2] D.B. Jones, K.E. Watkins, and M.L. Williams, "CPM3 Computer Code Manual, vol 1, Theory and Numerics Manual," EPR-CPM-001-M-001, Revision A, Electric Power Research Institute, 2000. 
[3] J. Rhodes and M. Edenius, "CASMO-4: A Fuel Assembly Burnup Program User's Manual," SSP-01/400 Rev 3, Studsvik Scandpower Inc., (2003).

[4] D.M. Ver Plank, "SIMULATE-3: Advanced Three-Dimensional Two-Group Reactor Analysis Code," STUDSVIK/SOA-96/12, Studsvik Scandpower Inc. (1996).

[5] Studsvik Scandpower, "HELIOS User Manual," April 2000.

[6] P. E. MacDonald, et al., "NGNP Preliminary Point Design - Results of the Initial Neutronics and Thermal-Hydraulic Assessments During FY-03", INEEL/EXT-03-00870 Rev. 1, Idaho National Engineering and Environmental Laboratory (2003).

[7] F. B. Brown, "MCNP - A General Monte Carlo N-Particle Transport Code, Version 5", LAUR-03-1987, Los Alamos National Laboratory (2003).

[8] F. C. Difilippo, "Monte Carlo Calculations of Pebble Bed Benchmark Configurations of the PROTEUS Facility," Nucl. Sci. Eng., 143, 240-253 (2003).

[9] T. Mori, K. Okumura, and Y. Nagaya, "Status of JAERI's Monte Carlo Code MVP," Proc. Monte Carlo 2000 Conference, Lisbon, 23-26 October (2000).

[10] M. Armishaw, N. Smith, E. Shuttlesworth, "Particle Packing Considerations for Pebble Bed Fuel Systems," Proc. ICNC 2003 Conference, JAERI-Conf-2003-019, Tokai-mura, Japan, Oct. 20-24 (2003).

[11] R. Plukiene and D. Ridikas, "Modeling of HTRs with Monte Carlo: from a homogeneous to an exact heterogeneous core with microparticles," Annals of Nuclear Energy 30, 1573-1585 (2003).

[12] A. Talamo, W. Gudowski, and F. Venneri, "The Burnup Capabilities of the Deep Burn Modular Helium Reactor analyzed by the Monte Carlo Continuous Energy Code MCB," Annals of Nuclear Energy 31, 173-196 (2004).

[13] F. B. Brown and W. R. Martin, "Stochastic Geometry Capability in MCNP5 for the Analysis of Particle Fuel," Annals of Nuclear Energy 31, 2039-2047 (2004).

[14] P. Wälti, "Evaluation of Grain Shielding Factors for Coated Fuel Particles," Nucl. Sci. Eng., 45, pp.321-330 (1971).

[15] The RELAP5-3D Code Development Team, "ATHENA Code Manual," INEEL-EXT-9800834, Rev. 2.2, Idaho National Engineering and Environmental Laboratory (2003).

[16] J. L. Conlin, W. Ji, J. C. Lee, and W. R. Martin, "Pseudo Material Construct for Coupled Neutronic-Thermal-Hydraulic Analysis of VHTGR," Trans. Am. Nucl. Soc. 92, 225-227, San Diego, CA (2005).

[17] R. E. MacFarlane and P. Talou, "DOPPLER: A Utility code for Preparing Customized Temperature-Dependent Data Libraries for the MCNP Monte Carlo Transport Code," Internal Memorandum, Los Alamos National Laboratory (2003).

[18] C. Davis, Private communication, June 2004.

[19] P. E. MacDonald, "NGNP Preliminary Point Design - Results of the Initial Neutronics and Thermal-Hydraulic Assessments," INEEL/EXT-03-00870 Rev. 1, Idaho National Engineering and Environmental Laboratory (2003).

[20] E. López-Honorato, C. Chiritescu, P. Xiao, D. G. Cahill, G. Marsh, and T. J. Abram, "Thermal Conductivity Mapping of Pyrolytic Carbon and Silicon Carbide Coatings on Simulated 
Fuel Particles by Time-domain Thermoreflectance," Journal of Nuclear Materials, 378, 35 (2008).

[21] H. D. Lewis and J. F. Kerrisk, "Electrical and Thermal Transport Properties of Uranium and Plutonium Carbides," UC-25 and UC-79b, Los Alamos Scientific Laboratory (1976).

[22] Olivier Froment, "Modeling of a Pebble Bed Reactor with MCNP," report of a summer internship, University of Michigan Department of Nuclear Engineering and Radiological Sciences, Ann Arbor, MI, July 2009.

[23] R. Vasques, E. W. Larsen,”Anisotropic diffusion in model 2-D - Pebble-bed reactor cores “, M\&C 2009, American Nuclear Society, Saratoga Springs, New-York (2009), on CD-ROM.

[24] Mark N. Mitchell, Alexander G. Polson, "Assessment of the loads on a solid centre reflector of a pebble bed reactor using DEM techniques", 18th International Conference on Structural Mechanics in Reactor Technology, Beijing, China, August 7-12, 2005, SMiRT18-S07-4.

[25] Dion Weatherley, "ESyS-Particle Users", Earth Systems Science Computational Centre, University of Queensland, 9 June 2009.

[26] Trevor Dudley, Piet de Villiers, Werner Bouwer, Oliver Tsaoi, Eben Mulder, "The Reactor Core Neutronic model for the Pebble Bed Modular Reactor", Nuclear Engineering and Design 238 (2008) 3002-3012.

[27] D. P. Griesheimer, W. R. Martin, and J. P. Holloway, "Convergence Properties of Monte Carlo Functional Expansion Tallies," Journal of Computational Physics, 211, 129-153 (January 2006). 


\section{Achievement of Grant Objectives and Principal Tasks}

\section{A. Grant Objectives}

The original proposal included six primary objectives. These are listed in Table 35 along with its status and a concise summary of why/why not the objective had been met.

Table 35. Primary Objectives for the Grant

\begin{tabular}{|c|c|c|c|}
\hline \# & Objective & Status & Explanation \\
\hline 1 & $\begin{array}{l}\text { Develop an Application Program } \\
\text { Interface (API) to couple CPM-3 } \\
\text { and MCNP5 for analysis of } \\
\text { VHTR reactor configurations. }\end{array}$ & Completed & $\begin{array}{l}\text { A preliminary version of the API was created and } \\
\text { tested, allowing concurrent execution of MCNP5 } \\
\text { and CPM3 on the same geometry. However, the } \\
\text { decision to focus on DHFs made the API } \\
\text { defunct, and it was set aside. }\end{array}$ \\
\hline 2 & $\begin{array}{l}\text { Demonstrate "proof of principle" } \\
\text { of the coupled CPM-3/MCNP5 } \\
\text { methodology by implementing } \\
\text { and testing on a test suite of } \\
\text { selected benchmark problems. }\end{array}$ & Completed & $\begin{array}{l}\text { The DHF methodology was tested on a range of } \\
\text { VHTR configurations ranging from single } \\
\text { microspheres to fuel compacts to fuel blocks to } \\
\text { full core. All comparisons were made with } \\
\text { reference solutions by MCNP5. }\end{array}$ \\
\hline 3 & $\begin{array}{l}\text { Apply the coupled CPM- } \\
\text { 3/MCNP5 methodology to a Deep } \\
\text { Burn configuration and assess its } \\
\text { capability to treat low-lying } \\
\text { resonances of plutonium isotopes. } \\
\text { Adapt the methodology as needed } \\
\text { to handle these important } \\
\text { resonances. }\end{array}$ & Completed & $\begin{array}{l}\text { The DHF methodology was applied to a Deep } \\
\text { Burn driver fuel configuration that consisted of } \\
\text { Pu-Np-CO fuel, representing the Pu-Np isotopics } \\
\text { in typical used nuclear fuel from light water } \\
\text { reactors, including Pu- } 239 \text { and } \mathrm{Pu}-240 \text {. The DHF } \\
\text { methodology worked very well for this case. }\end{array}$ \\
\hline 4 & $\begin{array}{l}\text { Demonstrate the capability of the } \\
\text { API to be used with a production } \\
\text { lattice physics code by using it to } \\
\text { couple MCNP5 and CASMO- } 4 \\
\text { and testing with the test suite. }\end{array}$ & Completed & $\begin{array}{l}\text { Studsvik-Scandpower modified HELIOS to allow } \\
\text { it to work with DHFs calculated by the UM for a } \\
\text { VHTR fuel block. The test was successful, } \\
\text { indicating that the DHF methodology can be } \\
\text { implemented into other lattice physics codes. }\end{array}$ \\
\hline 5 & $\begin{array}{l}\text { Verify and validate the coupled } \\
\text { CPM-3/MCNP5 methodology for } \\
\text { simple VHTR configurations as } \\
\text { well as critical experiments and } \\
\text { startup/operational data from Fort } \\
\text { St. Vrain (FSV) and Peach } \\
\text { Bottom. }\end{array}$ & $\begin{array}{l}\text { Partially } \\
\text { completed }\end{array}$ & $\begin{array}{l}\text { The DHF methodology has been shown to work } \\
\text { for a range of VHTR configurations ranging from } \\
\text { single microspheres to fuel compacts to fuel } \\
\text { blocks to full core. Due to the difficulty in } \\
\text { obtaining detailed information regarding the FSV } \\
\text { reactor, this effort was not completed. A follow- } \\
\text { on grant is now in place at the UM to carry out a } \\
\text { detailed benchmark calculation of FSV with the } \\
\text { assistance of General Atomics. }\end{array}$ \\
\hline 6 & $\begin{array}{l}\text { Assess the applicability of the } \\
\text { coupled methodology to analyze } \\
\text { pebble bed configurations. }\end{array}$ & $\begin{array}{l}\text { Partially } \\
\text { completed }\end{array}$ & $\begin{array}{l}\text { Effort was expended to model single pebbles and } \\
\text { a collection of pebbles. Several alternative } \\
\text { random arrangements of fuel and pebbles were } \\
\text { examined. The DHF methodology was not tested } \\
\text { but is expected to work. }\end{array}$ \\
\hline
\end{tabular}




\section{B. Principal Tasks}

The original proposal listed 12 principal tasks that were spread out over the 3 year duration of the project. (Actually, the original proposal had 13 tasks but two of the tasks were numbered 9 so these have been renumbered $9 \mathrm{a}$ and $9 \mathrm{~b}$ below.) The descriptions of the tasks are reproduced from the original proposal followed by a brief status report for each task. There is considerable overlap between these tasks, which are spread out over time and the project objectives in the section above, which are meant to be overarching goals, so there is some similarity in the reports below with the reports in Table 34.

Overall, the principal tasks have been completed successfully, with a few tasks set aside due to the major change in the research focus from simultaneous execution of MCNP5 and CPM3 to the DHF methodology, which decoupled the two codes, removing the need for the API.

\section{Task 1. Design of the API.}

This is the key module for linking CPM-3 and MCNP5. The API will accept data from CPM-3 to describe the geometry and material properties of the configuration that is being analyzed. This will include dimensions, isotopic densities, temperatures, and boundary conditions. It will prepare an MCNP5 input file based on this data. It will initiate execution of the MCNP5 code and receive the results from MCNP5, such as explicit resonance integrals or related quantities for each relevant isotope for each pin or region in question. It may be sufficient to communicate only the group microscopic absorption cross sections for the resonance groups to CPM-3, but detailed resonance integrals will be needed for debugging and validation. Special care will be taken to ensure that the API is a generic interface, usable by other lattice physics codes in addition to CPM-3. The initial version of the API will be completed during Year 1. This version will not handle low-lying resonances and the geometry will be limited to a single hexagonal VHTR fuel element with reflecting boundaries.

Status of Task 1: partially completed and set aside. A preliminary version of the API was created and tested, allowing concurrent execution of MCNP5 and CPM3 on the same geometry. However, the decision to focus on the DHF methodology removed the need for simultaneous execution of MCNP5 and CPM3, hence removing the need for the API. The preliminary version of the API was tested successfully by executing MCNP5 and CPM3 on separate computing platforms. However, since an API is not needed with the DHF methodology, it was set aside and not developed beyond its preliminary version. Details of the API and its performance are included in Appendix A.

\section{Task 2. Modification of CPM-3.}

The coordination of CPM-3 and the API is the key activity here, including creating the linkages to the API, both to send and receive information regarding the resonance absorption calculation, as decided in Task 1. This also will require thorough understanding of the CPM-3 resonance treatment, including internal data arrays that store the resonance integrals that MCNP5 will calculate. This task will include effort to verify the ability to handle hexagonal geometry, including comparison with MCNP5 results for a VHTR fuel element. This version will not handle low-lying resonances and the geometry will be limited to a single hexagonal VHTR fuel element with reflecting boundaries. This task will be completed during Year 1.

Status of Task 2: completed. A thorough examination of the CPM3 code was performed prior to creating the preliminary version of the API. Appendices B and C summarize the salient 
details of the CPM3 code structure that are pertinent to both the API and the DHF methodology that superseded the API.

\section{Task 3. Determination of VHTR Test Suite.}

A suite of test problems representative of VHTR configurations will be put together. These cases will be analyzed by MCNP5 and the MCNP5 predictions will be part of the test suite. This task will be completed during Year 1 or early in Year 2.

Status of Task 3: completed. The test problems include microsphere cells, fuel compact cells, hexagonal fuel blocks with reflecting boundary conditions, and fuel core configurations. All of these VHTR configurations are analyzed with either homogeneous fuel or heterogeneous fuel, where the TRISO fuel particles are resolved on a lattice without clipping.

\section{Task 4. Verification of CPM-3/MCNP5 methodology.}

This effort will include comparisons of the combined CPM-3/MCNP5 (and CASMO-4/MCNP5) methodology with standalone MCNP5 analyses. These comparisons will be done for the following configurations specific to the nominal VHTR design for prismatic fuel: (1) single TRISO microsphere cell, (2) TRISO fuel compact cell, (3) hexagonal VHTR fuel element, and (4) full core VHTR configuration. This comparison will include actual resonance integrals for individual resonances in specific nuclides and will assess the effect of centered versus random microspheres in the graphite matrix cell.

Status of Task 4: completed. All of the VHTR configurations have been modeled with the DHF methodology with excellent results. The body of this report gives ample details of this effort.

\section{Task 5. Specification of VHTR design parameters.}

The verification cases in Task 4 will be performed for configurations that represent the nominal VHTR design. The nuclear design parameters for the VHTR cases (at all levels) will be frozen early in the grant period.

Status of Task 5: completed. This was done and the body of the report contains the geometry and material specifications for all of the VHTR configurations that were examined during the course of this project. For examples, see Tables 7-8 and 17-18.

\section{Task 6. Porting of API to CASMO-4.}

The initial version of the API will be ported to work with CASMO-4 and tested with the VHTR test suite.

Status of Task 6: completed. Studsvik-Scandpower modified HELIOS (rather than CASMO-4 due to the advantage of HELIOS for analyzing hexagonal geometry) to allow it to work with DHFs calculated by the UM for a VHTR fuel block. The test was successful, indicating that the DHF methodology can be implemented into other lattice physics codes.

\section{Task 7. Low-Lying Resonances.}

The API and CPM-3 will be modified to handle low-lying resonances in $\mathrm{Pu}-239$ and $\mathrm{Pu}-240$. The resultant package will be tested against standalone MCNP5 calculations of Deep Burn designs. 
The need for a micro-depletion model for a fuel kernel will be assessed.

Status of Task 7: completed. The DHF methodology was applied to a Deep Burn driver fuel configuration that consisted of $\mathrm{Pu}-\mathrm{Np}-\mathrm{CO}$ fuel, representing the $\mathrm{Pu}-\mathrm{Np}$ isotopics in typical used nuclear fuel from light water reactors, including substantial amounts of $\mathrm{Pu}-239$ and $\mathrm{Pu}-240$. The DHF methodology worked very well for the plutonium isotopes.

\section{Task 8. Depletion.}

The API and CPM-3 will be updated to include depletion. At this point, the API will be complete for production analyses. Porting to CASMO-4 will be initiated towards the end of Year 2.

Status of Task 8: completed. The change to the DHF methodology removed the need to worry about depletion because the DHFs are precomputed and can be determined for whatever geometrical/material configuration is being analyzed by CPM3. However, as noted in Section V.F.2, the DHFs are insensitive to depletion, and this essentially negates the need to account for depletion as a practical matter.

\section{Task 9a. Develop Validation Test Suite.}

There are a number of high temperature graphite-moderated configurations that could be useful for benchmarking. A thorough examination of the various criticals and benchmark cases will be conducted and a set of cases will be selected. To the extent possible, these cases should span the range of parameters expected for the VHTR, including temperatures, power density, annular core, reflector control rods, depletion, etc. This effort will also include determination of operating reactor cases for comparison with predicted results, such as Fort St. Vrain and Peach Bottom. The choice of cases will be determined by the type and quality of the measured data.

Status of Task 9a: partially completed. The DHF methodology has been shown to work for a range of VHTR configurations ranging from single microspheres to fuel compacts to fuel blocks to full core, as described thoroughly in the body of this report. Due to the difficulty in obtaining detailed information regarding the FSV reactor, this effort was not completed. A follow-on grant is now in place at the UM to carry out a detailed benchmark calculation of FSV with the assistance of General Atomics.

\section{Task 9b. Validation of Coupled Methodology.}

Validation of the combined CPM-3/MCNP5 (and CASMO-4/MCNP5) methodology will be accomplished by running the validation test suite and comparing the results against benchmark results, experimental as well as standalone MCNP5 where applicable. Typical results that will be compared include keff, power distributions, temperature coefficients, control rod worths, and critical loadings. Comparisons will also be made with other published results, such as maintained by the IAEA.

Status of Task 9b: partially completed. The DHF methodology has been shown to work for a range of VHTR configurations ranging from single microspheres to fuel compacts to fuel blocks to full core, as described thoroughly in the body of this report. Due to the difficulty in obtaining detailed information regarding the FSV reactor, this effort was not completed. A follow-on grant is now in place at the UM to carry out a detailed benchmark calculation of FSV with the assistance of General Atomics. 


\section{Task 10. Generation of Cross Sections for Nominal VHTR Design.}

The combined CPM-3/MCNP5 and CASMO-4/MCNP5 methods will be used to generate a set of depletion-dependent cross sections for the nominal VHTR design as described in Task 5.

Status of Task 10: set aside. The DHF methodology removed the need to explicitly account for depletion. Moreover, the sensitivity studies described in Section V.F.2 indicate that the DHFs are not sensitive to the slow changes due to depletion, so there are no reasons to carry out this task.

\section{Task 11. Assess Potential for Analyzing Pebble Bed Fuel.}

Once the CPM-3/MCNP5 methodology has been verified for consistency with standalone MCNP5, its potential applicability for pebble bed analysis will be determined. This effort will involve a determination of what would be needed to allow the analysis of pebble bed configurations to be carried out with this methodology.

Status of Task 11: completed. A substantial effort was expended to model single pebbles and a collection of pebbles with MCNP5. Several alternative random arrangements of fuel and pebbles were examined. There not time to test the DHF methodology for pebble bed configurations but there is no reason to expect it not to work. This confidence is due to the fact that the key conceptual challenge for the DHF methodology is to account for the particle level heterogeneity when computing fine group resonance cross sections for use in the CPM3 transport calculation. This challenge was addressed successfully for the prismatic VHTR configuration and the physical phenomenon (i.e., the fuel kernel heterogeneity) is the same with pebble bed fuel. There are other challenges to pebble bed analysis, including the global analysis of the collection of pebbles, but this is well-removed from the fuel kernel heterogeneity.

\section{Task 12. Additional Activities.}

Time permitting, effort will be focused on topics to enhance the coupled CPM-3/MCNP5 methodology, including: (1) adding kernel depletion to CPM-3, (2) developing variance reduction techniques to speed up the MCNP5 resonance calculation, and (3) port the MCNP5 portion of the coupled methodology to a parallel processor.

Status of Task 12: partially completed. Each of these activities will be discussed briefly. (1) Adding specific kernel depletion (ala MICROBURN) was not specifically addressed during this project. (2) The use of variance reduction techniques is no longer a viable option as the MCNP5 runs are criticality calculations rather than source calculations because the timing results for the source calculations versus the criticality calculations were not that different and the criticality calculation is more realistic and easier to work with. Since most variance reduction techniques are not that effective for criticality calculations, this task was not pursued. (3) Early in the project the MCNP5 code (actually Monteburns with MCNP5) was implemented on our parallel cluster. Essentially all of the heterogeneous depletion runs were run on the cluster due to the substantial speedups compared to a workstation. Therefore, this item was successfully completed. 


\section{Related Research Resulting from the Grant}

This grant supported three doctoral students who helped to develop the DHF methodology and carry out the calculations and analyses for the VHTR configurations. These doctoral students carried out research on their $\mathrm{PhD}$ thesis topics while they were working on the grant. Since the thesis topics were related to the subject of Monte Carlo modeling of VHTR fuel, the PhD research represents a substantial contribution to the overall goal to improve the modeling of VHTR configurations. The doctoral students have all graduated and have found positions in the nuclear enterprise. They are listed in Table 36 along with the title of their PhD dissertations and their current places of employment.

Table 36. Doctoral Students who Worked on the Grant

\begin{tabular}{|l|l|l|l|}
\hline Name & Graduation & \multicolumn{1}{|c|}{ Title of PhD Thesis } & \multicolumn{1}{|c|}{$\begin{array}{c}\text { Current } \\
\text { Employer }\end{array}$} \\
\hline Wei Ji & $\begin{array}{l}\text { December } \\
2007\end{array}$ & $\begin{array}{l}\text { Neutronic Analysis of Stochastic Distribution of } \\
\text { Fuel Particles in Very High Temperature Gas- } \\
\text { Cooled Reactors }\end{array}$ & $\begin{array}{l}\text { Rensselaer } \\
\text { Polytechnic } \\
\text { Institute }\end{array}$ \\
\hline $\begin{array}{l}\text { Gokhan } \\
\text { Yesilyurt }\end{array}$ & June 2009 & $\begin{array}{l}\text { Advanced Monte Carlo Methods for Analysis of } \\
\text { Very High Temperature Reactors: On-the-Fly } \\
\text { Doppler Broadening and Deterministic /Monte } \\
\text { Carlo Methods }\end{array}$ & $\begin{array}{l}\text { Oak Ridge } \\
\text { National } \\
\text { Laboratory }\end{array}$ \\
\hline $\begin{array}{l}\text { Kaushik } \\
\text { Banerjee }\end{array}$ & $\begin{array}{l}\text { December } \\
2009\end{array}$ & $\begin{array}{l}\text { Kernel Density Estimator Methods for Monte } \\
\text { Carlo Radiation Transport }\end{array}$ & $\begin{array}{l}\text { Holtec } \\
\text { International }\end{array}$ \\
\hline
\end{tabular}

The following is a brief summary of the portions of these doctoral theses most relevant to this grant .

\section{A. Analysis of Stochastic Fuel Mixtures (Wei Ji)}

As part of his doctoral thesis on the neutronic analysis of VHTR fuel, Wei Ji made the following significant contributions to the analysis of TRISO fuel.

\section{Chord Length Sampling for Stochastic Mixtures}

The time-consuming portion of a Monte Carlo simulation of a stochastic mixture is the tracking of particle trajectories through the mesh. If a realization of the stochastic mixture is specified, then the neutron tracking is theoretically possible but there are so many regions in a typical TRISO fuel configuration ( 6000 in a single fuel compact) that the simulation will take an exorbitant amount of time to complete, if it can even get started. Wei Ji showed that chord length sampling can be used with orders of magnitude less time and excellent accuracy. Moreover, he was able to derive a theoretical expression for the chord length distribution that yielded excellent results compared to a benchmark Monte Carlo simulation of a true stochastic geometry.

\section{Analytical Expressions for Dancoff Factors for VHTR Configurations}

Using the chord length distribution functions in a manner similar to using the Dirac chord method to derive expressions for escape probabilities, Wei Ji derived analytical expressions for the average Dancoff factors for the following configurations of TRISO fuel particles: (1) an 
infinite medium, (2) a fuel compact, (3) a fuel pebble, (4) a finite collection of fuel compacts, and (5) a finite collection of fuel pebbles. These Dancoff factors agree to within 1-2\% of benchmark Monte Carlo results for a range of packing fractions from $1 \%$ to $35 \%$. This has important implications for VHTR analysis because Dancoff factors are important for deterministic neutronic analyses that involve approximate methods to handle resonance absorption.

\section{B. Neutronic Analysis of VHTRs (Gokhan Yesilyurt)}

Two major thrusts of Gokhan Yesilyurt's research that pertain to VHTR analysis are described below.

\section{Development of the DHF Methodology}

This subject has been thoroughly examined in the body of this report.

\section{Development of on-the-fly Doppler broadening}

The basic idea is to store only $0 \mathrm{~K}$ cross sections for all isotopes and when a neutron enters a region at some temperature $\mathrm{T}$, in the range $77 \mathrm{~K}-3200 \mathrm{~K}$, the cross sections for all isotopes in that region are immediately broadened to the temperature $\mathrm{T}$, using the $0 \mathrm{~K}$ cross sections. Therefore, the analyst does not need to generate cross sections at any elevated temperatures, only $0 \mathrm{~K}$, and the cross section storage is drastically reduced. Moreover, the cross sections are correctly broadened to the exact temperature $\mathrm{T}$ of the medium, and there is no error associated with having cross section sets generated at temperatures that differ from the desired region temperature $\mathrm{T}$.

\section{Monte Carlo Tallies using the Kernel Density Estimator (Kaushik Banerjee)}

Given the importance of Monte Carlo for the analysis of VHTR configurations, both prismatic and pebble bed concepts, Kaushik Banerjee's research on the application of the kernel density estimator (KDE) for Monte Carlo tallies is relevant to VHTR analysis. The two elements of his research that are particularly significant to VHTR analysis are the following.

\section{Higher order, mesh-free tallies with KDE}

It can be shown that KDE can be used to obtain higher order (i.e., shape) estimates of the scalar flux without imposing a mesh. The KDE tallies allow pointwise estimates of the scalar flux and its variance, similar to the Functional Expansion Method of David Griesheimer [27], but there is no need to impose a mesh. This has important implications for multiphysics feedback because the transport calculation can be done without a priori knowledge of the mesh used for the multiphysics analysis.

\section{Application of KDE to singular tallies}

Both the surface flux estimator (F2 in MCNP5) and the point detector estimator (F5 in MCNP5) are "singular" tallies in the sense that the variance for the F2 tally diverges and the variance for the F5 tally diverges in a scattering region. But the KDE method provides an estimate of the underlying probability density functions (PDFs) that govern the neutron distribution crossing a surface and the neutron distribution that scatters near a point detector. Knowing these approximate PDFs, variance reduction games are easily applied and the end result is that both the F2 and F5 estimators can be estimated without bias and with $1 / \mathrm{N}$ convergence of their variances, including the case when the point detector is in a scattering medium. 


\section{Students Supported by the Grant}

The following students were supported by the grant:

o Dr. Kaushik Banerjee - graduated December 2009 (now at Holtec International Inc.).

o Dr. Jeremy Conlin - graduated August 2009 (now at Los Alamos National Laboratory).

o Mr. Olivier Froment - exchange student from France.

o Dr. Wei Ji - graduated December 2007 (now at RPI).

o Ms. Shikha Prasad - doctoral student.

o Ms. Eva Sunny - doctoral student.

0 Mr. Etienne de Villèle - exchange student from France (now at Areva).

o Dr. Gokhan Yesilyurt - graduated June 2009 (now at Oak Ridge National Laboratory).

\section{Publications Directly Related to the Grant}

The following publications involve research supported by the grant:

1. G. Yesilyurt, W. R. Martin, and J. C. Lee, "Preliminary Analysis of VHTR Decay Heat Source," Trans. Am. Nucl. Soc. 95, 445-446, Albuquerque, NM (November 2006).

2. G. Yesilyurt, W. Ji, S. Prasad, W. R. Martin, and J. C. Lee, "Coupled Nuclear-ThermalHydraulics Analysis for VHTR,” Trans. Am. Nucl. Soc. 96, 580-581, Boston, MA (June 2007).

3. G. Yesilyurt, J.C. Lee, and W.R. Martin, "A Coupled Monte Carlo / Collision Probability Method for VHTR Analysis,” Trans. Am. Nucl. Soc. 99, 753-754, Reno, NV (November 2008).

4. G. Yesilyurt, W.R. Martin, and F.B. Brown, "On-The-Fly Doppler Broadening for Monte Carlo Codes," Proc. ANS Topical Meeting M\&C2009, International Conference on Mathematics, Computational Methods, \& Reactor Physics, American Nuclear Society, Saratoga, NY (May 2009).

\section{Other Publications}

The following publications involve research by students who were supported by the grant:

1. W. Ji and W. R. Martin, "Monte Carlo Simulation of VHTR Particle Fuel with Chord Length Sampling," Proc. M\&C Topical Meeting, American Nuclear Society, Monterey, CA (April 2007).

2. W. Ji and W. R. Martin, "Determination of Chord Length Distributions in Stochastic Media Composed of Dispersed Microspheres," Trans. Am. Nucl. Soc. 96, 467-469, Boston, MA (2007).

3. W. Ji and W. R. Martin, "Application of Chord Length Sampling to VHTR Unit Cell Analysis," Proc. ANS Topical Meeting PHYSOR'08, International Conference on the Physics of Reactors, Interlaken, Switzerland, September 2008.

4. K. Banerjee and W. R. Martin, "A Proposed Kernel Density Estimator Method for Monte Carlo Eigenvalue Calculations," Proc. ANS Topical Meeting PHYSOR'08, International Conference on the Physics of Reactors, Interlaken, Switzerland, September 2008.

5. F.B. Brown, W.R. Martin, R.D. Mosteller, "Monte Carlo - Advances and Challenges", Workshop presentation at the 2008 ANS Reactor Physics Division Topical Meeting (PHYSOR-08), Interlaken, Switzerland, Sept. 14, 2008 [ LA-UR-08-05891] 
6. K. Banerjee and W.R. Martin, "Monte Carlo Global Scalar Flux Estimation with Kernel Density Estimator,” Trans. Am. Nucl. Soc. 99, 346-347, Reno, NV (November 2008).

7. K. Banerjee and W.R. Martin, "Kernel Density Estimated Monte Carlo Global Flux Tallies," Proc. ANS Topical Meeting M\&C2009, International Conference on Mathematics, Computational Methods, \& Reactor Physics, American Nuclear Society, Saratoga, NY (May 2009).

8. K. Banerjee and W.R. Martin, "Applying the Kernel Density Flux Estimator to Estimate Flux at a Point,” Trans. Am. Nucl. Soc. 100, 294-296, Atlanta, GA (June 2009).

9. K. Banerjee and W.R. Martin, "Using Kernel Density Estimation for Monte Carlo Tallies with Unbounded Variance," presented at the 21st International Conference on Transport Theory (ICTT-21), Torino, Italy, (July 2009).

10. K. Banerjee and W.R. Martin, "Kernel Density Estimation Method for Monte Carlo Tallies with Unbounded Variance," Trans. Am. Nucl. Soc. 101, 430-432, Washington, DC (November 2009). 


\section{Appendix A CPM3 - MCNP5 Direct Coupling Methodology}

The CPM3 lattice physics code has been modified to incorporate problem dependent cross sections for resonance nuclides that have been generated by MCNP5 using the same geometric and material specifications as in CPM3.

A Fortran-90 code was implemented and embedded in the CPM3 source code to couple CPM3 and MCNP5. The Fortran-90 module prepares an MCNP5 input file to calculate 65-group resonance absorption and fission cross sections for all of the CPM3 resonance materials in the fuel region. The MCNP5 code is then executed and the resulting reaction rates are used to generate resonance absorption and cross sections for the resonance nuclides and these cross sections are communicated to CPM3 for its subsequent analysis.

The CPM-3 code includes a nuclear data file that contains cross-section data in 97 energy groups for over 300 nuclides, based on the ENDF/B-VI library, which was also used for the MCNP5 calculation.

The resonance groups in the 97-group CPM3 library are groups 25-89. The energy boundaries for these groups were utilized in the MCNP5 input file to tally the isotopic absorption and fission reaction rates (using FM cards) for the resonance nuclides, as well as the scalar flux. Resonance absorption and fission cross sections were then calculated by dividing the corresponding reaction rates by the fuel region volume-averaged neutron flux. For the MCNP5 calculation, 100,000 particles per cycle were used with a total of 500 active cycles.

The calculation of the fine group resonance cross sections is performed in subroutine EFRES1. Subroutines EFRES2 and SHDXS perform resonance calculations based on a two-term rational approximation. These subroutines are called within module AGXSEC and additional details regarding these subroutines are provided in Appendix B. A Fortran-90 code fragment was embedded into the subroutine called EFRES2 to stop the CPM3 effective multi-group resonance calculation, generate the MCNP5 input file, perform the MCNP5 calculation, calculate the fine group resonance cross sections, and update the CPM3 resonance cross section arrays prior to performing any region-wise macroscopic cross section and transport calculation.

The 65-group resonance cross sections determined by MCNP5 were imported back into CPM3 using a Fortran 90 module that couples the two codes. Two 2-D arrays were created in CPM3 to hold the MCNP5-generated 65-group resonance absorption and fission cross sections. These arrays, ABSMOD and FISMOD, are described below:
$\operatorname{ABSMOD}(1,1: 65) \Rightarrow \mathrm{U}-235$ absorption cross sections
$\operatorname{ABSMOD}(2,1: 65) \Rightarrow \mathrm{U}-238$ absorption cross sections
FISMOD $(1,1: 65) \Rightarrow$ U-235 fission cross sections
$\operatorname{FISMOD}(2,1: 65) \Rightarrow$ U-238 fission cross sections 


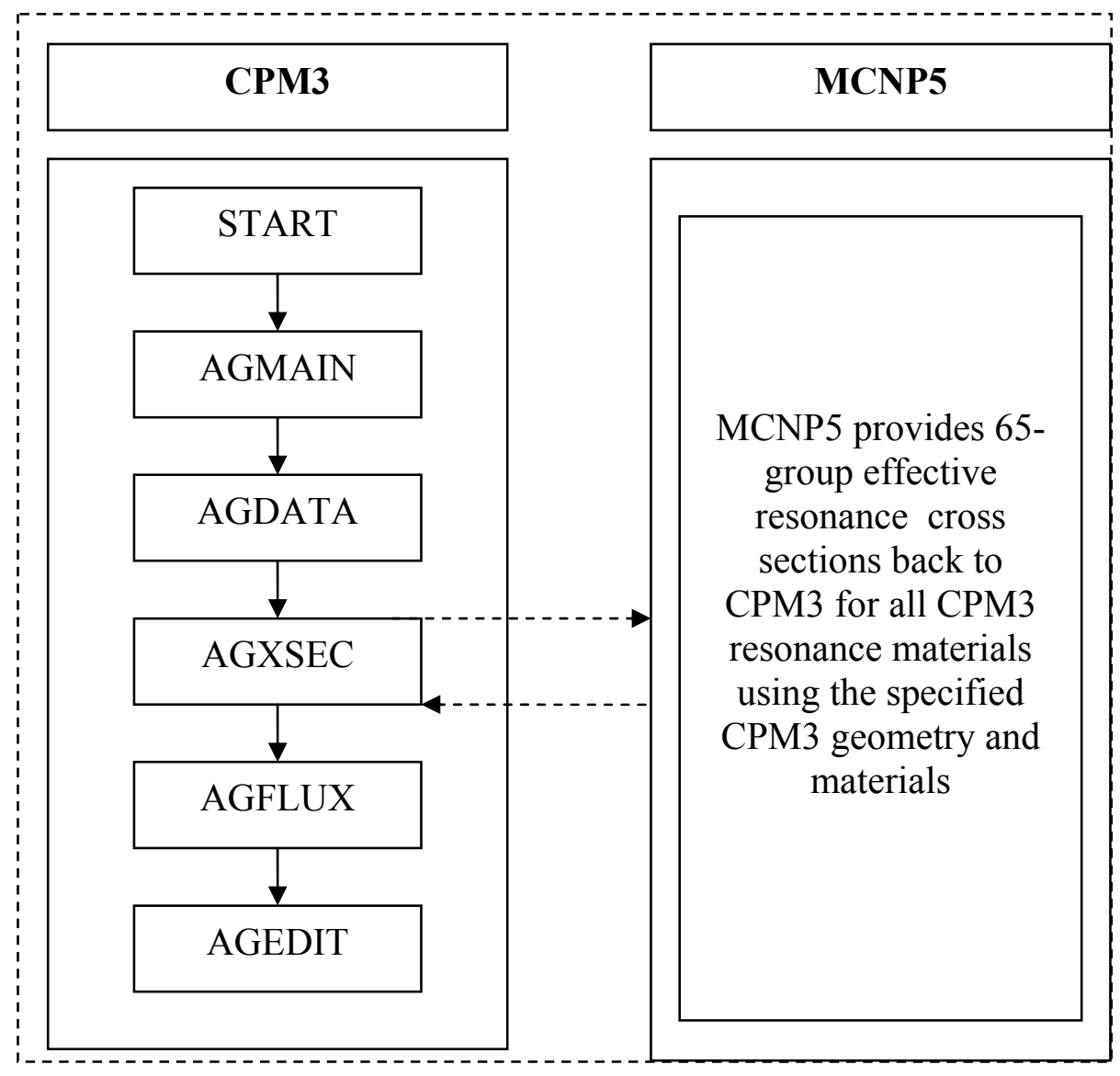

Figure A-1. CPM3-MCNP5 Coupling

The code in Figure A-2 was also implemented into the EFRES2 routine to set the MCNP5provided resonance cross sections in CPM3. In addition, 3-D arrays called SA, SNYF, and ANY in CPM3 hold the 65-group resonance absorption cross sections, $v$-fission cross sections and $v$ values, respectively, as shown in Figure A-2. The MCNP5-provided fission cross sections were multiplied by multigroup $v$ values to obtain $v$-fission cross sections for CPM3.

Do $\mathrm{NRG}=1$, $\mathrm{NRGS}$

If (NDRES(NRG).gt.0) Then

Do NRES $=1$, NDRES (NRG)

$\mathrm{N}=$ IDRES (NRES, NRG)

NUCID $=\operatorname{IDNUC}(\mathrm{N}, \mathrm{NRG})$

Do $\mathrm{NP}=1, \mathrm{NPX}$

If (IDPX (NP) .eq. NUCID) Then

Do $I G=1$, NRL

$S A(I G, N R E S, N R G)=A B S M O D(N R E S, I G)$

SNYF (IG, NRES, NRG) $=$ FISMOD (NRES, IG)*ANY (IG, NRES , NRG)

\section{End Do}

End If

End Do

End Do

End If

End Do

Figure A-2. Code to Import MCNP5-generated resonance cross sections in EFRES2 
After importing and setting the new 65-group resonance cross sections in CPM3, all of the microscopic cross section data is written into a CPM3 internal file by the code to calculate the region-wise macroscopic cross sections and perform the flux calculation.

Table C-1 in Appendix C tabulates the energy boundaries for the 97-group CPM3 library. Groups marked with red are the 65 resonance groups for which the resonance cross sections are determined by MCNP5. 


\section{Appendix B Structure and Flow of CPM3}

CPM-3 is a modular code system comprised of six code modules, ten external data files, and several internal data structures. A detailed description of the structure and flow of CPM3 is given in Appendix A. A brief summary is given here along with a more detailed description of the AGSEC module. The six code modules that comprise the CPM-3 program are listed below:
AGMAIN - main program
AGDATA - input processing
AGXSEC - cross section processing
AGFLUX - flux and eigenvalue calculation
AGEDIT - edits calculation
AGBURN - isotopic burnup calculation

Each code module performs a specific function which ranges from processing user input data, to performing the flux calculation to editing the results of the calculations. One loop through the program is needed for an eigenvalue calculation, a coefficient calculation, or a burnup step. A logic flow diagram of the CPM-3 code is shown in Figure B-1.

Most of the changes needed to implement the coupling to MCNP5 were made to module AGXSEC. This module is the cross section processing module for the CPM-3 code. AGXSEC prepares microscopic and macroscopic cross sections for each nuclide and each material in the problem. The microscopic cross sections for each nuclide are needed to compute material macroscopic cross sections and to perform reaction rate edit calculations and burnup calculations. The macroscopic cross sections are used to perform the flux and edit calculations. Module AGXSEC includes special treatments for the determination of Dancoff factors and resonance self-shielding effects.

The resonance calculation performs self-shielding calculations for absorber materials that have strong resonance absorption characteristics, taking into account the effects of heterogeneities in the lattice. A spatial variation function (SVF) treatment is used to compute space-dependent, shielded cross sections within a fuel pellet. Generalized Dancoff factors are computed for all resonance absorber regions in the two-dimensional lattice (including non-uniformities) in generalized geometry using ray-tracing techniques.

Resonance calculations are performed for all fuel, burnable absorber, and control rod nuclides that have resonance parameters and shielding factor data in the CPM-3 nuclear data file. Macroscopic cross sections are generated for both the neutron and gamma-ray transport problems. The cross sections processed by AGXSEC are read from the CPM-3 nuclear data and gamma data files.

The calling sequences of sub-program units within AGXSEC are provided in Figure B-2. 


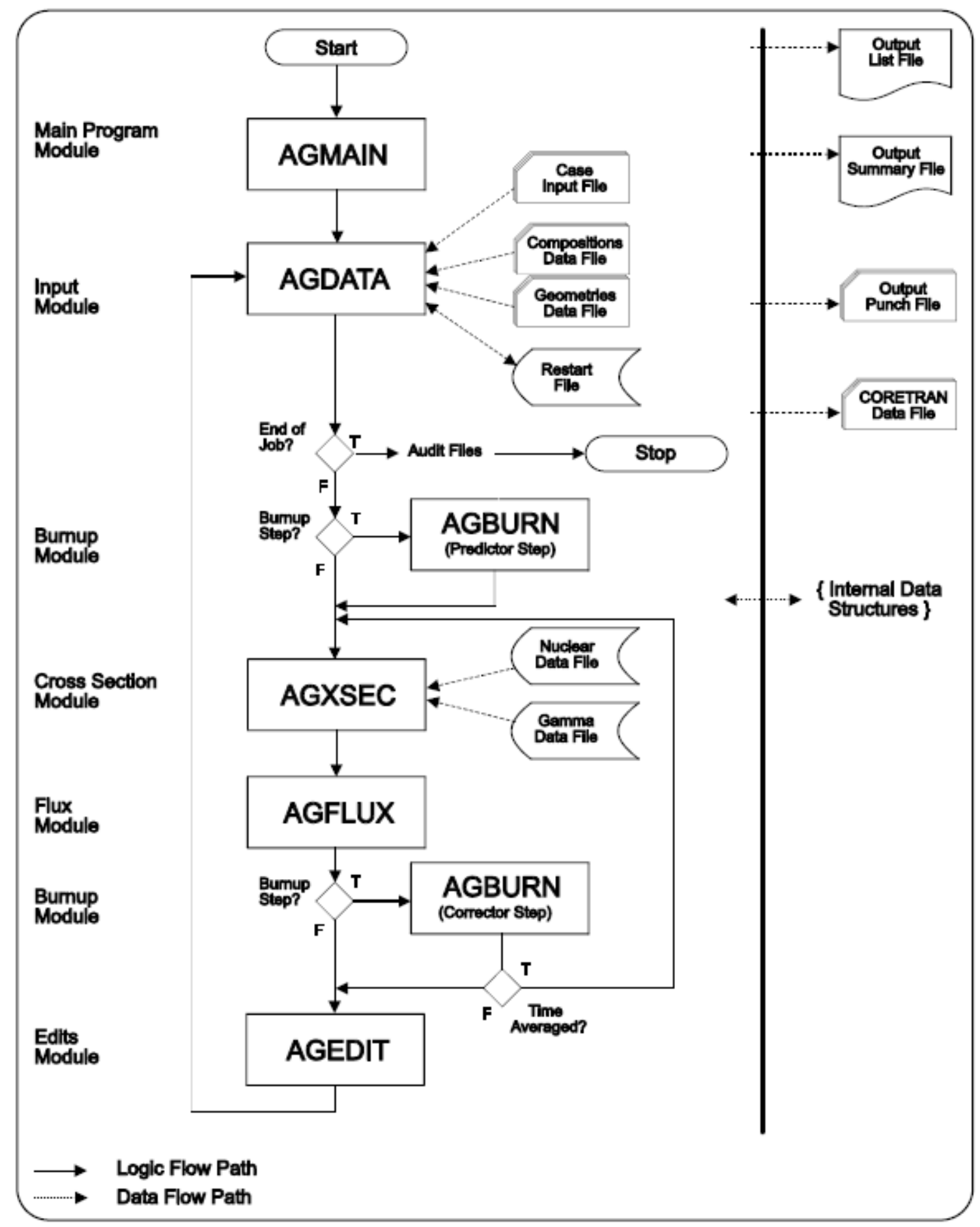

Figure B-1. Logic Flow Diagram for CPM3 


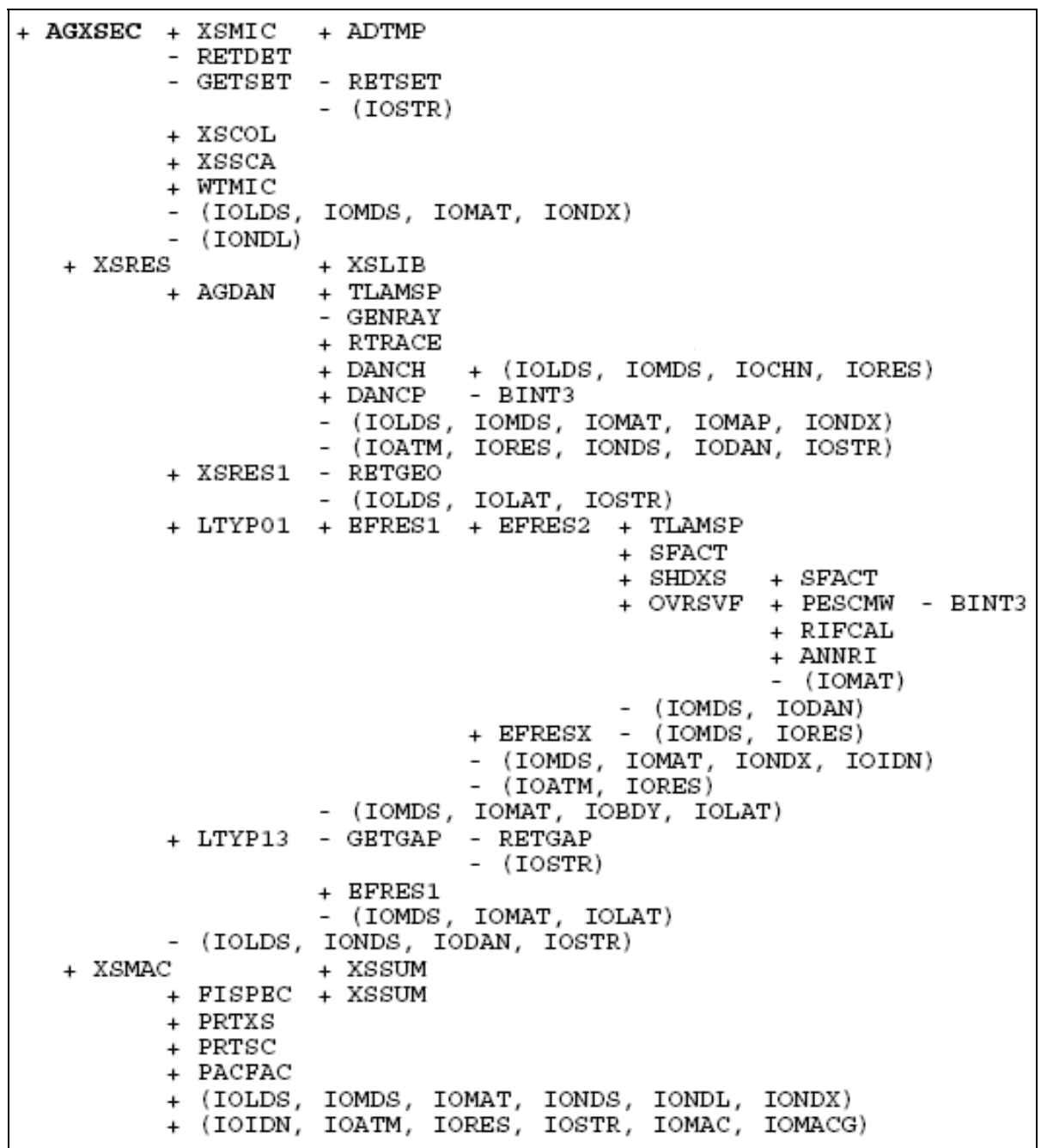

Figure B-2. Calling Diagram for Module AGXSEC

Brief descriptions of the subroutines used with module AGXSEC are given below.

\section{Routine Description}

AGXSEC Main routine for calculating resonance parameters and microscopic and macroscopic cross sections.

ADTMP Adds temperatures to the list of interpolation temperatures.

AGDAN Performs Dancoff calculations in arbitrary geometry.

ANNRI Calculates Spatial Variation Function (SVF) in absorber pins.

DANCH Determines chain sets for the Dancoff calculation.

DANCP Calculates Dancoff factors using the ray-tracing method.

EFRES1 Calculates effective resonance group cross sections.

EFRES2 Performs the resonance calculation.

EFRESX Writes the calculated resonance data to the internal data file.

FISPEC Calculates the fission spectrum for fuel materials.

LTYP01 Performs resonance treatments for geometry type 1.

LTYP13 Performs resonance treatments for geometry type 13. 
OVRSVF Calculates resonance interference factors (RIF) and the spatial-variation function (SVF) to be applied to shielded group cross-sections.

PACFAC Calculates factors for packing the scattering matrices.

PRTXS Prints cross-section data.

PRTSC Prints unpacked scattering matrix data.

RIFCAL Calculates resonance interference factors.

SFACT Interpolation routine for determining F-factors.

SHDXS Calculates effective cross-sections without RIF correction.

TLAMSP Calculates temperature-dependent Lambda-Sigma P correction factors.

WTMIC Writes the microscopic cross-section data to the internal nuclear data file.

XSCOL Collapses microscopic cross-sections using library spectra.

XSSCA Collapses microscopic scattering cross-sections using library spectra.

XSLIB Reads resonance parameters and self-shielding factors from the nuclear data file.

XSMAC Calculates macroscopic cross sections for all materials.

XSMIC Main routine for calculating microscopic cross-sections for all nuclides at all temperatures required for the problem. Microscopic cross-section data is read from the nuclear data file.

XSRES Main routine for performing the resonance calculation.

XSRES1 Performs resonance group cross section calculations for resonance absorber materials. 


\section{Appendix C CPM3 Energy Group Structure}

The CPM-3 code package includes a nuclear data file derived from ENDF/B-VI that contains cross-section data and nuclear parameters in 97 energy groups for over 300 nuclides. Multigroup energy boundaries of CPM3 are shown in Table C-1. Resonance groups are marked with red.

Table C-1. CPM3 97 Multi-Group Energy Boundaries.

\begin{tabular}{|c|c|c|c|c|c|c|c|c|c|}
\hline Grp & Energy & Range (eV) & Grp & Energy & & ige $(e V)$ & Grp & \multicolumn{2}{|c|}{ Energy Range (eV) } \\
\hline 1 & $1.00 \mathrm{E}+07$ & $7.79 \mathrm{E}+06$ & 34 & $2.61 \mathrm{E}+03$ & - & $2.04 \mathrm{E}+03$ & 67 & $1.31 \mathrm{E}+00$ & $1.17 \mathrm{E}+00$ \\
\hline 2 & $7.79 \mathrm{E}+06$ & $-\quad 6.07 \mathrm{E}+06$ & 35 & $2.04 \mathrm{E}+03$ & - & $1.59 \mathrm{E}+03$ & 68 & $1.17 \mathrm{E}+00$ & $1.10 \mathrm{E}+00$ \\
\hline 3 & $6.07 \mathrm{E}+06$ & $-4.72 \mathrm{E}+06$ & 36 & $1.59 \mathrm{E}+03$ & - & $1.23 \mathrm{E}+03$ & 69 & $1.10 \mathrm{E}+00$ & $1.07 \mathrm{E}+00$ \\
\hline 4 & $4.72 \mathrm{E}+06$ & $-\quad 3.68 \mathrm{E}+06$ & 37 & $1.23 \mathrm{E}+03$ & - & $9.61 \mathrm{E}+02$ & 70 & $1.07 \mathrm{E}+00$ & $1.06 \mathrm{E}+00$ \\
\hline 5 & $3.68 \mathrm{E}+06$ & $2.87 \mathrm{E}+06$ & 38 & $9.61 \mathrm{E}+02$ & - & $7.49 \mathrm{E}+02$ & 71 & $1.06 \mathrm{E}+00$ & $1.05 \mathrm{E}+00$ \\
\hline 6 & $2.87 \mathrm{E}+06$ & $-2.23 \mathrm{E}+06$ & 39 & $7.49 \mathrm{E}+02$ & - & $5.83 \mathrm{E}+02$ & 72 & $1.05 \mathrm{E}+00$ & $1.04 \mathrm{E}+00$ \\
\hline 7 & $2.23 \mathrm{E}+06$ & $-\quad 1.74 \mathrm{E}+06$ & 40 & $5.83 \mathrm{E}+02$ & - & $4.54 \mathrm{E}+02$ & 73 & $1.04 \mathrm{E}+00$ & $1.01 \mathrm{E}+00$ \\
\hline 8 & $1.74 \mathrm{E}+06$ & $-\quad 1.35 \mathrm{E}+06$ & 41 & $4.54 \mathrm{E}+02$ & - & $3.54 \mathrm{E}+02$ & 74 & $1.01 \mathrm{E}+00$ & $9.51 \mathrm{E}-01$ \\
\hline 9 & $1.35 \mathrm{E}+06$ & $-\quad 1.05 \mathrm{E}+06$ & 42 & $3.54 \mathrm{E}+02$ & - & $2.75 \mathrm{E}+02$ & 75 & $9.51 \mathrm{E}-01$ & 7.82E-01 \\
\hline 10 & $1.05 \mathrm{E}+06$ & $8.21 \mathrm{E}+05$ & 43 & $2.75 \mathrm{E}+02$ & - & $2.15 \mathrm{E}+02$ & 76 & $7.82 \mathrm{E}-01$ & $6.25 \mathrm{E}-01$ \\
\hline 11 & $8.21 \mathrm{E}+05$ & $-\quad 6.39 \mathrm{E}+05$ & 44 & $2.15 \mathrm{E}+02$ & - & $1.67 \mathrm{E}+02$ & 77 & $6.25 \mathrm{E}-01$ & $5.03 \mathrm{E}-01$ \\
\hline 12 & $6.39 \mathrm{E}+05$ & $-\quad 4.98 \mathrm{E}+05$ & 45 & $1.67 \mathrm{E}+02$ & - & $1.30 \mathrm{E}+02$ & 78 & $5.03 \mathrm{E}-01$ & 4.17E-01 \\
\hline 13 & $4.98 \mathrm{E}+05$ & $-\quad 3.88 \mathrm{E}+05$ & 46 & $1.30 \mathrm{E}+02$ & - & $1.01 \mathrm{E}+02$ & 79 & 4.17E-01 & $3.58 \mathrm{E}-01$ \\
\hline 14 & $3.88 \mathrm{E}+05$ & $3.02 \mathrm{E}+05$ & 47 & $1.01 \mathrm{E}+02$ & - & $7.89 \mathrm{E}+01$ & 80 & $3.58 \mathrm{E}-01$ & $3.21 \mathrm{E}-01$ \\
\hline 15 & $3.02 \mathrm{E}+05$ & $-\quad 2.35 \mathrm{E}+05$ & 48 & $7.89 \mathrm{E}+01$ & - & $6.14 \mathrm{E}+01$ & 81 & $3.21 \mathrm{E}-01$ & $3.01 \mathrm{E}-01$ \\
\hline 16 & $2.35 \mathrm{E}+05$ & $-\quad 1.83 \mathrm{E}+05$ & 49 & $6.14 \mathrm{E}+01$ & - & $4.79 \mathrm{E}+01$ & 82 & $3.01 \mathrm{E}-01$ & $2.91 \mathrm{E}-01$ \\
\hline 17 & $1.83 \mathrm{E}+05$ & $-\quad 1.43 \mathrm{E}+05$ & 50 & $4.79 \mathrm{E}+01$ & - & $3.73 \mathrm{E}+01$ & 83 & $2.91 \mathrm{E}-01$ & $2.71 \mathrm{E}-01$ \\
\hline 18 & $1.43 \mathrm{E}+05$ & $-\quad 1.11 \mathrm{E}+05$ & 51 & $3.73 \mathrm{E}+01$ & - & $2.90 \mathrm{E}+01$ & 84 & $2.71 \mathrm{E}-01$ & $2.51 \mathrm{E}-01$ \\
\hline 19 & $1.11 \mathrm{E}+05$ & $-\quad 8.65 E+04$ & 52 & $2.90 \mathrm{E}+01$ & - & $2.26 \mathrm{E}+01$ & 85 & $2.51 \mathrm{E}-01$ & $2.28 \mathrm{E}-01$ \\
\hline 20 & $8.65 \mathrm{E}+04$ & $-\quad 6.74 \mathrm{E}+04$ & 53 & $2.26 \mathrm{E}+01$ & - & $1.76 \mathrm{E}+01$ & 86 & $2.28 \mathrm{E}-01$ & $1.84 \mathrm{E}-01$ \\
\hline 21 & $6.74 \mathrm{E}+04$ & $-\quad 5.25 \mathrm{E}+04$ & 54 & $1.76 \mathrm{E}+01$ & - & $1.37 \mathrm{E}+01$ & 87 & $1.84 \mathrm{E}-01$ & $1.46 \mathrm{E}-01$ \\
\hline 22 & $5.25 \mathrm{E}+04$ & $-\quad 4.09 \mathrm{E}+04$ & 55 & $1.37 \mathrm{E}+01$ & - & $1.07 \mathrm{E}+01$ & 88 & $1.46 \mathrm{E}-01$ & $1.12 \mathrm{E}-01$ \\
\hline 23 & $4.09 \mathrm{E}+04$ & $-\quad 3.18 \mathrm{E}+04$ & 56 & $1.07 \mathrm{E}+01$ & - & $8.32 \mathrm{E}+00$ & 89 & $1.12 \mathrm{E}-01$ & $8.20 \mathrm{E}-02$ \\
\hline 24 & $3.18 \mathrm{E}+04$ & $-\quad 2.48 \mathrm{E}+04$ & 57 & $8.32 \mathrm{E}+00$ & - & $6.48 \mathrm{E}+00$ & 90 & $8.20 \mathrm{E}-02$ & $5.69 \mathrm{E}-02$ \\
\hline 25 & $2.48 \mathrm{E}+04$ & $-\quad 1.93 \mathrm{E}+04$ & 58 & $6.48 \mathrm{E}+00$ & - & $5.04 \mathrm{E}+00$ & 91 & $5.69 \mathrm{E}-02$ & $4.28 \mathrm{E}-02$ \\
\hline 26 & $1.93 \mathrm{E}+04$ & $-\quad 1.50 \mathrm{E}+04$ & 59 & $5.04 \mathrm{E}+00$ & - & $3.93 \mathrm{E}+00$ & 92 & $4.28 \mathrm{E}-02$ & $3.06 \mathrm{E}-02$ \\
\hline 27 & $1.50 \mathrm{E}+04$ & $-\quad 1.17 \mathrm{E}+04$ & 60 & $3.93 \mathrm{E}+00$ & - & $3.06 \mathrm{E}+00$ & 93 & $3.06 \mathrm{E}-02$ & $2.05 \mathrm{E}-02$ \\
\hline 28 & $1.17 \mathrm{E}+04$ & $-\quad 9.12 \mathrm{E}+03$ & 61 & $3.06 \mathrm{E}+00$ & - & $2.38 \mathrm{E}+00$ & 94 & $2.05 \mathrm{E}-02$ & $1.24 \mathrm{E}-02$ \\
\hline 29 & $9.12 \mathrm{E}+03$ & $-\quad 7.10 \mathrm{E}+03$ & 62 & $2.38 \mathrm{E}+00$ & - & $1.86 \mathrm{E}+00$ & 95 & $1.24 \mathrm{E}-02$ & $6.33 \mathrm{E}-03$ \\
\hline 30 & $7.10 \mathrm{E}+03$ & $-\quad 5.53 \mathrm{E}+03$ & 63 & $1.86 \mathrm{E}+00$ & - & $1.73 \mathrm{E}+00$ & 96 & $6.33 \mathrm{E}-03$ & $2.28 \mathrm{E}-03$ \\
\hline 31 & $5.53 \mathrm{E}+03$ & $-\quad 4.31 \mathrm{E}+03$ & 64 & $1.73 \mathrm{E}+00$ & - & $1.60 \mathrm{E}+00$ & 97 & $2.28 \mathrm{E}-03$ & $2.53 \mathrm{E}-04$ \\
\hline 32 & $4.31 \mathrm{E}+03$ & $-\quad 3.36 \mathrm{E}+03$ & 65 & $1.60 \mathrm{E}+00$ & - & $1.46 \mathrm{E}+00$ & & & \\
\hline 33 & $3.36 \mathrm{E}+03$ & $-\quad 2.61 \mathrm{E}+03$ & 66 & $1.46 \mathrm{E}+00$ & - & $1.31 \mathrm{E}+00$ & & & \\
\hline
\end{tabular}

Neutron cross section data is provided in 97 energy groups over the energy range of 0-10 MeV. Gamma-ray cross-section data is provided in 18 energy groups up to $10 \mathrm{MeV}$. The user may 
specify condensed energy group structures for both eigenvalue and editing calculations by using the discrete energy group boundaries given on the nuclear data file. There are 65 resonance energy groups range that are numbered from 25 to 89. Groups 1-24 are the fast neutron groups where there are no resolved resonances, and groups 90-97 are the lower thermal energy groups that are below the resonance range.

The CPM3 data file is based on ENDF/B-VI Release IV whereas MCNP5 uses ENDF/B-VI Release V. It was reported in CPM3 nuclear data manual[43] that ENDF/B-VI Release V virtually gives identical results as ENDF/B-VI Release IV for thermal reactors. 